Revue d'histoire de l'Amérique française

ALS REVUE D.HISTOIRE DE L'AMÉRIQUE FRANÇAISE

\title{
La restauration de la Tour de Babel ou « La vie à Québec au milieu du XVII ${ }^{\mathrm{e}}$ siècle "
}

\section{André Vachon}

Volume 24, numéro 2, septembre 1970

URI : https://id.erudit.org/iderudit/302974ar

DOI : https://doi.org/10.7202/302974ar

Aller au sommaire du numéro

\section{Éditeur(s)}

Institut d'histoire de l'Amérique française

\section{ISSN}

0035-2357 (imprimé)

1492-1383 (numérique)

Découvrir la revue

\section{Citer cet article}

Vachon, A. (1970). La restauration de la Tour de Babel ou « La vie à Québec au milieu du XVII ${ }^{\mathrm{e}}$ siècle ». Revue d'histoire de l'Amérique française, 24(2), 167-250. https://doi.org/10.7202/302974ar d'utilisation que vous pouvez consulter en ligne. 


\title{
LA RESTAURATION DE LA TOUR DE BABEL
}

\author{
ou \\ "LA VIE À QUÉBEC AU MILIEU \\ DU XVII ${ }^{\text {SIECLE" * }}$
}

\author{
ANDRÉ VACHON \\ Université Laval
}

La contestation étant propre à la jeunesse, il est normal à bien des égards d'entendre nos historiens de la nouvelle vague dénoncer l'historiographie "traditionnelle", et rassurant de les voir chercher laborieusement, par des voies qu'ils veulent différentes des nôtres, une connaissance plus approfondie et plus exacte du passé. Mais la jeunesse est impulsive, voire impétueuse; elle a beau tirer vanité de ses méthodes scientifiques rigoureuses, il lui arrive trop souvent d'en rompre impatiemment le joug pour sauter aux conclusions - surtout quand ces dernières présentent l'attrait quasi invincible de contredire celles des aînés. Contradictions et oppositions, à la vérité, sont plus apparentes que réelles : beaucoup de prétendues découvertes n'en sont point, et beaucoup d'affirmations à la mode ne sont que la reprise, dans un vocabulaire vaguement ésotérique, de données familières. Plus que le conflit des générations, ce qui nous menace, en effet, c'est la confusion du verbe. Ces jeunes gens, qui ne maîtrisent pas toujours la langue usuelle et qui parviennent difficilement à équilibrer une phrase de trois lignes, plutôt que de se donner une véritable formation en sociologie, en économique ou en psychanalyse, se contentent généralement d'emprunter à ces disciplines une terminologie flottante, d'en alourdir leurs textes et de semer - scientifiquement ! - l'incertitude et l'obscurité.

* NDLR - Lors de la réunion annuelle de l'Institut d'histoire de l'Amérique française tenue à l'Université Laval, en mai 1969, M. Jacques Mathieu présentait une communication qui a suscité un vif intérêt. La Revue la publiait dans son no de décembre 1969. C'est à la suite de cette publication qu'une autre étude sur le même sujet, celle de $\mathbf{M}$. André Vachon, nous a été remise. Dans les circonstances, nous avons cru, à eause de l'importance de cette étude, devoir la présenter aux lecteurs de la Revue en une seule tranche. 
Le résultat le plus net de cette ignorance grandissante de la langue commune et de l'adoption d'un vocabulaire technique encore en gestation ${ }^{1}$ a pu être observé au cours de récents colloques d'histoire où les participants s'épuisèrent à disputer pendant des heures sur le sens des mots, sans jamais tomber d'accord.

Ces tendances des jeunes historiens, je les retrouve toutes, à des degrés divers, dans un article publié ici même et intitulé "La vie à Québec au milieu du XVII e siècle. Etude des sources" ${ }^{2}$. Cette étude bouleverse, à première vue, bien des données traditionnelles; en fait, elle ne résiste guère à l'analyse. Mais le risque est grand, à cause de la réputation de l'auteur et des nombreuses considérations de méthodologie dont il a embrouillé son texte, que plusieurs de ses conclusions ne soient adoptées d'emblée et que, répétées à l'infini comme cela se produit souvent dans notre historiographie, elles ne soient utilisées comme rampes de lancement pour d'autres recherches. Aussi m'apparaît-il nécessaire de faire d'urgence un certain nombre de mises au point.

\section{A. La critique externe des sources : plaidoyer}

Essentiellement, cet article est un plaidoyer en faveur de la critique externe des sources, "approche [sic] primordiale" pour "arriver à une synthèse globale véridique" de l'histoire ( $p .404)$. L'auteur propose, en somme, de pousser l'examen des sources au-delà du document particulier en replaçant ce dernier dans l'ensemble, série ou groupe, auquel il appartient. Cet ensemble, en vertu du principe qu'un document est "créé par et pour une administration" (p. 405), l'historien en évaluera les ressources et les limitations à proportion de sa connaissance de l'organisme qui l'a produit :

Seule, la connaissance approfondie du fonctionnement de l'administration permettra alors de replacer le document dont le chercheur dispose, [sic] dans un cadre plus vaste. L'histoire globale est à ce prix: une période de recherche intensive dans l'ensemble des documents produits par une administration, un contrôle des avancés par l'étude des fonds d'archives

1 Moins on connaît une langue, surtout la sienne propre, plus facilement on la déclare impuissante à rendre certaines réalités. De là le recours abusif aux vocables nouveaux, habituellement qualifiés de scientifiques, et à des mots étrangers qui n'auraient pas, dit-on, d'équivalents en français.

2 RHAF, XXIII, no 3 (décembre 1969): 404-424. 
eux-mêmes. Car, [sic] un document est créé par et pour une administration; il reflète l'activité et le fonctionnement de cette administration, sa compétence et sa juridiction. (p. 405)

Cette démarche préalable permettra à l'historien d'éviter de présenter une image faussée de la Nouvelle-France, par suite de généralisations faites à partir d'une seule série de documents" (p. 406).

Tout cela est fort judicieux. Mais l'auteur, avec moins d'à propos, donne l'exemple d'une "erreur fréquente" d'interprétation due à "l'absence de critique externe des sources, [à] la méconnaissance de l'administration et [à] l'absence de certaines séries de documents" :

L'analyse des ordonnances permet de constater la présence d'un grand nombre d'actes se rapportant à la terre, aux limites des seigneuries, aux droits et devoirs des seigneurs et des censitaires. Il semble logique alors de conclure à l'importance de la culture de la terre au Canada sous le régime français et même, [sic] à l'existence d'une société agraire.

Mais il suffit de replacer "ces ordonnances dans le cadre de l'administration gouvernementale" pour constater qu'en matière commerciale "on avait [...] rarement recours à l'intendant" :

On conçoit bien qu'un litige entre des marchands se réglait devant une cour de justice à moins de cas vraiment exceptionnels. De plus, les contraventions aux règlements commerciaux faisaient l'objet d'une poursuite [...] par l'agent de la compagnie [...] Par contre, le seigneur récalcitrant à remplir ses devoirs avait directement affaire à l'intendant. [...] S'il reste vrai que les ordonnances des intendants ont souvent rapport à la terre, il devient fort restrictif [sic], sinon faux, de parler de société agraire. (p. 406)

Si j'analyse ce passage particulièrement nébuleux d'un article où les conditions de visibilité sont parfois singulièrement mauvaises, je ne peux m'arrêter qu'à l'interprétation suivante : les ordonnances des intendants relatives à "la terre" et au régime seigneurial sont plus nombreuses que celles qui ont trait au commerce; en Nouvelle-France, le commerce est néanmoins plus important que l'agriculture; cela ressort de la critique externe des sources, laquelle consiste en l'occurrence à replacer "ces ordonnances dans le cadre de l'administration gouvernementale". L'auteur, il est vrai, n'énonce pas les choses aussi clairement. Mais il a certainement voulu dire que les ordonnances sur les 
questions agricoles sont les plus nombreuses, car autrement ce n'est pas à "l'importance de la culture de la terre" qu'il eût été "logique [...] de conclure"; il n'affirme pas ouvertement, non plus, que le commerce fut dans la colonie plus important que l'agriculture, mais il écrit que c'est une "erreur fréquente" - que tout au moins il est "fort restrictif [sic], sinon faux" de croire à une "société agraire" au Canada sous le régime français, ce qui revient à dire, étant donné la comparaison qu'il développe entre le commerce et l'agriculture, que la colonie était surtout fondée sur le commerce.

Je n'ai pas l'intention de soulever, dans le cadre de cet article, un débat sur le caractère agricole ou commercial du Canada sous le régime français. Ce caractère, du reste, a pu se modifier considérablement au cours des années - possibilité dont l'auteur ne semble pas tenir compte. Quoi qu'il en soit de la justesse de sa remarque sur le peu d'importance de l'agriculture, il ne l'appuie sur aucune démonstration, l'enrobant tout au plus dans des considérations spécieuses sur le nombre des ordonnances. Lui qui prône la méthode statistique (p. 407), il ne pèche point ici par excès de précision : "un grand nombre d'actes", "rarement", "souvent". Intrigué, je me suis livré à un petit calcul, auquel il aurait dû s'astreindre le premier.

Plusieurs ordonnances des intendants antérieures au 7 septembre 1705 ont été perdues ${ }^{3}$; il n'est même pas sûr que nous ayons toutes celles qui, en 1705, furent émises après le 7 septembre, bien qu'à partir de ce jour-là elles aient été, en principe, transcrites dans des registres ${ }^{4}$. J'ai donc compté, pour l'année 1706, et ensuite de dix ans en dix ans, les ordonnances se rapportant à "la terre" et celles se rapportant au commerce, pour finalement établir le pourcentage des unes et des autres par rapport au nombre total des interventions des intendants. En voici le tableau : [Voir tableau I, page 171.]

Les ordonnances sur les questions commerciales seraient donc les plus nombreuses. Bien qu'elle détruise le fondement sur

3 Il n'est pas rare, dans les registres des cours de justice et dans les inventaires après décès, par exemple, de trouver certaines références à des ordonnances qui ne nous sont pas parvenues.

$4 \mathrm{AQ}$, NF 2. On connaît au moins deux ordonnances postérieures au 7 septembre 1705 , l'une du 24 octobre, l'autre du 20 novembre, qui n'apparaissent pas dans le premier registre des ordonnances des intendants. Elles ont été publiées par Pierre-Georges Roy, édit., Ordonnances, commissions, etc, etc, des gouverneurs et intendants de la Nouvelle-France, 16391706 [sic] (Roy, édit., Ord., comm.), 2 vol. (Beauceville, 1924), II : 330-334. 
TABLEAU I

Ordonnances des intendants relatives au commerce et au régime seigneurial

\begin{tabular}{lcccc}
\hline & Commerce & Seigneuries & Autres & Total \\
\hline 1706 & 57 & 32 & 32 & 121 \\
1716 & 19 & 28 & 10 & 57 \\
1726 & 19 & 16 & 19 & 54 \\
1736 & 40 & 30 & 38 & 108 \\
1746 & 17 & 14 & 13 & 44 \\
1756 & 14 & 3 & 15 & 32 \\
Total & 166 & 123 & 127 & 416 \\
Pourcentage & $39,9 \%$ & $29,6 \%$ & $30,5 \%$ & $100 \%$ \\
\hline
\end{tabular}

lequel l'auteur prétend asseoir son argument, cette constatation, on le notera, n'ébranle en rien son affirmation sur le peu d'importance de l'agriculture dans la colonie. Voilà bien le plus grave, car cela illustre parfaitement l'absence de lien entre la pseudodémonstration de l'auteur et sa conclusion apparente. Soudainement mise à nu, son affirmation se présente comme un de ces postulats - pas forcément erroné - qu'il déplore un peu plus loin (p. 407). Mais peut-être ai-je tort ? En ce cas, le paragraphe consacré par l'auteur aux ordonnances des intendants prouverait que la critique externe des sources, bien ou mal faite, est sans influence sur les conclusions du chercheur.

N'allons point minimiser, toutefois, pour un paragraphe malheureux - et quelques passages obscurs comme celui où apparaît le nom de Vauban (p. 407) - , l'apport de l'auteur dans les pages 404 à 407 . Volontiers, on admettra la nécessité de la critique externe des sources. Je connais cependant plus d'un historien qui sera moins réceptif au premier des deux reproches que nous fait l'auteur : on n'aurait pas, jusqu'ici, pratiqué la critique externe (p. 404) ; on aurait, de plus, utilisé trop exclusivement des témoignages "à caractère qualitatif" au lieu de "quantifier" (sic) les données (p. 407). Cela n'empêche pas "certaines monographies [d'être] quasi définitives; elles vaudront en tout cas pendant encore une génération" (p. 407) - 
le temps, j'imagine, d'être entièrement balayées par la nouvelle vague.

Convaincu, pour sa part, qu'un "bon article" et "des points de repère précis valent plus pour l'histoire du Canada qu'une œuvre monumentale fautive parce que mal orientée au départ ou basée sur des postulats erronés", c'est dans une "optique d'histoire globale et de critique externe des sources" que l'auteur entend maintenant étudier "la vie à Québec au milieu du XVII ${ }^{e}$ siècle" (p. 407). Enoncé d'une façon moins redondante, le sujet soudain s'atténue : "nous ${ }^{5}$ nous limitons à deux années (1667-1668) [et] à un survol de l'ensemble des sources publiques disponibles et des champs d'activité de la population" (p. 407). Le titre de l'article annonçait beaucoup plus et beaucoup mieux. - Notons dès maintenant que l'auteur ne traitera pas de la ville de Québec (en dépit du titre), mais du gouvernement de Québec. Il écrira tantôt "à Québec" (p. 409), tantôt "dans la région de Québec" (p. 409), ou parlera sans plus de précision de "la population québécoise" (p. 414s.) et des "Québécois" (p. 418) ; deux fois seulement il utilisera "gouvernement de Québec", seule expression exacte pourtant, et la seule qui soit acceptable sur le plan de l'administration et de la critique externe.

\section{B. La critique externe des sources : illustration}

Comme suite à son plaidoyer en faveur de la critique externe, l'auteur entreprend en premier lieu d'analyser "les sources publiques disponibles" (p. 407). Il s'arrête à six séries de documents : "les édits et ordonnances du roi" (p. 408), "les ordonnances des intendants et des gouverneurs" (p. 408s.), "la correspondance générale" (p. 409), "les actes notariés" (p. 409s.), "le Conseil souverain [sic]" (p. 410s.) et "la Prévôté de Québec [sic]" (p. 411). De nouveau, on discerne mal son propos : veut-il présenter "l'ensemble des sources publiques" (p. 407) du régime français ou "l'ensemble des sources publiques disponibles" pour les années 1667 et 1668 seulement ? Dans la première hypothèse,

5 L'auteur emploie indifféremment le $j e$ et le nous, même à deux lignes de distance (p. 407). Détail entre plusieurs qui montrent à quel point il a peu soigné un texte dans lequel, par exemple, j'ai compté une quarantaine de fautes d'accord, parfois aussi grossières que celle-ci : "Si la fréquentation assidue des cours de justice par les Canadiens peut illustrer son mode de vie, elle peut aussi refléter la mentalité de la population." (p. 419). On se demande même, à certains moments, si l'on est devant un cas d'ignorance de la grammaire ou d'incohérence de la pensée : "L'intérêt de ces registres n'en est que plus grand, puisqu'il traduit plutôt un type de société qu'une mentalité chicanière." (p. 419). 
il n'aurait retenu qu'une faible partie de la documentation officielle existante; dans la seconde, il aurait oublié, entre autres séries, les procès-verbaux des grands voyers ${ }^{6}$, qui commencent en 1668, et l'important papier terrier de la Compagnie des Indes occidentales, confectionné en 1667 et 1668, qu'on trouve dans les registres de foi et hommage ? Cette omission de documents seigneuriaux est d'autant plus regrettable que tout l'article repose en définitive sur une comparaison continue, bien que plus ou moins explicite, entre l'activité commerciale et l'activité agricole en Nouvelle-France.

La manière de l'auteur, dans cette seconde partie, n'est pas sans quelques faiblesses. Il avait bien indiqué, précédemment, la marche à suivre : "l'histoire globale du régime français reste impossible à faire tant qu'on n'aura pas étudié à fond le fonctionnement des administrations et les documents qu'elles ont produits" (p. 407). D'autres passages (v.g. p. 405) suggéraient la même idée : étude de l'administration d'abord, des ensembles de documents ensuite. Or, l'auteur n'a pas jugé bon de suivre ses propres recommandations, ne s'intéressant qu'à la deuxième phase de la critique externe : l'analyse des séries de documents. Cette faute de méthode explique plusieurs des lacunes et des erreurs que je noterai en leur temps. Il me paraît certain qu'il eût fallu décrire, même sommairement, la structure administrative de la Nouvelle-France et montrer les inter-relations de ses parties composantes. Fondée sur les grands documents officiels, comme l'édit de création du Conseil souverain et les commissions des gouverneurs et des intendants, cette description aurait été par la suite précisée, voire corrigée, par l'étude des diverses séries de documents publics, lesquels permettent de constater ce que devinrent dans la pratique et comment s'agencèrent les pouvoirs conférés parfois d'une façon un peu théorique aux administrateurs de la colonie.

Ainsi, eût-il examiné les rouages administratifs de la Nouvelle-France en 1667 et 1668, l'auteur n'aurait pas oublié comme il l'a fait - la Compagnie des Indes occidentales, dont la présence dans la colonie est essentielle à ce moment, et il ne se serait certes pas avisé de parler, sinon avec d'infinies précautions, d'un "gouvernement royal" en ces années-là ( $v . g . \mathrm{pp}$. $422,423)$. L'oubli est d'autant moins excusable que la Prévôté

\section{${ }^{6} \mathrm{AQ}, \mathrm{NF} 7$.}

7 AQ, NF 6, vol. I et IV. Voir aussi Pierre-Georges Roy, édit., Papier terrier de la Compagnie des Indes occidentales, 1667-1668. Beauceville, 1931. $378 \mathrm{p}$. 
de Québec, sur laquelle il a centré toute sa recherche, était le propre tribunal de la compagnie, qui en nommait les officiers chargés de rendre la justice et de publier des ordonnances en son nom! L'auteur, qui venait d'insister avec raison sur la nécessité de tenir compte même des séries de documents perdues (p. 405), a une fois encore eu le tort de trahir ses excellents principes. En partant des documents existants, il n'a pas pu rencontrer la Compagnie des Indes occidentales, qui n'a pas laissé d'archives organisées, si ce n'est les registres des prévôtés de Québec et de Trois-Rivières qui devinrent en 1674 la propriété des juridictions royales, et certains documents seigneuriaux ( $v . g$. le papier terrier de 1667-1668) qui furent incorporés aux archives de l'intendance.

Il faudrait relever quelques autres faiblesses de cette seconde partie: l'absence de distinction, par exemple, entre les sources communes à toute la colonie et celles qui sont particulières au gouvernement de Québec, et surtout l'incertitude dans laquelle

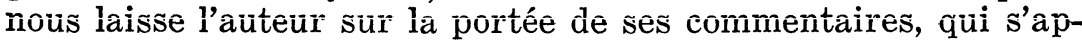
pliquent sans avertissement soit aux seules années 1667 et 1668, soit à des périodes plus longues, voire à tout le régime français. Constatons une fois pour toutes que, si on en juge par cet article, la rigueur et la précision ne sont point les qualités maîtresses de l'auteur.

Cette absence de rigueur et de précision est due pour une part à une extrême pauvreté de la langue aggravée par une construction grammaticale souvent déficiente. J'en donnerai pour preuve, dans un instant, le paragraphe consacré aux "édits et ordonnances du roi" (p. 408), qui n'est pas nécessairement plus mauvais que d'autres. Je m'y arrêterai pour montrer comment une forme défectueuse introduit souvent dans un texte des erreurs de faits ou des difficultés d'interprétation, et aussi pour expliquer dès maintenant l'origine de maintes affirmations erronées ou ambiguës que je discuterai plus loin. - De l'influence de la forme sur le fond, à laquelle refusent de croire plusieurs de mes jeunes amis, je propose, avant d'aller plus loin, les deux exemples suivants: "Le recensement de 1666, écrit l'auteur, révèle [...] la présence à Québec de 441 hommes servant comme domestique [sic]", etc. (p. 409) ; or, c'est du gouvernement de Québec qu'il s'agit, la ville n'en comptant que 148. Ou encore: "c'est le cas [...] de 206 domestiques et engagés, des 72 ecclésiastiques et de leurs hommes de travail" (p. 412); l'auteur ne veut pas dire, malgré les apparences, qu'il y avait dans le gouvernement de Québec 72 ecclésiastiques, recensés en 1666, mais bien 
72 ecclésiastiques et hommes de travail à leur emploi, ou, plus précisément, 30 ecclésiastiques ayant à leur service 42 hommes, pour un total de $72^{8}$. L'historien pense avoir écrit une chose, le lecteur en lit une autre, et la tour de Babel s'édifie.

\section{1. "Les édits et ordonnances du roi"}

Aux fins énoncées dans le paragraphe précédent, examinons, $\mathrm{du}$ seul point de vue de l'expression d'abord, le passage sur "les édits et ordonnances du roi" (p. 408), en nous gardant bien de prendre dans leur acception rigoureuse les mots "arrêts" et "édits", que l'auteur semble considérer comme synonymes:

Les édits et ordonnances du roi illustrent l'état de tutelle de la Nouvelle-France par rapport à la métropole.

Cette phrase, je le crains, ne signifie rien, "par rapport à" n'ayant que deux sens en français: pour ce qui est de et par comparaison à. Par ailleurs, étant une colonie, la Nouvelle-France ne pouvait qu'être sous la tutelle de la métropole. C'est un pur truisme. Peut-être l'auteur voulait-il insister sur le fait qu'elle jouissait de fort peu d'autonomie, les édits et ordonnances du roi illustrant à quel point elle était tenue en tutelle par la métropole?

On y trouve aussi bien des documents relatifs à des problèmes immédiats qu'à des politiques générales.

Chaque partie de la locution "aussi bien ... que" devant nécessairement être suivie de deux mots ou membres de phrase parallèles, la construction est fort boiteuse. Il fallait dire: relatifs aussi bien à des problèmes immédiats qu'à des politiques générales, ou encore: relatifs à des problèmes immédiats aussi bien qu'à des politiques générales ${ }^{9}$.

Dans l'un et l'autre cas toutefois, certains arrêts n'ont aucunement influencé l'administration ou la vie au Canada, et même ne correspondaient pas toujours à la réalité.

8 L'auteur est souvent brouillé avec les chiffres: dans le cas présent, le recensement donne les noms de 30 ecclésiastiques qui employaient 43 hommes, soit au total 73 individus.

9 Tout aussi boiteuse la construction suivante: "Comme le livre du marchand faisait foi de reçu [sic], il arrivait que l'homme d'affaires oubliât d'inscrire certains paiements et traduisait ses clients en cour [sic]." (p. 418) Ou celle-ci: "De plus, les contraventions aux règlements commerciaux faisaient l'objet d'une poursuite en cour [sic] par l'agent de la compagnie qui détenait le monopole et réclamait [qui réclamait ?] le respect de ses [?] prérogatives." (p. 406) C'est à la douzaine qu'on pourrait citer des phrases de ce type. 
Noterai-je en passant que, dans cette phrase introduite par l'adjectif indéterminé "certains", le "pas toujours" ne saurait se justifier, à mon avis, surtout quand la seconde proposition commence par "et même"? Il faudrait dire: et même ne correspondaient pas à la réalité; ou bien: d'autres ne correspondaient pas à la réalité. Mais s'agissait-il, dans les deux cas, des mêmes arrêts?

Ainsi en est-il des Edits de Marly en 1711 faussement basés sur les pouvoirs des seigneurs et qui plus est, ne furent pas respectés [...]

Ces édits sont en réalité deux arrêts, comme on peut le vérifier en retournant aux documents ${ }^{10}$. De plus, l'auteur ne révélant point l'objet ou le sujet de ces édits, le fait qu'ils soient "faussement basés sur les pouvoirs des seigneurs" paraît ici sans intérêt. Mais tout cela n'est rien devant l'énormité qui suit: l'emploi inouï de l'expression "et qui plus est", qui signifie en outre, dans le sens de et qui de plus, le qui prenant figure de pronom relatif, sujet du verbe "ne furent pas respectés"!

... ou de la dépendance, qui s'est avérée toute théorique, des commissaires ordonnateurs de l'Ile Royale et de la Louisiane envers l'intendant de la Nouvelle-France.

"S'avérer" étant d'un usage fort délicat, il eût mieux valu, dans cette phrase où le sens étymologique du verbe ne trouve pas son compte, recourir à "se révéler". Quoi qu'il en soit, il faut critiquer l'emploi d" "envers", qui ne peut être placé de cette façon qu'après un mot exprimant un sentiment ou une action, ou devant un nom désignant une chose morale. Il était facile de contourner la difficulté en parlant de l'autorité toute théorique des intendants sur les commissaires ordonnateurs de l'Ile Royale et de la Louisiane.

Encore plus probants sont les édits royaux qui supprimèrent, puis rétablirent officiellement la Prévôté de Québec en 1674 et 1677 alors que cette cour de justice fut plus active que jamais au cours de cette période de suspension, sans compter le refus d'insinuer et donc d'appliquer certains édits.

A qui sait lire, il apparaîtra, il me semble, que des édits royaux supprimèrent la Prévôté de Québec à une date que l'auteur ne donne pas, que d'autres la rétablirent en 1674 et en 1677, ce qui n'est pas exact. On s'interrogera cependant sur la portée

${ }^{10}$ Edits, ordonnances royaux, déclarations et arrêts du conseil d'état du roi concernant le Canada (Edits, ord., I), (Québec, 1854): 324-326. 
des premiers édits, dont l'auteur affirme d'abord qu'ils supprimèrent la prévôté, tout en suggérant ensuite qu'ils la suspendirent seulement; on se demandera encore quel rapport l'auteur veut établir entre "cette période de suspension" et le "refus d'insinuer" certains édits. Ce rapport - le croirait-on? - n'existe pas: les "refus d'insinuer" ne viennent pas de la Prévôté de Québec, mais du Conseil souverain, et ils n'ont rien à voir avec les années 1674 à 1677, la remarque s'appliquant, dans l'esprit de l'auteur, à tout le régime français!

Dans un article comme celui que j'étudie, rempli d'affirmations gratuites et de faits erronés, je n'ai pas d'autre choix - on le comprendra - que de suivre l'auteur à la trace, au risque d'impatienter le lecteur par de fréquentes interruptions. L'auteur, par exemple, vient de parler de la suppression ou de la suspension de la Prévôté de Québec, puis de son rétablissement. On a, il est vrai, dit et répété unanimement jusqu'ici que ce tribunal fut aboli en 1674 et rétabli en 1677, sans que pour autant il cessât de siéger. On s'en est étonné; l'auteur y voit, pour sa part, la preuve la plus évidente que certaines décisions du roi n'étaient pas appliquées dans la colonie - ce qui tendrait à infirmer quelque peu sa phrase sur "l'état de tutelle" de la Nouvelle-France. Cette affaire de suppression vaut d'être examinée d'un peu plus près.

Sa charte lui ayant concédé les droits de justice en NouvelleFrance ${ }^{11}$, la Compagnie des Indes occidentales avait établi, en 1667, deux prévôtés, l'une à Québec, l'autre à Trois-Rivières. Or, nul édit particulier ne vint supprimer la Prévôté de Québec; c'est plutôt dans l'édit portant révocation de la compagnie, abolie en décembre 1674, qu'il en fut question. En supprimant la compagnie et en réunissant à la Couronne ses possessions, droits et privilèges, Louis XIV devait prendre des dispositions pour que la justice continuât d'être rendue au Canada:

Comme aussi en conséquence de l'extinction, suppression et révocation de la compagnie, [...] voulons [...] que la justice y soit rendue en notre nom, par les officiers qui seront par nous pourvus; jusqu'à ce, pourront tous les officiers de la compagnie continuer [...] en notre nom les fonctions de leurs offices et charges en vertu des présentes lettres [...] ${ }^{12}$.

11 "Etablissement de la Compagnie des Indes Occidentales" (mai 1664), clause XXXI, dans Edits, ord., I: 46.

12 "Edit du roi portant révocation de la Compagnie des Indes Occidentales et union au domaine de la Couronne, des terres, isles, pays et droits de la dite Compagnie..." (déc. 1674), dans ibid., 77s. 
Les tribunaux établis par la compagnie continueraient donc de rendre la justice, mais au nom du roi, en attendant qu'il eût nommé de nouveaux officiers ou confirmé ceux qui étaient en place. Louis XIV, cependant, fit une exception pour le siège de la Prévôté de Québec,

... que nous avons éteint et supprimé, éteignons et supprimons: voulons et ordonnons que la justice y soit rendue par le conseil [souverain] en première instance, ainsi qu'elle l'étoit auparavant l'établissement de la compagnie [...] (p. 78).

Cette suppression - et non point suspension - ne touchait aucunement la Prévôté de Trois-Rivières, qui continuait d'exister, mais comme tribunal royal. Il me paraît évident, dès lors, qu'en abolissant la Prévôté de Québec le roi visait à ne pas multiplier les juridictions, le Conseil souverain siégeant déjà à Québec.

$\mathrm{Au}$ printemps de 1675, Louis XIV s'appliqua à reprendre en main l'administration de la justice en Nouvelle-France. Vraisemblablement à la demande de la Compagnie des Indes occidentales, qui avait été constamment mise en échec par Talon et Boutroue, le roi s'était abstenu en 1672 de donner un successeur à Talon; le 5 juin, il nomma un intendant, Jacques Duchesneau ${ }^{13}$. Le même jour, il confirmait l'établissement du Conseil souverain ${ }^{14}$, dont il avait désigné les membres les 26 et 27 avril ${ }^{15}$. Le 15 avril, il avait maintenu Gilles de Boyvinet dans sa charge de lieutenant général de la Prévôté de TroisRivières ${ }^{16}$ qu'il occupait depuis 1672 . Or, après son édit de décembre 1674, Louis XIV avait sans doute eu l'occasion d'entendre certaines représentations sur l'abolition de la Prévôté de Québec, peut-être de la part de Talon, qu'il écoutait volontiers, ou de Mgr de Laval, alors en France. De toute façon, le roi se ravisa, conserva ce tribunal et y renomma le lieutenant général Louis-Théandre Chartier de Lotbinière le 13 mai et le greffier Gilles Rageot le 17 mai ${ }^{17}$.

Si l'on veut bien se rappeler les conditions de la navigation à cette époque, on ne se surprendra pas que les documents royaux

13 Complément des ordonnances et jugements des gouverneurs et intendants du Canada, précédé des commissions des dits gouverneurs et intendants et des différents officiers civils et de justice (Edits, ord., III), (Québec, 1856), 42s.

14 Edits, ord., I: 83s.

$15 \mathrm{AQ}, \mathrm{NF} 12, \mathrm{I}: 57 \mathrm{v} .-62$.

16 Ibid., 74.

17 Ibid., 62v.s., 70. 
de décembre 1674, d'avril et de mai 1675, de même que du 5 juin 1675, apportés à Québec par Duchesneau, n'y soient arrivés que vers la fin d'août ou le début de septembre 1675; à l'exception de l'édit portant révocation de la compagnie, ils furent tous examinés le même jour (23 septembre 1675) par le Conseil souverain ${ }^{18}$. Pour les administrateurs coloniaux, les commissions de Chartier et de Rageot, qu'ils enregistrèrent au greffe du conseil, corrigeaient amplement le passage relatif à la Prévôté de Québec dans l'édit de décembre 1674, que du reste ils n'enregistrèrent pas, à supposer même qu'ils en reçurent copie. Dans la colonie, la Prévôté de Québec ne fut donc jamais abolie, le contre-ordre du roi, exprimé par les commissions de Chartier et de Rageot, arrivant en même temps que l'ordre d'abolition du tribunal - si, encore une fois, l'édit de décembre 1674 fut envoyé au Canada, ce qui n'est pas certain. Il est donc impossible de voir en tout cela, comme l'a fait l'auteur, une preuve que “certains édits" n'avaient pas d'effet sur l'administration coloniale ou qu'ils n'étaient simplement pas appliqués en NouvelleFrance. Il restait néanmoins, dans un acte officiel, une clause abolissant la Prévôté de Québec; seul un acte de même nature pouvait lever toute ambiguité sur le statut du tribunal québecois. Cet acte - un édit -, le roi le signa en mai 1677, établissant - ou rétablissant - la Prévôté de Québec ${ }^{19}$.

Cela dit, il me faut revenir à des considérations beaucoup plus générales sur la manière dont l'auteur fait la critique externe de cette première série de documents que sont les "édits et ordonnances du roi" - auxquels il ne se référera pas une seule fois dans le cours de son étude. Il eût été souhaitable, d'abord, que l'auteur insistât davantage sur la nature des documents émanant du roi : édits, ordonnances, déclarations, arrêts, règlements et mandements, bien sûr, mais aussi commissions des gouverneurs, des intendants et des officiers de la justice royale, confirmations de concession, lettres de noblesse, de naturalité, de dispense d'âge, etc.; souhaitable également qu'il décrivît mieux les séries où l'on retrouve ces divers documents: les neuf registres dont il parle ( $\mathrm{AQ}, \mathrm{NF} 16)$, mais aussi les dix registres des insinuations du Conseil souverain (AQ, NF 11) où furent consignés, entre autres, les décisions, directives et règlements royaux en vigueur dans la colonie. Ces deux séries sont indissociables et, à vrai dire, la seconde est de loin la plus

18 Jugements et délibérations du Conseil souverain de la NouvelleFrance (Jug. et délib.), 6 vol. (Québec, 1885-1891), I: 988-994.

10 Edits, ord., I: 90 s. 
complète et la plus utile ${ }^{20}$. En citant les insinuations du Conseil souverain, l'auteur eût mis en lumière la procédure administrative: le document signé de la main du roi devait être examiné par le Conseil souverain et enregistré sur son ordre pour être exécutoire; il eût encore fait état du droit de remontrance que le Conseil souverain acquit en 1667 et qui lui permettait de faire au roi ses critiques, commentaires et recommandations avant d'enregistrer un document qu'il tenait pour inadapté à la réalité canadienne ou préjudiciable à la colonie. S'il se fût rappelé tout cela, l'auteur eût certainement nuancé sa phrase sur "l'état de tutelle" de la Nouvelle-France.

Cette phrase, il l'eût peut-être entièrement remaniée, au demeurant, s'il avait vraiment fait la critique externe de l'ensemble des documents royaux, au lieu de se contenter de quelques mises en garde particulières qui ne sauraient tenir lieu d'analyse approfondie. Ce qu'il fallait expliquer, c'est la façon dont ces documents étaient préparés. Il est bien certain que le roi, même assisté par le ministre responsable de la Nouvelle-France, était incapable, à distance, de concevoir une législation particulière pour la colonie. Dans la plupart des cas, si l'on veut bien y faire réflexion, cette législation ne pouvait qu'être mise au point par les administrateurs coloniaux et recommandée par eux au ministre et au roi. De même que les commissions des officiers de justice, les confirmations de concession, les lettres de naturalité et de dispense d'âge, par exemple, étaient accordées par le roi sur proposition de l'intendant ou du gouverneur, de même, le plus souvent, la législation proprement dite était-elle, en quelque sorte, dictée au roi par ses représentants en Nouvelle-France. Ainsi voit-on fréquemment les gouverneurs et les intendants demander au roi telle ou telle ordonnance dont ils proposent même le contenu ${ }^{21}$.

20 L'auteur (note 10, p. 408) ne réfère le lecteur qu'à la série NF 16; assez curieusement, il le renvoie néanmoins à la série des $E d i t s$, ord. (3 vol., Québec, 1854-1856), laquelle reproduit un grand nombre de documents royaux, mais presque tous tirés des insinuations du Conseil souverain ( $A Q$, NF 11) qu'il ne cite pas - pas plus du reste que l'inventaire qu'on en a publié (Pierre-Georges Roy, Inventaire des Insinuations du Conseil souverain de la Nouvelle-France. Beauceville, 1921. $325 \mathrm{p}$.). Il faut noter en outre que la description des Edits, ord. faite par l'auteur est défectueuse: le lecteur comprendra que plusieurs documents royaux ont été publiés dans le tome I d'un premier ouvrage, dans le tome II d'un second et dans le tome III d'un troisième !

21 Voir par exemple la "Correspondance échangée entre la cour de France et l'intendant Talon...", dans Rapport de l'archiviste de la Province de Québec (RAPQ), 1930-31: 87s., 91; et la "Correspondance échangée entre la cour de France et le gouverneur de Frontenac pendant sa première administration (1672-1682)", ibid., 1926-27: 11, 34, 105, etc. 
Je cite enfin deux cas, choisis entre plusieurs, qui illustrent bien une autre manière d'élaborer les lois: le premier porte sur l'ordonnance interdisant la traite de l'eau-de-vie dans les bois, du 24 mai $1679^{22}$, le second, sur la déclaration du roi pour la conservation des minutes des notaires, du 2 août $1717^{23}$. Invité à légiférer sur la traite de l'eau-de-vie, Louis XIV demanda d'abord que fussent consultés vingt des principaux notables de la colonie, qui donnèrent leur opinion le 28 octobre 1678; le gouverneur et l'intendant, à leur tour, firent part au roi de leur sentiment; Louis XIV confia au Père de La Chaise et à l'archevêque de Paris le soin de lui faire rapport sur les divers mémoires en sa possession, puis rendit son ordonnance du 24 mai 1679, après avoir entendu Mgr de Laval. En 1717, le procureur général Collet, de passage à Paris, soumit aux autorités métropolitaines un projet de règlement pour la conservation des minutes des notaires. Elaboré entièrement au Canada, ce projet fut adopté à peu près tel quel et reproduit dans la déclaration du 2 août. Je ne veux pas multiplier les exemples. Il apparaît déjà que le court paragraphe consacré par l'auteur aux "édits et ordonnances du roi" n'apporte à peu près rien et ne peut qu'engager le lecteur dans des voies sans issue.

\section{2. "Les ordonnances des intendants et des gouverneurs"}

En abordant ce nouvel ensemble de documents, l'auteur note avec raison qu'on n'est pas certain de posséder "toutes les ordonnances émises par le "gouvernement" de la NouvelleFrance en 1667 et 1668" 24, étant donné, ajoute-t-il inconsidérément, qu' "elles ne furent pas transcrites dans des registres officiels avant $1705 "$ (p. 408). De nouveau, par sa façon mala-

${ }^{22}$ Edits, ord., I: 235s.

23 Ibid., I: 372-375.

${ }^{24}$ Les références de l'auteur sont souvent erronées. Après avoir décrit correctement, dans la note 13 (p. 408), les deux volumes d'ordonnances compilées par P.-G. Roy (Roy, édit., Ord., comm.), il cite l'inventaire, en quatre tomes, que Roy a publié des ordonnances des intendants rendues de 1705 à 1760 , mais en ajoutant au titre les dates "1706-1760", qui n'y apparaissent pas, la date de 1706 étant au surplus inexacte (Pierre-Georges Roy, Inventaire des ordonnances des intendants de la Nouvelle-France....Inv. ord. int. - 4 vol. Beauceville, 1919). Puis il ajoute: "Pour la période étudiée, 1667-1668, les ordonnances sont publiées dans le premier volume: 51-76." A la lecture de cette phrase qui suit immédiatement la description de l'inventaire de Roy, on sera bien excusable de comprendre qu'il s'agit du premier volume de cet ouvrage plutôt que de la compilation du même auteur dans laquelle se trouvent en effet ces ordonnances; par ailleurs, les ordonnances pour 1667 et 1668 sont aux pages 51 à 85, les pages citées par l'auteur correspondant aux ordonnances de 1667 seulement. 
droite de s'exprimer, l'auteur introduit dans son texte une double erreur: jamais, en effet, contrairement à ce qu'il vient d'écrire, les ordonnances de 1667 et 1668 ne furent transcrites dans des registres, la plus ancienne à l'avoir été portant la date du 7 septembre 1705; au demeurant, seules les ordonnances émanées de l'intendant furent ainsi conservées dans des registres, et non point, comme il l'affirme, toutes celles du "gouvernement" de la Nouvelle-France. L'auteur poursuit:

\begin{abstract}
De plus, l'imprécision des tâches se retrouve constamment à ce niveau [?]. Les ordonnances furent le fait de Talon, de Tracy, ou du triumvirat Tracy, Courcelles [sic] et Talon; elles avaient une portée plus ou moins grande et on en trouve, en outre, à d'autres niveaux de l'administration. Ce dernier facteur [?] est d'ailleurs capital pour préciser les préoccupations des administrateurs de la colonie. (p. 408s.)
\end{abstract}

Voilà tout ce que dit l'auteur au chapitre des ordonnances. C'est bien peu et par trop vague. On eût aimé qu'il montrât mieux "l'imprécision des tâches", qu'il nommât les "autres niveaux de l'administration" et qu'il dégageât un peu les "préoccupations des administrateurs". Ainsi livrées en vrac, ses considérations trop superficielles n'enrichissent guère le lecteur avide de se renseigner.

Ce seul passage justifierait de très longs commentaires. Je me limiterai à quelques remarques essentielles. Si, d'abord, il s'intéressait dans le paragraphe précédent à tout le régime français, l'auteur se restreint ici aux seules années 1667 et 1668 . Cela aurait dû l'inciter à examiner la structure administrative de la colonie pendant ces deux années. Il eût découvert que l'imprécision des tâches n'était point alors aussi grande qu'il le prétend, même si la création de la Compagnie des Indes occidentales en 1664 introduisit un élément perturbateur dans le système administratif mis en place en 1663 , et si la présence d'un lieutenant général (Tracy) de l'été de 1665 à l'été de 1667 relégua momentanément le gouverneur (Courcelle) au second rang. Des ordonnances étaient rendues, il est vrai, à différents échelons de la hiérarchie coloniale: par le lieutenant général, le gouverneur, l'intendant, le Conseil souverain, les prévôtés de Québec et de Trois-Rivières, et les justices seigneuriales; mais, pour bien comprendre le mécanisme législatif à ce moment précis, il faut, au préalable, se rendre compte de la situation fausse dans laquelle se trouvait l'administration coloniale depuis la création de la Compagnie des Indes occidentales. La grande faiblesse de l'article que j'étudie vient en effet de ce que l'auteur paraît 
ignorer totalement la présence de cette compagnie au Canada; du moins ne la nomme-t-il pas une seule fois et n'y fait-il aucune allusion.

Peu après la démission de la Compagnie des Cent Associés et la rétrocession de la Nouvelle-France au domaine royal (1663), Louis XIV nomma d'abord un intendant, qui ne passa pas au Canada, puis il établit un Conseil souverain à Québec ${ }^{25}$. Ce conseil était appelé à jouer, en plus de son rôle proprement judiciaire, un rôle administratif considérable: c'est lui qui contrôlerait les finances de la colonie, régirait la traite des fourrures, règlerait la police générale, réglementerait le commerce et nommerait les juges, les officiers de justice et les notaires. Quant au gouverneur, membre du conseil, il en était déjà réduit, individuellement, aux affaires militaires et diplomatiques. Or, en mai 1664, Louis XIV créait la Compagnie des Indes occidentales et lui remettait la Nouvelle-France en toute propriété, justice et seigneurie $^{26}$.

L'édit du roi pour l'établissement de la Compagnie des Indes occidentales ne fut enregistré par le Conseil souverain que le 6 juillet 1665, le même jour que la commission du lieutenant général Tracy, et immédiatement après elle ${ }^{27}$. Jusqu'à cette date, le régime royal instauré en 1663 s'était continué, et le Conseil souverain avait siégé régulièrement. L'acte d'établissement enregistré, le conseil ne fut plus convoqué qu'une fois en dix-sept mois, le 23 septembre 1665, aux fins d'ordonner l'enregistrement des commissions du gouverneur Courcelle, de l'intendant Talon et de l'agent général de la compagnie, Le Barroys ${ }^{28}$. Nommé par la compagnie, ce dernier avait reçu sa commission de Louis XIV, le 10 avril précédent. En sa qualité d'agent général, il avait séance et voix délibérative au Conseil souverain, "audessus du premier Conseiller" 29 . Une fois remplies les formalités de l'enregistrement, il eût été normal que la compagnie prît en main l'entière administration de la Nouvelle-France, laquelle venait de passer sous sa juridiction seigneuriale. Mais la compagnie faisait face à une sérieuse difficulté. Sa charte lui accordait le droit de nommer le gouverneur et les officiers du

25 "Edit de création du Conseil supérieur de Québec" (avril 1663), dans Edits, ord., I: 37-39.

26 "Etablissement de la Compagnie des Indes occidentales" (mai 1664), ibid., I: 40-48.

27 Jug. et délib., I: 364.

28 Ibid., 364-366.

29 Ibid., 366. 
Conseil souverain, auxquels le roi délivrerait leurs commissions; or, Louis XIV avait lui-même choisi et nommé le gouverneur, et même un intendant dont il n'était pas question dans l'acte d'établissement de mai $1664^{30}$; en outre, Tracy venait de débarquer à Québec avec le titre de lieutenant général. Ces trois personnages représentaient le roi, et non pas la compagnie. Deux pouvoirs coexistaient donc dans la colonie, qui allaient tôt ou tard s'affronter. Il faut voir un premier indice de tiraillements dans le fait que le Conseil souverain ne s'assembla pas avant le 6 décembre 1666. Ce jour-là, les trois représentants du roi nommèrent eux-mêmes les conseillers ${ }^{31}$. L'agent général n'était pas présent au conseil, et il n'y siégea jamais par la suite. Le conseil, néanmoins, dut céder à la compagnie la plupart de ses pouvoirs administratifs.

Sans la présence d'un intendant, tout se fût peut-être assez bien passé dans l'administration coloniale. Mais Talon était arrivé avec une juridiction civile étendue, concurrente avec celle de la compagnie elle-même: de par sa commission - dans laquelle, cela est à noter, il n'était fait aucune allusion à la compagnie -, l'intendant avait de grands pouvoirs dans le domaine de la justice, dont celui de "juger souverainem [en]t seul en matière Civile"; dans le vaste champ de la police, il avait pouvoir "de tout ordonner" ainsi qu'il verrait "estre juste \& a propos"; il

30 Louis XIV, il est vrai, prétendit avoir fait ces nominations avec l'accord de la compagnie: "comme la Compagnie connoist assez qu'elle ne pourroit pas trouver des personnes qui eussent assez de mérite et qui fussent assez autorisées pour occuper ces postes et les remplir dignement, elle a esté bien aise que le Roy fist cette nomination jusques à ce que, [...] cette Colonie s'augmentant considérablement, lad. Compagnie puisse alors par elle mesme trouver des sujets propres pour y envoyer." ("Correspondance échangée entre la cour de France et l'intendant Talon...", $R A P Q$, 1930-31: 6.) Cette explication m'a toujours paru controuvée. Il est certain, quoi qu'il en soit, que le roi se comportait avec le gouverneur et l'intendant comme avec ses représentants personnels; Courcelle et Talon, au reste, ne se considérèrent jamais sous l'autorité de la compagnie. Talon, pour sa part, manifestait fort peu d'intérêt pour cette dernière, allant jusqu'à déclarer à Louis XIV que "si sa Maté [Majesté] regarde bien ce vaste pays en toute son Estendue, quels changemens il peut recevoir a l'avenir par l'accroissement de ses habitations et la multiplication de ses colons et les avantages qu'Elle et ses successeurs en peuvent tirer, Elle y voudra tousjours des Gouverneurs de sa part qui n'estant pas aux gages de la Compe [Compagnie] et dans sa despendance ne se croiront pas obligez de se partager entre les Interests de sa Maté dans l'Establissem ${ }^{t}$ du pays et ceux de lad. comp. ${ }^{\text {e fort }}$ souvent opposez." (Ibid., 12.)

$31 \mathrm{Jug}$. et délib., I: $366 \mathrm{~s}$. Le roi lui-même les avait autorisés à faire ces nominations, et même à "changer l'establissement \& le pouvoir" du conseil, s'ils le jugeaient expédient. "Correspondance échangée entre la cour de France et l'intendant Talon...", $R A P Q, 1930-31: 4,7$. 
devait en outre avoir l'œil aux finances coloniales, dont il serait en quelque sorte le contrôleur ${ }^{32}$. Le roi, il est vrai, apporta dans la suite quelque tempérament à ces prérogatives: dans le domaine de la justice, par exemple, “quoy qu'il luy soit conféré l'authorité de juger seul souverainement et en dernier ressort les causes civiles, il [serait] bon néantm[oin]s qu'il ne s'en [servît] pas que dans une nécessité absolue, estant de conséquence de traiter les affaires dans leur ordre naturel et de n'en point sortir, que par des occasions indispensables" 33 ; pour les règlements de police, le roi lui rappelle sans cesse de les préparer en accord avec le Conseil souverain et même avec les principaux habitants du pays ${ }^{34}$. Vu la nature de ses attributions, l'intendant n'avait, face à la compagnie, qu'une alternative: ou se subordonner à cette dernière - ce qu'un officier royal ne pouvait accepter que provisoirement, d'autant qu'il lui eût fallu la complicité du roi - ou bien se donner autorité et prestige en empiétant toujours davantage sur les prérogatives de la compagnie ce qu'il fit, et son successeur (Boutroue) après lui. Perceptibles déjà de 1665 à $1668^{35}$, les entreprises des intendants sur les pouvoirs de la compagnie furent plus nombreuses et se firent plus ouvertement à partir de 1669 , sous Boutroue. Il reste que, pendant la première administration de Talon, l'intendant, cheville ouvrière du progrès de la Nouvelle-France et animateur par excellence de la vie coloniale, ne jouissait encore, sur les plans administratif et surtout législatif, que d'une autonomie fort limitée.

A l'automne de 1665, en somme, au moment où elle aurait dû assumer les destinées de la colonie, la Compagnie des Indes occidentales se trouvait dans un état d'impuissance presque totale. Théoriquement, elle avait entière juridiction sur les affaires militaires et diplomatiques; en fait, reprise par le roi, cette juridiction avait été confiée au lieutenant général et au gouverneur. Sur le plan de l'administration civile, la compagnie était, en vertu de sa charte, quasi souveraine; mais la présence d'un intendant, représentant le pouvoir royal, menaçait ses droits exclusifs, d'autant plus que la compagnie ne possédait pas encore d'organe législatif. Le Conseil souverain, le plus haut tribunal de la colonie, lui avait échappé entièrement, et

32 "Correspondance échangée entre la cour de France et l'intendant Talon ...", RAPQ, 1930-31: 3s.

33 Ibid., 7.

34 Ibid., 8, 10, 26.

35 Voir, par exemple, Roy, édit., Ord., comm., I: 49. 
les prévôtés de Québec et de Trois-Rivières (établies en 1667) n'auraient qu'une juridiction limitée, de sorte qu'elle devrait s'en remettre presque entièrement, sur le plan législatif, au Conseil souverain et aux représentants du roi, lesquels s'insinueraient par ce biais dans les questions administratives qui lui étaient propres.

En plus des attributions administratives, ce qui nous intéresse ici, ce sont les divers organes législatifs de la colonie. Or, pour voir clair dans la hiérarchie pendant les années 1667 et 1668 , il faut tenir compte à la fois des prérogatives propres aux divers échelons, du pouvoir représenté par chacun et de sa juridiction territoriale. Ainsi le lieutenant général, le gouverneur et l'intendant représentaient le pouvoir royal et avaient juridiction dans toute la Nouvelle-France; les prévôtés représentaient la Compagnie des Indes occidentales et leur juridiction était limitée au gouvernement où elles siégeaient; chaque justice seigneuriale représentait un seigneur particulier et sa juridiction ne dépassait pas les bornes de la seigneurie; quant au Conseil souverain, qui avait juridiction dans toute la NouvelleFrance et représentait le pouvoir royal, il légiférait souvent, de par la volonté même du roi ${ }^{36}$, dans les domaines réservés à la Compagnie des Indes occidentales, laquelle, au demeurant, n'avait en propre aucun organe législatif dont la juridiction territoriale lui permît d'atteindre l'ensemble des gouvernements et des postes sous son autorité. - Il était essentiel, dans le cadre de cette étude, de bien comprendre que seuls les représentants du pouvoir royal (lieutenant général, gouverneur, intendant et Conseil souverain) avaient, en 1667 et 1668 , le pouvoir de légiférer dans toute la Nouvelle-France.

Les cours seigneuriales ne possédaient que des attributions législatives fort réduites, dans le domaine de la police particulière; les prévôtés pouvaient intervenir dans les domaines civils non réservés exclusivement au Conseil souverain ou aux représentants du roi, ce qui ne leur laissait, en pratique, que la réglementation de la police dans le gouvernement où elles siégeaient, et dans la mesure seulement où elles n'allaient pas à l'encontre de la législation générale; le Conseil souverain, dont étaient membres le lieutenant général, le gouverneur et l'intendant, publiait des ordonnances dans tous les domaines de la vie civile; l'intendant, même lorsqu'il n'avait pas l'obli-

36 Je rappelle les directives de Louis XIV à Talon de préparer et de publier les règlements de police en collaboration avec le Conseil souverain. Notons que la police désignait à cette époque toute l'administration civile à l'exception seulement de la justice et des finances. 
gation de faire adopter ses projets de règlements par le Conseil souverain, lui faisait souvent entériner ses ordonnances, afin d'éviter un affrontement trop direct avec la compagnie; le gouverneur, enfin, - ou le lieutenant général pendant qu'il fut au Canada - n'avait juridiction exclusive que sur les affaires militaires et diplomatiques, mais il s'associait souvent, à toutes les époques, aux ordonnances des intendants, en les contresignant, surtout quand elles avaient trait aux questions religieuses, sur lesquelles il devait exercer une surveillance spéciale.

A la fin de son article, l'auteur revient sur la question des ordonnances et apporte quelques précisions supplémentaires : “à Québec [sic], en 1667 et en 1668”, les ordonnances provenaient "de trois niveaux administratifs différents : du gouverneur ou de l'intendant, du Conseil souverain et de la Prévôté de Québec" (p. 423). Il oublie, bien sûr, le lieutenant général et les justices seigneuriales; en revanche, il nomme le gouverneur qui, en 1667 et 1668, n'a laissé aucune ordonnance signée de lui seul. Il note même que les ordonnances de la Prévôté de Québec "ne couvraient [sic] que la région [sic] de Québec"; puis il ajoute : "par contre [sic], la juridiction royale de Trois-Rivières et le bailliage de Montréal émettaient aussi des ordonnances" (p. 423, note 62). (Il faut bien peu connaître l'administration de la colonie pour parler d'une "juridiction royale" à TroisRivières sous le régime de la Compagnie des Indes occidentales - ou encore d'un "procureur général" (p. 414) à la Prévôté de Québec.) L'auteur, qui a entrevu momentanément les limitations territoriales de certaines juridictions, n'en tient plus compte dans la suite :

L'étude du contenu de ces ordonnances n'a toutefois de valeur pour une si courte période que si elle permet de préciser la portée des unes par rapport aux autres, afin de déterminer s'il y a partage de juridiction au niveau administratif entre chacune des administrations concernées. (p. 423)

Voilà une question qu'il fallait examiner. Or, l'auteur s'est contenté à son habitude de deux ou trois notations toutes superficielles :

En fait, aux trois niveaux, l'on trouve des ordonnances à portée limitée à un individu [sic] et d'autres étendues [?] à toute la population. De plus, même si à une occasion le Conseil souverain reprit une ordonnance émise d'abord par la Prévôté ${ }^{37}$, il ne semble y avoir eu aucune tentative de la

37 Il s'agit d'une ordonnance rendue par la prévôté le 22 avril 1667 , enjoignant aux habitants de Québec et des lieux circonvoisins de garder 
part des autorités supérieures pour réprouver ou approuver les ordonnances émises à un niveau inférieur.

La question posée reste sans réponse, parce que l'auteur n'a pas compris les bases du "partage" des juridictions dont il parle.

Pour illustrer en quelque sorte visuellement le mécanisme législatif de la Nouvelle-France en 1667 et 1668, j'ai fait l'inventaire des ordonnances émises aux différents échelons administratifs et j'en ai dressé un tableau. Sur cinquante-cinq ordonnances, une fut rendue par le lieutenant général, neuf par l'intendant ${ }^{38}$, trois conjointement par le lieutenant général, le gouverneur et l'intendant ${ }^{39}$, vingt-six par le Conseil souverain ${ }^{40}$,

leurs cochons enfermés ( $A Q, N F$ 19, I, 2e partie: 6v.s.). Elle fut reprise par le Conseil souverain le 28 avril 1667 (Jug. et délib., I: 395s.). Cet emprunt n'est pas anormal sur le plan de l'administration et on n'en doit tirer qu'une conclusion: que l'ordonnance de la prévôté n'avait pas produit le résultat recherché. L'auteur aurait dû noter qu'à son tour, le 13 juillet 1668, la Prévôté de Québec (AQ, NF 19, II : 91v.) reprenait une ordonnance du Conseil souverain du 20 juin 1667 obligeant les colons à couper les chardons (Jug. et délib., 1: 406). Cette dernière ordonnance du conseil s'adressait à tous les habitants de la colonie; celle de la prévôté, aux habitants du gouvernement de Québec seulement. La Prévôté de Québec rendit, en 1668, le 28 avril et le 26 juin respectivement, deux autres ordonnances relatives l'une à la garde des bestiaux, l'autre à celle des volailles (AQ, NF 19, II: 51v. et 72).

38 Parmi les "ordonnances" compilées par Roy (P.-G. Roy, édit., Ord., comm.), deux documents préparés par Talon ne peuvent pas être considérés comme des ordonnances de ce dernier. Il s'agit de ses "projets de règlements" sur la justice (I: 51-54) et "sur la distribution des terres du Canada" (I: $55-64)$. En réalité, le premier de ces textes était déjà rédigé le 9 septembre 1666, puisque Talon s'y réfère dans un document de ce jour (I: 39); il en fut probablement de même pour les règlements sur la distribution des terres. Talon ne pouvait mettre lui-même ces règlements en vigueur parce que l'administration de la justice et le régime seigneurial dépendaient exclusivement de la Compagnie des Indes occidentales, propriétaire de la Nouvelle-France en toute justice et seigneurie, et aussi parce que le roi lui avait enjoint de rendre les règlements de police conjointement avec le conseil. L'intendant attendit le rétablissement du Conseil souverain, lequel adopta ses règlements et leur donna force de loi le 24 janvier 1667 (Jug. et délib., I: 374). Dans le tableau II, j'ai donc compté ces deux documents comme des ordonnances du Conseil souverain. - Il est encore à noter que l'ordonnance de Talon "sur les assemblées de pieuses femmes ou filles connues sous le nom de la Sainte-Famille" (Roy, Ord., comm., I : 64s.), enregistrée par le Conseil souverain le 14 mars 1667, fut peu après rayée des registres du conseil avec le consentement de Talon (Jug. et délib., I: 384). Je l'ai néanmoins inscrite dans mon tableau. - Enfin, la "déclaration de M. Talon au sujet de la demande de concession de l'île Bourdon faite par M. D'Ailleboust de Musseaux", du 27 juin 1668 (Roy, édit., Ord., comm., I: 83), n'est pas une ordonnance et je ne l'ai pas retenue.

39 L'auteur (p. 423, note 62) attribue à Tracy, Courcelle et Talon trois ordonnances conjointes; or, une seule des trois qu'il cite fut émise 
et seize par la Prévôté de Québec ${ }^{41}$; les registres seigneuriaux des années 1667 et 1668 n'ont pas été conservés et aucune ordonnance des justices seigneuriales ne nous est parvenue; nous n'avons pas non plus une seule ordonnance signée par le gouverneur. [Voir tableau II, page 190.]

Ce tableau fait bien ressortir le partage des responsabilités, en 1667 et 1668, sur le plan législatif. Le Conseil souverain, par exemple, a juridiction exclusive sur la monnaie, le commerce et la traite de l'eau-de-vie, de même que sur la politique seigneuriale et l'organisation judiciaire. Tous ces domaines, notons-le, étaient de la compétence administrative des seigneurs de la Nouvelle-France, la Compagnie des Indes occidentales, et c'est peut-être, en certains cas, à la demande de ces derniers ou du moins avec leur aveu qu'on légiférait en ces matières. Le conseil avait encore juridiction exclusive sur les prix; la Prévôté de Québec, il est vrai, fixa, le 19 juillet 1667, le prix des "souliers sauvages", mais, outre le fait que ces souliers n'étaient pas marchandises d'importation, il s'agissait, semble-t-il, d'un cas particulier qui n'intéressait peut-être que certains individus du seul gouvernement de Québec ${ }^{42}$. Le tableau paraît indiquer, cependant, des attributions communes au Conseil souverain et à la Prévôté de Québec sous les rubriques suivantes : ordre ou permission de s'assembler; législation relative aux volontaires, travaillants et domestiques; voirie; et règlements concernant les bestiaux, chardons, etc. Là encore, pourtant, le partage des tâches subsiste. Le 24 janvier 1667, le Conseil souverain permet la tenue d'une assemblée pour pro-

conjointement, les deux autres étant signées respectivement par Talon et Tracy.

40 Je n'ai pas retenu comme ordonnances les ordres de comparaître, de faire assigner les témoins et autres concernant un procès en particulier, ni les "commissions" à divers fonctionnaires pour enquêter sur un litige ou sur un délit.

41 L'auteur (p. 423, note 62) a trouvé " 24 ordonnances et avis" dans les registres de la Prévôté de Québec pour 1667 et 1668. Pour ma part, j'y ai relevé seize ordonnances, six en 1667 et dix en 1668. En cette dernière année, je compte une ordonnance du 21 août dont je n'ai pas retrouvé le texte, mais qui est résumée dans une autre ordonnance du 24 septembre (AQ, NF 19, II: 134v.). Pour ce qui est des "avis", je n'ai aucune idée de ce dont il s'agit ici. Au reste cela importe peu, l'essentiel étant de savoir ce qu'est une ordonnance.

$42 \mathrm{AQ}, \mathrm{NF}$ 19, I, 2e partie: 36v. Un mot illisible, dans le texte de cette courte ordonnance, empêche d'en déterminer exactement la portée: "Ont esté taxez les souliers sauvages aprestez par les [? ] a trente sols la paire Usage d'homme..." 
TABLEAU II

Ordonnances, 1667 et 1668

Légime seign.: législation
règlements particuliers

Justice : organisation règlements particuliers

Commission d'huissier

Ordres de publier des documents

Ordres de faire enquête

Ordire ou permission de s'assembler

Expulsion de la colonie

Dîme

Défense de médire

Législation relative aux volontaires, travaillants et domestiques

Monnaie : valeur, contrôle

Commerce

Traite de l'eau-de-vie

Prix, tarifs

Voirie (cas particuliers)

Règlements concernant les bestiaux, chardons, etc.

Droits de propriété

Divers

TOTAL

Lt gén.,

Lt gén. Int. gouv., int. Cons. s. Prév. Q.

$\begin{array}{lll}3 & 1 \\ & 3\end{array}$

1
1
3

1

1

2

2

1

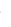

1

11

24

1

11

19

3

26 
céder à l'élection d'un syndic ${ }^{43}$; en conséquence de cette permission, le 5 février suivant, la prévôté ordonne aux habitants de se réunir pour tenir l'élection ${ }^{44}$. Ces deux ordonnances se situent donc à des niveaux d'autorité bien distincts. Le 14 mars 1667, le conseil rend une ordonnance concernant les domestiques qui quittent le service de leurs maîtres ${ }^{45}$; la prévôté, le 6 décembre 1667, oblige tous les volontaires et travaillants à prendre une concession ou à se mettre au service des habitants ${ }^{46}$. Les deux ordonnances sont de même nature, sans doute, mais la première, rendue par le conseil, fait loi dans toute la colonie ${ }^{47}$, alors que la seconde, rendue par la prévôté, ne vaut que dans le gouvernement de Québec. Moins nettement tranché, toutefois, apparaît le cas de la juridiction du conseil et de la prévôté en matière de voirie : le 20 juin 1667, le conseil détermine le tracé et la largeur d'un chemin entre Québec et la côte Sainte-Geneviève, et oblige les habitants à participer à sa construction et à son entretien ${ }^{48}$; la prévôté, pour sa part, émet le 18 novembre 1667 une ordonnance pour la réparation du chemin entre la haute et la basse ville de Québec ${ }^{49}$. A titre d'hypothèse, je propose l'explication suivante : le tracé des chemins entre la ville et les seigneuries ou entre ces dernières relevait à l'époque $\mathrm{du}$ Conseil souverain, cependant que la réparation et l'entretien des chemins situés dans la censive de Québec, laquelle dépendait directement de la compagnie (comme une seigneurie de son seigneur), tombaient sous la juridiction du tribunal de la compagnie, c'est-à-dire la prévôté. Quant aux règlements de police concernant les bestiaux, les mauvaises herbes, etc., j'en ai parlé dans la note 37 . Ces règlements étaient de la juridiction des prévôtés (voire des justices seigneuriales), et le conseil ne s'y intéressait guère que pour deux raisons : leur conférer une plus grande autorité ou en étendre l'application à toute la colonie. Le Conseil souverain possédait donc des attributions extrêmement précises, et jouait dans la colonie un rôle qui lui était exclusif.

43 Jug. et délib., I: 372s.

$44 \mathrm{AQ}, \mathrm{NF} 19, \mathrm{I}, 1$ ère partie: 10 .

$45 \mathrm{Jug}$. et délib., I: 382s.

$46 \mathrm{AQ}, \mathrm{NF}$ 19, I, 2e partie: 93.

47 On a ici un exemple de la nécessité d'intervenir dans laquelle se trouvaient le Conseil souverain ou les représentants du roi, quand un règlement, même de peu d'importance, devait être mis en vigueur dans toute la colonie.

$48 \mathrm{Jug}$. et délib., I: 409s.

$49 \mathrm{AQ}, \mathrm{NF} 19$, I, 2e partie: 84. 
La même chose peut être dite de la Prévôté de Québec. Outre les ordonnances citées dans le paragraphe précédent, elle en rendit quelques autres : deux pour obliger les habitants de la seigneurie de Maure à fournir à leur seigneur copies de certains titres ${ }^{50}$ (classées sous "divers" dans le tableau II); une autre interdisant aux habitants du fort Saint-FrançoisXavier de médire ${ }^{51}$; trois ordonnances relatives aux heures d'ouverture, de fermeture et aux vacances du tribunal ${ }^{52}$, et deux sur les procédures d'assignation ${ }^{53}$, les cinq dernières ordonnances étant en quelque sorte des règlements de régie interne. La Prévôté de Québec avait donc des attributions propres, dans le domaine de la police, et une juridiction territoriale précise, si bien qu'en 1667 et 1668 elle ne se trouva en concurrence - et encore moins en opposition - avec aucun autre échelon de la hiérarchie coloniale.

Nous n'avons qu'une seule ordonnance du lieutenant général pour la partie de l'année 1667 pendant laquelle il résida dans la colonie. Elle est datée du 27 juillet et permet aux jésuites de nommer tel passeur qu'il leur plaira sur la rivière SaintCharles ${ }^{54}$. Ce document sans signification particulière aurait pu être signé tout aussi bien par le gouverneur ou l'intendant; les jésuites s'étant adressés à lui, c'est Tracy qui la rendit. On peut remarquer que, durant son séjour de deux ans au Canada, Tracy n'émit seul que deux autres ordonnances, semble-t-il, toutes deux à la demande de la Compagnie des Indes occidentales, antérieurement à l'enregistrement des commissions de Talon et de Courcelle et pendant la période d'inactivité du Conseil souverain ${ }^{55}$. Courcelle, pour sa part, qui fut sept ans gouverneur (1665-1672), n'a laissé qu'une seule ordonnance signée de lui seul : elle est du 12 juillet 1670 et renouvelle l'interdiction déjà faite par le Conseil souverain de porter de l'eau-de-vie dans les bois ${ }^{56}$. Le rôle individuel du lieutenant général et du gouverneur sur le plan de la législation paraît donc négligeable à cette époque, et plus particulièrement en 1667 et 1668 .

En 1667, peu avant le départ de Tracy, les représentants royaux rendirent ensemble trois ordonnances : une portait sur

50 Ibid., II : 134v. (21 août et 24 septembre 1668). Voir note 41.

51 Ibid., I, 2e partie: 19v. (17 juin 1667).

52 Ibid., II : 47 (13 avril 1668), 97v. (20 juillet 1668) et 121v. (17 août 1668).

53 Ibid., II : 3 (27 janvier 1668) et 108 ( 7 août 1668).

54 Roy, édit., Ord., comm., I: 70.

55 Ibid., I : 22-25 (15 et 21 juillet 1665).

56 Ibid., I: 95s. 
la dîme et l'entretien des cures (23 août) ${ }^{57}$, une deuxième expulsait un militaire de la colonie ( 27 août) ${ }^{58}$, et une troisième ordonnait la confection du papier terrier de la Compagnie des Indes occidentales (26 juillet) ${ }^{59}$. On ne connaît que trois autres ordonnances conjointes du lieutenant général, du gouverneur et de l'intendant ${ }^{60}$ : la première, dont on ignore la date, est mentionnée dans le règlement du 23 août et avait trait à la dîme; les deux autres, des 9 et 31 mai 1666, mettaient fin aux démêlés qui avaient troublé la courte administration de Mézy ${ }^{61}$. Que conclure de l'examen de ces documents pour ce qui nous occupe ? D'abord, rien n'indique que certaines matières eussent été réservées à ce "triumvirat" (p. 408) comme tel. Les deux ordonnances de 1666 sur l'affaire Mézy furent publiées ensuite de l'ordre particulier du roi de la régler de concert et définitivement ${ }^{62}$, et partant elles ne tirent pas à conséquence dans l'étude de la répartition des tâches. Les ordonnances sur la dîme eussent été, en temps normal, de la juridiction du gouverneur, comme représentant personnel du souverain et, à ce titre, délégataire du droit d'exercer une surveillance constante sur la vie religieuse; or, en 1667, c'est le lieutenant général (Tracy) qui représentait temporairement la personne du roi dans la colonie, et c'est à lui qu'il revenait de les signer; mais, d'une part, Louis XIV avait confié à Tracy, Courcelle et Talon le soin d'étudier conjointement la question des dîmes ${ }^{63}$ et, d'autre part, Mgr de Laval, qui demanda ces ordonnances, avait adressé ses requêtes aux trois représentants du roi ${ }^{64}$. Talon rédigea tout au moins le second règlement ${ }^{65}$, aux nombreuses implications économiques et sociales, et le signa avec ses deux collègues. De l'ordonnance du 27 juillet 1667 pour la confection

57 Ibid., I: 70-74.

58 Ibid., I: 74.

59 Roy, édit., Papier terrier ..., 7-9.

60 On ne saurait donner le nom d'ordonnance aux réponses que Tracy, Courcelle et Talon firent aux demandes de Le Barroys, l'agent de la Compagnie des Indes occidentales (septembre 1666). Ce texte, qui n'intéressait pas directement la population, ne fut ni publié ni affiché dans la colonie; il fut seulement enregistré au greffe du conseil, le 16 septembre 1666, "pour servir aux dits seigneurs [la compagnie] ce qu'il appartiendra". (Roy, édit., Ord., comm., I: 33-44.)

61 Roy, édit., Ord., comm., I: 28-32.

62 "Correspondance échangée entre la cour de France et l'intendant Talon ...", RAPQ, 1930-31: 6 .

63 Ibid., 10.

64 Ibid., 75.

65 Loc. cit. 
du papier terrier, émise conformément au vœu formulé par la compagnie en septembre $1666^{66}$, l'un ou l'autre eût pu se charger seul, ainsi que Talon le fit, en pareille matière, à deux reprises ${ }^{67}$; s'ils l'émirent collectivement, ce fut vraisemblablement pour donner plus d'éclat et de solennité à la publication d'un document qui intéressait au premier chef les seigneurs de la NouvelleFrance. L'ordre d'expulsion du 27 août 1667 contre le sieur de la Fredière, enfin, requérait nécessairement l'intervention du lieutenant général ou du gouverneur (qui commandaient les troupes), cet individu, neveu de $M$. de Salière, étant capitaine et major au régiment de Carignan; en outre, c'est le gouverneur qui délivrait en général les congés permettant de quitter la colonie; la triple signature peut s'expliquer par le désir - à cause de l'opposition violente de Salière - de faire preuve de beaucoup d'autorité ${ }^{88}$, et aussi par le fait que, selon les termes de sa commission ${ }^{69}$, l'intendant aurait mené l'enquête sur la conduite excessive de ce militaire. Peu importent, au reste, les raisons exactes de cette collaboration occasionnelle des représentants du roi pendant le sćjour de Tracy dans la colonic, puisque, dans les domaines où leur participation personnelle était obligatoire, ni le lieutenant général ni l'intendant ne manquèrent d'apposer leurs signatures au bas des ordonnances; par ailleurs, collectivement, les trois ne s'immiscèrent dans aucune affaire qui fût de la compétence d'un échelon inférieur. On objectera peut-être que le Conseil souverain s'occupa lui aussi des dîmes; cela est vrai, mais pour arrêter une simple modalité, à savoir que le propriétaire d'une terre et son fermier paieraient l'un et l'autre la dîme, à proportion de leurs revenus respectifs en grains et en argent ${ }^{70}$. On ne saurait donc, ici non plus, parler d'imprécision des tâches et de chevauchement des juridictions sur le plan législatif.

Selon le tableau II toujours, l'intendant est le seul à s'occuper, en 1667 et 1668, des questions suivantes : commission d'huissier, ordres de faire enquête, et droits de propriété. Or, la commission d'huissier qu'il accorda à Romain Becquet le 20 mars 1668, Talon la signa "au nom de la Compagnie des Indes occidentales" ${ }^{71}$ et certainement à la requête de cette dernière. Les

${ }_{66}$ Roy, édit., Ord., comm., I: 41 (XXV).

67 Ibid., I: 47-49, 79.

68 "Correspondance échangée entre la cour de France et l'intendant

Talon ...", $R A P Q, 1930-31: 85,89$.

69 Ibid., 3.

70 Jug. et délib., I: 480s. (20 mars 1668).

71 Roy, édit., Ord., comm., I: 77s. 
ordres de faire enquête ${ }^{72}$ découlaient des attributions de l'intendant dans le domaine de la justice, et n'auraient pas à vrai dire une bien grande signification, n'eût été la suite réservée à celui qui visait les Dames de la Sainte-Famille. Cette ordonnance fut enregistrée par le Conseil souverain (voir note 38) qui, peu après, la fit rayer de ses registres d'insinuation : on peut voir là, à bon droit, une indication de la puissance du conseil à cette époque, lequel dominait à bien des égards l'intendant lui-même. Quant à l'ordonnance du 13 septembre $1667{ }^{73}$, elle confirmait, à la demande des sulpiciens, l'arrêt rendu le 20 août précédent par le Conseil souverain relativement à leurs droits de propriété sur un emplacement revendiqué par Pierre Normand dit $\mathrm{La}$ Brière ${ }^{74}$. Dans une autre ordonnance, du 27 février 1668, Talon, qui n'aurait pu agir de la sorte dans le cas de ses règlements personnels, ordonnait au Conseil souverain l'enregistrement d'un édit du roi contre les blasphémateurs ${ }^{75}$; le conseil, les prévôtés et les justices seigneuriales étaient autorisés cependant à enregistrer et à faire publier leurs propres ordonnances et les documents les concernant: le conseil le fit à deux reprises pendant la courte période qui nous intéresse ${ }^{76}$. Trois autres ordonnances de Talon sont des règlements particuliers relatifs au régime seigneurial. Celle du 22 mai 1667, toutefois, qui oblige "les concessionnaires de terre à abattre le bois et à mettre deux arpents en culture chaque année" ${ }^{77}$, est la reprise d'un passage de la législation "sur la distribution des terres du Canada" adoptée par le Conseil souverain le 24 janvier 1667 (voir note 38). En rappelant ce document, Talon n'innovait donc pas, non plus du reste qu'en rendant son ordonnance du 25 mai 1668 pour la confection du papier terrier du gouvernement de Trois-Rivières ${ }^{78}$, laquelle fut publiée à la demande du procureur fiscal, représentant de la compagnie, et en vertu de l'ordonnance du 26 juillet 1666 signée par Tracy, Courcelle et Talon. Reste l'interdiction, datée du 22 mai 1667, de cueillir des grains la nuit, etc. ${ }^{79}$. Avec les ordres de faire enquête cités précédemment, cette ordonnance est la seule qui paraisse une initiative personnelle de l'intendant; il semble en

72 Ibid., I: 64 s., $68 \mathrm{~s}$.

73 Ibid., I: 75s.

74 Jug. et délib., I: 444-446.

75 Roy, édit., Ord., comm., I: 77.

76 Jug. et délib., I: 401s., 521.

77 Roy, édit., Ord., comm., I: 66-68.

78 Ibid., I: 79.

79 Ibid., I: 65s. 
même temps qu'elle aurait pu être émise tout aussi bien par le Conseil souverain, et que partant on serait justifié de parler enfin de double juridiction, voire d" "imprécision des tâches". Cela n'est point : cette ordonnance, qui présentait un caractère d'urgence, fut rendue à Montréal où Talon séjournait pour lors, et ne s'adressait qu'aux habitants de ce gouvernement. Il est certain qu'on a simplement profité de la présence de l'intendant pour conférer plus d'autorité à un règlement que le bailliage de Montréal (justice seigneuriale) avait le pouvoir d'imposer dans sa juridiction ${ }^{80}$. La dernière ordonnance de Talon pour l'année 1668 - et la dernière dont nous avons à faire état dans cet article - est une invitation aux habitants à lui soumettre leurs griefs avant son départ pour la France ${ }^{81}$. Sa commission lui donnait en effet le droit d" informer" de toutes plaintes qu'on lui soumettrait; il pouvait même, à sa discrétion, rendre jugement lui-même ou référer les justiciables à un tribunal régulier. L'intendant, en prononçant ses sentences, ne troublait point l'ordre de la justice, ayant été fait juge par le roi; toutefois, Talon, comme Hocquart au XVIII siècle, abusa quelque peù de ce privilège dont le roi - on l'a dit précédemment - voulait qu'il usât seulement dans des circonstances exceptionnelles. A l'examen des neuf ordonnances de Talon pour 1667 et 1668 , on est donc forcé de conclure que l'intendant ne fut en conflit de juridiction, sur le plan législatif, avec aucun officier ou aucun tribunal de la Nouvelle-France.

De ce long développement sur les pouvoirs administratifs et surtout législatifs des divers échelons hiérarchiques de la colonie, il ressort clairement, à mon avis, que n'existait point cette "imprécision des tâches" dont l'auteur écrit qu'il la "re-

80 Il ne faudrait pas oublier que, en bonne administration, le supérieur détient généralement tous les pouvoirs délégués à l'inférieur; aussi, avant de parler d'imprécision ou de dédoublement des tâches, convient-il d'examiner si c'est le supérieur qui intervient pour de bonnes raisons dans les affaires ordinairement réservées à l'inférieur, ce qui est légitime, ou si c'est l'inférieur qui s'arroge les pouvoirs et les prérogatives du supérieur; dans les occasions où l'inférieur paraît s'ingérer dans les responsabilités du supérieur, il est nécessaire de se demander s'il ne le fait pas de l'aveu de ce dernier, en vertu par exemple d'une délégation temporaire de pouvoirs. - Ajouterai-je que, dans le Canada moderne, on rencontre, de même qu'autrefois en Nouvelle-France, des juridictions diverses s'exerçant dans un domaine unique - la justice par exemple - sans que pour autant règne la confusion; les gouvernements fédéral, provinciaux et municipaux possèdent des tribunaux, et aux trois échelons on détient, dans les domaines des finances, des travaux publics, etc., des attributions propres dans des limites territoriales précises.

81 Roy, édit., Ord., comm., I : 83-85. 
trouve constamment" au "niveau" du "gouvernement" de la Nouvelle-France (p. 408). Au contraire, autant qu'on en peut juger par les ordonnances qui ont été conservées, on peut affirmer avec beaucoup de justesse que les juridictions étaient pour ainsi dire tranchées au couteau. On ne trouve rien non plus qui puisse étayer l'affirmation de l'auteur que "les procès-verbaux de ces registres [de la Prévôté de Québec] contiennent [...] des ordonnances et des avis [?] de portée aussi grande que celles [sic] émises par les juridictions supérieures : gouverneur, intendant et Conseil souverain" (p. 411). Il apparaît enfin que l'auteur serait bien embarrassé de devoir préciser "les préoccupations des administrateurs de la colonie" à partir des ordonnances émises par les divers "niveaux" de l'administration (p. 408s.).

$\mathrm{Si}$, des quelques réflexions de l'auteur sur "les ordonnances des intendants et des gouverneurs", il ne reste rien qui vaille, la longue analyse que je viens de faire aura néanmoins quelque utilité - du moins je l'espère - puisqu'elle montre le rôle absolument primordial du Conseil souverain de la NouvelleFrance en 1667 et 1668. En pratique, il détenait alors l'autorité suprême dans la colonie, dont il réglait presque toute l'activité. Jamais plus il n'aura une importance aussi grande qu'en ces quelques années. L'intendant, par contre, appelé à devenir l'administrateur le plus puissant du Canada, n'a encore que fort peu d'autonomie. Son action individuelle est entravée en 1667 et 1668 par les privilèges de la Compagnie des Indes occidentales tout autant que par l'obligation dans laquelle il se trouve de travailler en étroite collaboration avec le conseil. L'obstacle majeur reste la compagnie. C'est Boutroue, dont en général on ignore jusqu'au nom, qui, pendant sa courte administration (1668-1670), fera la percée décisive contre la compagnie et qui en précipitera la décadence. Au retour de Talon, en 1670, la conjoncture administrative sera pour la première fois favorable à l'essor de l'intendant.

\section{3. "La correspondance générale"}

A ma première lecture de l'article que j'examine ici, j'attendis ce passage avec impatience. Dès son entrée en matière, en effet, l'auteur, qui reprochait aux historiens d'avoir jusqu'à lui négligé la critique externe des sources, avait piqué ma curiosité par la remarque suivante :

On a tout au plus mentionné que la correspondance officielle des administrateurs canadiens [?] altérait parfois la vérité et dissimulait une partie des faits. (p. 404) 
Je me réjouissais à l'idée qu'il pousserait beaucoup plus loin que ses devanciers l'analyse d'un ensemble si important de documents. Arrivé à ce paragraphe (p. 409), je me précipitai sur la première phrase :

Les lettres et les mémoires de Talon (comme ceux de tous les autres intendants et gouverneurs [sic]) ne relatent pas tout.

L'auteur, me suis-je dit, commence par répéter ce que ses aînés ont affirmé unanimement avant lui. C'est conforme aux règles de la pédagogie ; aller du connu à l'inconnu, méthode infaillible et ... traditionnelle.

Ils pèchent surtout par omission: on ne tenait pas en effet à dévoiler des activités plus ou moins honnêtes.

J'étais, je le sentais, sur le bord de troublantes révélations. L'accusation en tout cas était belle : la correspondance de tous les gouverneurs et de tous les intendants comportant des omissions, tous ces officiers et tous ces administrateurs, Talon en tête, connaîtraient enfin une juste réprobation. Accusation "globale", me suis-je dit, comme l'histoire que pratiquent les historiens de la nouvelle vague; mais, ayant achevé ma lecture de ce paragraphe sans rencontrer la moindre preuve d'un délit quelconque, j'ajoutai à ma précédente réflexion : accusation gratuite aussi.

De plus, ces documents ne livrent souvent que des bribes de la vie à Québec.

Encore des omissions ! Si la répétition est la mère de la connaissance, elle l'est parfois de l'ennui ...

Force m'était de constater que l'auteur n'avait encore rien écrit de plus que les vieux historiens, et même qu'il en avait écrit beaucoup moins. Déçu, je vis se dessiner tout aussitôt une nouvelle accusation :

On pensait bien plus à l'avenir qu'à décrire l'activité même des gens. On vivait de projets.

Ces deux phrases sonnent encore bien étrangement à mon oreille. Le gouverneur et l'intendant n'avaient pas pour tâche de faire de la littérature, que je sache, mais de bâtir un pays. On ne vivait pas uniquement de projets pour autant, et Talon n'avait rien d'un rêveur. J'ai tort, dira-t-on, de pressentir ici tout au moins un reproche à l'intendant ? Poursuivons notre lecture jusqu'à la fin de ce court paragraphe : 
Il n'est qu'à considérer le "Mémoire de Talon sur l'état
présent du Canada (1667)" pour s'en persuader. Ayant décrit
le Canada en 3 paragraphes, l'administrateur en consacre
le double aux possibilités de développement. Par la suite, il
accorde $11 / 2$ page à la description de l'état ecclésiastique et
surtout à la nécessité de limiter le pouvoir des religieux
[sic] sur le temporel, mais il règle le cas du peuple en 7 lignes.

Le dépit n'est-il point perceptible dans la chute de cette dernière phrase, comme si l'auteur en voulait à Talon de n'avoir pas pensé davantage à faciliter le travail des historiens quand il écrivait au ministre?

Certes, Talon n'a pas tout dit, Dieu merci : il écrirait encore et c'en serait fait de nous, pauvres historiens, dont le métier trouve son fondement le plus solide dans les omissions et les contradictions des documents existants et dans l'absence des autres. Il est exact aussi que Talon se soucie beaucoup de l'avenir, car il n'ignore pas qu'administrer c'est prévoir; mais il ne le dissocie jamais du présent, qui fait tout de même, quoi qu'en dise l'auteur, l'objet principal de sa correspondance. L'auteur tire son affirmation de l'analyse d'un seul document, un "Mémoire sur l'état présent du Canada" (1667), qui n'est pas nécessairement un bon exemple. Il aurait dû examiner plutôt l'ensemble de cette correspondance. Mais à quoi tiennent les choses ? Le mémoire de 1667 lui-même consacre trois fois plus d'espace à décrire la situation existante qu'à évoquer des "perspectives d'avenir". Outre les sujets mentionnés par l'auteur, Talon traite aussi, dans ce document, de la noblesse, de la justice et de la guerre ${ }^{82}$. - Eût-il lu avec attention la correspondance de Talon, l'auteur aurait sans doute remarqué ce passage d'une lettre de l'intendant à Colbert (19 octobre 1667) :

Si je n'estois bien persuadé que vous avez de plus agréables et de plus importantes affaires que ne sont celles du Canada, je vous en donnerois un destail dans lequel je n'obmettrois rien des moindres particularités de ce qui s'y passe: mais il ne seroit d'aucune utilité. ${ }^{83}$

Mon rôle n'étant point de refaire l'article de l'auteur mais d'en montrer les faiblesses les plus graves, je n'ai pas à entreprendre ici la critique externe de la correspondance générale. Je note tout au plus qu'il eût été nécessaire d'expliquer que les lettres de Tracy et de Courcelle n'ont pas été conservées et que

82 "Correspondance échangée entre la cour de France et l'intendant Talon ...", $R A P Q, 1930-31$ : 63 .

83 Ibid., 90. 
la série connue sous le nom de correspondance générale comprend, outre les lettres expédiées du Canada au ministre et au roi, celles de ces derniers aux administrateurs de la colonie. Il eût été non moins important de faire rapidement l'inventaire des lettres expédiées et reçues en 1667 et 1668, en tenant compte de celles qui ont été perdues, et surtout de rappeler que lettres et mémoires étaient invariablement accompagnés de nombreuses pièces annexes, voire de dossiers complets, dont il eût fallu montrer l'intérêt et dire ce qu'il en advint. Il eût été essentiel enfin de décrire les conditions particulières dans lesquelles s'échangeait cette correspondance par suite de la distance, de la fermeture du fleuve pendant huit ou neuf mois de l'année, et des risques de la navigation; essentiel aussi de montrer, comme l'a fait Frégault ${ }^{84}$, comment les lettres et les mémoires des administrateurs de la Nouvelle-France étaient reçus, dépouillés, analysés dans les bureaux du ministère, et comment s'élaboraient les réponses du ministre et, du même coup, les politiques et la législation qu'on voulait appliquer au Canada.

\section{4. "Les actes notariés"}

Les actes notariés "constituent [...] une mine de renseignements fort utiles", mais "ils doivent être soumis à une critique externe rigoureuse" :

De prime abord, il faut signaler que tout n'était pas objet d'un acte devant notaire, d'où la nécessité d'apporter des nuances majeures à l'étude quantitative [sic] de ces données [?] Nuance [sic] que la comparaison avec d'autres sources rend heureusement possible. (p. 409)

Plus je relis ces phrases, moins j'y vois clair. L'emploi du mot tout ("tout n'était pas objet d'un acte devant notaire"), comme précédemment dans le paragraphe sur la correspondance générale (qui "ne relate pas tout"), est beaucoup trop vague, en tout cas, pour que saute aux yeux la nature des "nuances majeures" dont parle l'auteur.

Ainsi les greffes des notaires exerçant leur profession dans la région [sic] de Québec en 1667 comprennent moins de [?] 585 engagements sur un total de 313 actes. Le recensement

84 Guy Frégault, Le XVIIIe siècle canadien. Etudes (Montréal, 1968), 166-169, 172 .

85 "Moins de 5", serait-ce là un des "points de repère précis" (p. 407) que prétend fournir l'auteur? 
de $1666^{86}$ révèle pourtant la présence à Québec [sic] de 441 hommes servant comme domestique, engagé, volontaire ou travaillant [sic]. (p. 409s.)

Deux remarques d'ordre exégétique s'imposent ici : l'une, pour rappeler que c'est du gouvernement de Québec que parle l'auteur, et non point de la ville ou de la région de Québec; l'autre, pour corriger l'impression que les 313 actes notariés sont tirés de l'ensemble des "greffes des notaires exerçant leur profession dans la région de Québec en 1667", alors que ces actes représentent le total de leurs minutes pour l'année 1667 seulement parmi lesquelles se trouvent un nombre indéterminé d'engagements.

Mais aussi bien le déclarer net : l'auteur s'est complètement fourvoyé dans ses statistiques sur les notaires du gouvernement de Québec en 1667. Selon lui, il y en aurait eu quatre en exercice : Claude Aubert (sic), Romain Becquet, Pierre Duquet et Paul Vachon (p. 409, note 17). Or, il a oublié Michel Filion et le plus important de tous, Gilles Rageot (pourtant greffier de la Prévôté de Québec). D'après lui encore, Auber, Becquet, Duquet et Vachon auraient reçu "un total de 313 actes"; leurs répertoires pourtant n'en énumèrent que 243 pour l'année $1667^{87}$ et leurs greffes n'en contiennent que 194. A cela s'ajoute une erreur de méthode : en se limitant aux actes notariés de l'année 1667 seulement, dont par la suite il comparera néanmoins certaines données avec celles des registres de la prévôté pour les deux années 1667 et 1668 , l'auteur se condamne fatalement à fausser les perspectives et à multiplier les fautes d'interprétation.

En conséquence, il m'apparaît nécessaire, pour évaluer correctement les conclusions de l'auteur dans le reste de son étude, de dresser dès maintenant le tableau des actes notariés reçus en 1667 et 1668 dans le gouvernement de Québec. Dans la première colonne, on trouvera le nombre des actes inscrits au répertoire de chaque notaire, et dans la deuxième, le nombre des actes

86 Dans sa référence au recensement de 1666 (p. 409, note 18), l'auteur commet de nouveau deux erreurs: dans le titre et dans la date (qui sert de tomaison). Au lieu de Rapport des Archives de la Province de Québec (1930-31): 1-154, il aurait fallu: Rapport de l'archiviste de la Province de Québec, 1935-36: 1-154.

87 Les greffes de tous ces notaires ont été inventoriés par PierreGeorges et Antoine Roy, Inventaire des greffes des notaires du régime français, tomes I à IV (Québec, 1942-43): Claude Auber (I: 115-149), Romain Becquet (II: 252-279, III: 3-195), Pierre Duquet (II: 109-248), Paul Vachon (II: 6-89), Michel Filion (II: 94-109) et Gilles Rageot (III: 197-300, IV : 3-254). 
qui, bien qu'au répertoire du notaire, sont disparus de son greffe ${ }^{88}$.

TABLEAU III

Actes notariés dans le gouvernement de Québec (1667 et 1668)

\begin{tabular}{cccc}
\hline Notaire & Années & Au répertoire & Absents \\
\hline Claude Auber & 1667 & 30 & \\
Romain Becquet & 1668 & $\frac{35}{65}$ & \\
& 1667 & 110 & 44 \\
Pierre Duquet & 1667 & $\frac{209}{319}$ & $\frac{1}{45}$ \\
& 1668 & 43 & 5 \\
Paul Vachon & 1667 & $\frac{44}{87}$ & $\mathbf{5}$ \\
& 1668 & 60 & 10 \\
Michel Filion & 1667 & $\frac{59}{119}$ & 1 \\
& 1668 & $\frac{4}{6}$ & \\
Gilles Rageot & 1667 & $\frac{213}{175}$ &
\end{tabular}

Total des actes : $1667: 458-1668: 526-1667-68: 984$

Parmi les quatre cent cinquante-huit actes notariés de 1667, on ne compte que sept engagements. L'auteur a raison de noter combien ils sont peu nombreux. Mais, avant de déclarer que ceci ou cela n'était pas "objet" d'un acte notarié, il aurait dû, selon les exigences d'une critique externe "rigoureuse", se demander si les actes notariés du gouvernement de Québec en 1667 et 1668 nous sont tous parvenus. Je n'ai pas à répondre

${ }^{88} \mathrm{Ce}$ tableau comprend les quittances, annulations, avenants, etc. des années 1667 et 1668 rédigés au bas d'actes notariés des années antérieures. 
à cette question; c'était à l'auteur de le faire. Je me bornerai ici encore à montrer la nécessité qu'il y avait de se la poser. Tout d'abord, le tableau III indique que quarante-neuf actes de 1667, inscrits aux répertoires, ne se trouvent plus dans les minutiers. L'auteur ne s'y est point arrêté. Un septième notaire, que l'auteur ne mentionne pas, exerça aussi dans le gouvernement de Québec en 1668. Il s'agit de Jean Leconte, nommé le ler mars 1668 (AQ, NF 19, II : 28v.), dont le greffe et le répertoire sont perdus. En outre, un simple sondage, fort sommaire à la vérité, donne néanmoins des résultats propres à faire réfléchir. La collection de pièces judiciaires et notariales des Archives du Québec $(A Q, N F 25)$ regroupe un grand nombre d'expéditions d'actes notariés; on en trouve en particulier huit de Becquet et quatre de Rageot; or, trois minutes de ces expéditions de Becquet et trois de celles de Rageot sont absentes de leurs greffes et ne sont pas inscrites dans leurs répertoires, soit six sur douze. Voici un autre exemple : l'auteur fait état quelque part (p. 413) de trois contrats insinués après les délais fixés. Ces contrats avaient été signés respectivement par Filion, Audouart et Becquet ${ }^{89}$; des trois, seul le premier est décrit au répertoire du notaire et conservé dans son greffe. Enfin, on rencontre souvent dans les insinuations de la Prévôté de Québec ${ }^{90}$ des actes dont on n'a aucune connaissance par les autres sources : Pierre-Georges Roy en a publié deux, l'un de Rageot, l'autre de Vachon, ce dernier du 2 novembre $1667^{\circ 1}$. Il semble donc, à première vue du moins, que les greffes et les répertoires des notaires, tels qu'ils nous sont connus, soient loin d'être complets. C'est une question qui reste à élucider, mais qu'on ne saurait négliger sans de grands inconvénients dans une étude comme celle que s'était proposée l'auteur.

Pour la première fois, il se réfère ici au recensement de 1666, document capital pour son étude ultérieure de la population du gouvernement de Québec. On s'étonne, cependant, qu'il ne cite nulle part le recensement de $1667^{92}$, alors que son article porte sur cette année-là. L'utilisation de ce document lui aurait permis d'indispensables comparaisons avec le recensement de 1666, et aurait été, surtout, l'occasion d'évaluer son postulat de

89 Jug. et délib., I: 386, 391s., 456, 458s.

90 Douze registres conservés aux Archives judiciaires de Québec, inventoriés par Pierre-Georges Roy, Inventaire des insinuations de la Prévôté de Québec (Inv. ins. Prév. Q.), 3 vol. (Beauceville, 1936).

91 Roy, Inv. ins. Prév. Q., III : 181-183, 192s.

$92 \mathrm{Ce}$ recensement a été publié par Benjamin Sulte, Histoire des Canadiens-français, 1608-1880, IV (Montréal, 1882), 64-78. 
départ sur le caractère commercial de la Nouvelle-France, puisque le recensement de 1667 fournit pour chaque terre le nombre des bestiaux et des arpents en culture, ce que ne donne point celui de 1666. Ne dirait-on pas que, des deux documents, il a retenu le moins utile à son propos et le plus éloigné de son sujet de recherche? Sans cette faute de jugement, l'auteur, qui s'intéresse si fort dans la suite au genre d'activité de la population et singulièrement aux hommes de métier, aurait eu la possibilité de calculer, par exemple, la proportion des artisans qui possédaient des terres et de constater avec quelle vigueur ils les cultivaient, de façon à déterminer dans quelle mesure les artisans du Canada vivaient réellement de leur métier; de même, il eût fourni de précieux renseignements sur l'exploitation commerciale de la terre par des fermiers aux gages de citadins ou de gros cultivateurs de la campagne; il eût ainsi évité les approximations excessives dont il se contentera vers la fin de son article.

Vu l'usage que l'auteur fait du recensement de 1666, il est important de s'assurer de l'exactitude des données qu'il en a tirées. A plusieurs reprises il parlera de domestiques, d'engagés, de volontaires et de travaillants. Voyons comment ces divers groupes de travailleurs mâles, célibataires ou dont l'épouse n'avait point encore passé au pays, se répartissaient dans le gouvernement de Québec en 1666. Mais entendons-nous d'abord sur le sens des mots. On peut partager ces travailleurs en deux grandes catégories : les engagés (tenus de servir un maître pendant une période de temps déterminée) et les hommes libres, qualifiés de volontaires (venus dans la colonie de leur propre initiative) ou de travaillants, deux termes qui, en pratique, étaient synonymes. Le volontaire était un travaillant, bien que ce dernier ne fût pas forcément un volontaire; les travaillants se recrutaient parmi les anciens engagés et les fils de la colonie qui ne vivaient plus chez leurs parents; du moment où ils obtenaient une terre ou se mariaient, volontaires et travaillants n'étaient plus désignés que comme habitants, ou charpentiers, arquebusiers, etc., selon leur métier. Les engagés étaient tous, par la force des choses, des domestiques, de même que les volontaires et les travaillants qui se donnaient un maître, sans égard au fait qu'ils possédaient ou non un métier. C'est dire que tout individu qui travaillait à plein temps pour un maître était réputé domestique ${ }^{93}$. Dans le tableau IV, j'ai tenu compte de ces dis-

93 Quand l'auteur écrit, par exemple, que "le gouvernement de Québec comptait plus de domestiques et d'engagés que de ménages" (p. 413), le mot engagés ne peut qu'embrouiller son affirmation sans y rien ajouter. 
tinctions : sous la rubrique domestiques, on trouve à la fois des engagés et des hommes libres; sous volontaires et travaillants, on ne trouve que des hommes libres qui n'avaient point de maîtres au moment du recensement. On peut donc lire ce tableau de la façon suivante : à Québec, par exemple, il y avait 116 domestiques, dont 34 avaient un métier, et 32 volontaires et travaillants, dont 23 avaient un métier, soit un total de 148 individus, dont 57 avaient un métier; des 116 domestiques, 90 étaient des engagés, dont 21 avaient un métier, ce qui laisse 26 domestiques non engagés; enfin, un calcul légèrement plus compliqué permet de trouver le nombre des hommes de métier non engagés : il faut soustraire le nombre des hommes de métier engagés de celui des hommes de métier servant comme domestiques, et additionner le résultat au nombre des hommes de métier volontaires et travaillants, ce qui donne 36 individus pour la ville de Québec. - A noter enfin que j'ai tenu compte du fait que cinq noms apparaissent en double au recensement ${ }^{94}$. [Voir tableau IV, page 206.]

Quatre cent quarante hommes engagés ou susceptibles de s'engager en 1666, et sept contrats d'engagement seulement en 1667. Y a-t-il lieu de s'en surprendre ? Non pas. A qui connaît le mode de recrutement pratiqué à l'époque pour assurer au Canada une main-d'œuvre indispensable et éventuellement des colons, ce petit nombre d'engagements notariés paraîtra normal. Ecartons tout de suite de la discussion ces engagements de jeunes gens de la colonie à un artisan en vue de l'apprentissage d'un métier, ou bien à un maître pour lui tenir lieu de domestique pendant une période de temps déterminée. Les sept engagements de 1667 sont de cette sorte. Or, cela n'a rien à voir avec la très grande majorité, sinon avec la totalité des deux cent vingtneuf engagés du gouvernement de Québec en 1666. Ces derniers, en effet, s'étaient engagés en France à servir pendant trois années au Canada, moyennant vingt à trente écus par année ${ }^{95}$ et le passage gratuit sur le navire qui les amènerait dans la colonie, et les en ramènerait au bout de trois ans s'ils décidaient de ne point s'y établir. Ils recevaient avant l'embarquement une avance de salaire d'environ vingt-cinq ou trente livres. A leur arrivée, ils étaient distribués aux habitants par les soins du Conseil souverain ou de l'intendant, qui tenaient registre de leur affectation.

${ }^{94}$ Ce sont, à Beaupré, ceux de Charles Garnier ( $R A P Q, 1935-36$ : 32 et 53) et de Nicolas Verieu (p. 52); à l'île d'Orléans, ceux d'Antoine Baillon (pp. 72 et 76), de Guillaume LeMieux (pp. 69 et 84) et de Jean LeVasseur (pp. 70 et 79).

95 En 1664, l'écu valait quatre livres au Canada (Jug. et délib., I : 205). 


\section{TABLEAU IV}

Domestiques, engagés, volontaires et travaillants (gouvernement de Québec, 1666)

\begin{tabular}{|c|c|c|c|c|c|c|c|c|c|c|}
\hline & \multicolumn{2}{|c|}{ Domestiques } & \multicolumn{2}{|c|}{ Volont. et trav. } & \multicolumn{2}{|c|}{ Grand Total } & \multicolumn{2}{|c|}{ Engagés } & \multirow{2}{*}{$\begin{array}{c}\text { Domes- } \\
\text { tiques } \\
\text { non } \\
\text { engagés }\end{array}$} & \multirow{2}{*}{$\begin{array}{c}\text { H.de } \\
\text { Métier } \\
\text { non } \\
\text { engagés }\end{array}$} \\
\hline & Total & H. de M. & Total & H. de M. & Individus & H. de M. & Total & H. de M. & & \\
\hline Québec & 116 & 34 & 32 & 23 & 148 & 57 & 90 & 21 & 26 & 36 \\
\hline Beaupré & 47 & 13 & 31 & 9 & 78 & 22 & 32 & 8 & 15 & 14 \\
\hline Beauport & 33 & 12 & 0 & 0 & 33 & 12 & 27 & 10 & 6 & 2 \\
\hline Ile d'Orléans & 35 & 6 & 46 & 17 & 84 & 23 & 33 & 5 & 2 & 18 \\
\hline Saint-Jean, etc. & 30 & 3 & 8 & 4 & 38 & 7 & 21 & 3 & 9 & 4 \\
\hline Sillery, etc. & 22 & 2 & 6 & 0 & 28 & 2 & 20 & 2 & 2 & 0 \\
\hline N.-D. des Anges & 16 & 5 & 16 & 6 & 32 & 11 & 4 & 1 & 12 & 10 \\
\hline Lauzon & 2 & 0 & 0 & 0 & 2 & 0 & 2 & 0 & 0 & 0 \\
\hline TOTAL & 301 & 75 & 139 & 60 & 440 & 135 & 229 & 50 & 72 & 84 \\
\hline
\end{tabular}


En les recevant, les habitants devaient rembourser le conseil des avances de salaire et s'engager à ne point donner congé à leurs domestiques, et les domestiques à ne point quitter le service de leurs maîtres, pendant les trois années de l'engagement. S'il arrivait qu'un maître voulût se défaire de son engagé, il devait le remettre à la garde du conseil, qui le confiait, aux mêmes conditions, à un autre habitant. ${ }^{96}$ Il n'y avait donc pas de place, dans toute cette procédure, pour la rédaction d'un contrat notarié, du moins pas au Canada, et soulever la question des engagements de la façon que l'a fait l'auteur, c'est à la fois poser un faux problème et induire le lecteur en erreur, sans pour autant prouver que "tout n'était pas objet d'un acte devant notaire", puisque aussi bien il existe d'autres engagements notariés.

Les actes notariés, selon l'auteur, présentent bien des lacunes :

Il en est également ainsi 97 pour les ententes à caractère commercial qui semblent se faire à l'amiable d'autant plus que les échéances sont à court terme: elles font donc rarement l'objet d'actes notariés. (p. 410)

Je soupçonne l'auteur d'être encore sous le charme de son postulat sur le caractère commercial de la colonie, de sorte qu'il n'a pas pu s'empêcher, une autre fois, de sauter aux conclusions : les ententes "semblent se faire à l'amiable", donc elles font "rarement l'objet d'actes notariés". L'auteur suppose ici trois choses, et il n'en démontre aucune : les ententes commerciales étaient relativement nombreuses, elles étaient à courte échéance et elles faisaient rarement l'objet d'actes notariés. Au demeurant, cette phrase eût-elle quelque portée, elle saperait la vraisemblance du postulat de l'auteur : conçoit-on, en effet, une activité commerciale un peu importante sans transactions à long terme ? Il y a plus : l'auteur éprouve, pour les registres de la prévôté, une sorte d'amour exclusif, volontiers jaloux, qui obnubile son sens de l'objectivité, un peu comme il arrive parfois au biographe pour son personnage. Parmi les sources qu'il passe en revue, aucune ne vaut la sienne : la correspondance générale ne livre "souvent que des bribes de la vie à Québec" (p. 409), les actes notariés sont "décrits à la légère comme les documents les plus intéressants de notre histoire" (p. 409), les registres du Conseil souverain ne comportent "qu'un nombre restreint d'individus"

96 Voir Jug. et délib., I : 29, 30, 31, 76, 77s., 104, 201-206, 222s., 223s., 262s., 275, 303, 305, 310, 312, 313, 320, 321, 326s., 328, 359, 382s., 449, 589.

97 On ne voit pas à quoi cela se rapporte exactement. 
et d' "assez rares" renseignements sur la société, et comptent peu de "procès-verbaux" (p. 410s.).

Les actes notariés, cela est évident, n'ont point la sympathie de l'auteur :

Il faut aussi se méfier des contrats qui n'ont pas de suite.

C'est le cas des concessions de terre en série à des gens qui quittèrent Québec [sic] assez tôt et ne laissèrent pas d'autres traces de leur séjour dans la colonie. (p. 410)

A vue de nez, la mise en garde est opportune. Mais, à la réflexion, un contrat qui n'a pas de suite, qu'est-ce à dire ? Les contrats de mariage, de vente, les bails, les engagements, les testaments ont toujours une suite obligatoire, à moins d'être invalidés par un tribunal. Car un acte notarié, c'est une loi privée qui règle, dans une affaire particulière, la conduite des parties; seuls un amendement à cette loi par le moyen d'un autre contrat ou sa résiliation pure et simple, du consentement des parties, peuvent en modifier ou en supprimer le caractère contraignant ${ }^{98}$. Mais peūt-être n'eñ allait-il pas ainsi pour les "concessions de terre en série" ? La question ne devrait même pas être posée. L'auteur, encore une fois, aura oublié les usages de l'époque dont il parle. Qui étaient, en effet, les concessionnaires de terres ? Si l'on exclut les habitants qui recevaient une seconde concession, c'étaient ou d'anciens engagés ou des volontaires et des travaillants. L'ancien engagé qui demandait une terre offrait en général de bonnes garanties de sérieux, voire de compétence : si, après trois années de service obligatoire et d'apprentissage chez un habitant, il avait librement choisi de rester dans la colonie, c'est d'une part qu'il s'y était acclimaté, et que d'autre part il se sentait apte à défricher et à cultiver désormais à son propre compte. Le plus souvent, au moment de la concession, pour ne pas dire toujours, il avait depuis quelque temps commencé, avec l'accord du seigneur, à mettre en valeur la terre qu'il convoitait. De même, au volontaire ou au travaillant, on ne remettait d'habitude un contrat de concession notarié qu'après une période de probation d'une année ou deux. De sorte que, dans la majorité des cas, la terre qu'on concédait n'était plus, au moment de l'acte notarié, entièrement en friche; souvent elle comptait quelques arpents en culture. C'est le contrat de con-

98 Dans le greffe de Becquet, par exemple, on trouve en 1667 un acte d'obligation du 22 août qui fut amendé les 6 et 11 mai 1668; on y rencontre aussi cinq actes annulés: une obligation du 24 novembre, trois contrats de mariage du 18 octobre et un du 25 octobre. Tous ces actes sont suivis soit d'un avenant, soit d'un acte de résiliation, de sorte que l'historien ne peut s'y tromper. 
cession qui était la suite de l'exploitation de la terre plutôt que l'inverse. L'auteur semble oublier du reste que les seigneurs n'avaient aucun intérêt à distribuer les terres à l'aveuglette; on m'objectera le fait que ces mêmes seigneurs n'avaient pas le loisir de refuser une terre à qui la demandait; cela est vrai, et c'est pourquoi on inventa le billet de concession - aussi appelé "billet d'assurance" - ou promesse de concéder une terre après un certain temps, quand le requérant en aurait diligemment poussé les travaux de défrichement et commencé la mise en valeur ${ }^{99}$. C'est l'usage de la période probatoire et du billet de concession qui explique les "concessions en série", décernées le même jour à des dizaines de colons, et non point des impulsions périodiques, aussi subites qu'irréfléchies, de la part des seigneurs ou des concessionnaires comme paraît le suggérer l'auteur.

$\mathrm{Au}$ demeurant, l'acte de concession avait la même force contraignante que tout autre acte notarié. Plusieurs de ces contrats, au dire de l'auteur, n'eurent point de suite. Faut-il comprendre - en supposant qu'il n'y aurait pas eu dans ces cas de période probatoire - que les concessionnaires ne prenaient même pas possession de leurs terres ? Cela est peu probable, puisque celles-ci leur étaient concédées sur leur demande explicite. Il serait plus vraisemblable que certains colons se fussent découragés après des tentatives peu fructueuses ou qu'ils eussent été happés par la traite des fourrures et la course des bois. Dans l'une et l'autre éventualité, ou l'habitant aurait vendu sa terre pour la valeur des travaux qu'il y aurait faits, ou le seigneur l'aurait réunie temporairement au domaine pour la concéder de nouveau à la première occasion. Quoi qu'il arrivât, l'acte de concession notarié avait donc toujours une suite. Pour la découvrir, cependant, l'auteur aurait dû, en plus du "curriculum vitæ" des concessionnaires qu'il affirme avoir retracé (p. 416), étudier les mutations de propriété depuis la concession originale. C'est alors seulement qu'il eût été en mesure de se prononcer correctement sur cette question.

Examinons, par exemple, certaines "séries" de concessions de l'année 1668. Si, dans un premier temps, je choisis cette année de préférence à celle de 1667, c'est pour tirer avantage des ren-

${ }^{99}$ Le 3 septembre 1677, par exemple, René Robineau de Bécancour, propriétaire de la seigneurie de Portneuf, présentait son aveu et dénombrement: sept colons étaient établis dans sa seigneurie, mais aucun n'avait encore reçu ses titres notariés de propriété, chacun devant toutefois exécuter les "clauses et conditions portées par le Billet d'asseurance que le dit Sieur de Becancour luy en a donné en attendant qu'il luy donne contract de concession". $R A P Q, 1925-26$ : 340-342. 
seignements qu'apporte le recensement de 1667 sur le statut des concessionnaires un an avant la concession notariée. En 1668, donc, Joseph Giffard donna une première concession le 26 octobre, douze autres le 10 décembre et une dernière le 18 décembre, toutes dans la seigneurie de Beauport ${ }^{100}$. Deux concessions, cependant, furent accordées au même individu (Jacques Tardif), de sorte que mon analyse porte sur treize concessionnaires. Pour tenter de contrôler les différentes affirmations de l'auteur, j'ai indiqué, dans le tableau qui suit, les concessionnaires qui apparaissent aux recensements de 1666 et de 1667 , ceux qui étaient encore dans la seigneurie - ou du moins dans la colonie - en 1681 (année où l'on a recensé la population canadienne ${ }^{101}$ ), la date de leur mariage, leur occupation en 1667 et le nombre d'arpents en culture qu'ils déclarèrent au recensement de cette année-là quand il $\mathrm{y}$ a lieu. On voit tout de suite mon propos : chercher à savoir si les concessionnaires étaient dans le gouvernement de Québec depuis quelques années au moment de la concession et s'ils s'y établirent définitivement, de façon à vérifier s'il est vrai, dans ce cas particulier, que les concessionnaires "quittèrent Québec [sic] assez tôt et ne laissèrent pas d'autres traces de leur séjour dans la colonie" (p. 410). [Voir tableau V, page 211.]

A l'exception de Pierre Langlois, dont ne sait rien, tous les concessionnaires de Beauport en 1668 sont bien identifiés et tous ont laissé des "traces de leur séjour dans la colonie". Sauf Avisse, qui n'était déjà plus célibataire à son arrivée à Québec, ils se sont tous mariés au Canada; ils y sont tous morts aussi, moins Pierre Langlois peut-être. Cinq d'entre eux étaient dans la colonie en 1666, et neuf en 1667; il est à peu près certain que, sans les lacunes des recensements ${ }^{102}$, on les $\mathrm{y}$ aurait tous trouvés, car il n'était point dans les habitudes de concéder des terres à

100 Toutes ces concessions furent signées par le notaire Vachon. L'auteur parle de 30 concessionnaires qui auraient reçu leurs titres notariés de Vachon en 1668 (p. 416, note 37). Or, il s'y trouve 38 actes de concession et 36 concessionnaires, compte tenu que deux de ces derniers reçurent deux terres cette même année et que la concession de Mgr de Laval à Jean Jouanne, qui apparaît sous la date de 1668 dans Roy, Inventaire des greffes des notaires ..., II : 29, est en réalité de 1667. Jusqu'ici, pas un seul des chiffres avancés par l'auteur n'est exact.

$101 \mathrm{Ce}$ recensement a été publié par Benjamin Sulte, Histoire des Canadiens-français ..., V (Montréal, 1882), 53-88.

102 Il manque, en particulier, au moins un feuillet au recensement de Beauport pour l'année 1666. On remarquera, en effet, que c'est la seule seigneurie du gouvernement de Québec - avec celle de Lauzon où le document est manifestement amputé de quelques bonnes pages - qui ne comporte pas une liste des travaillants et des volontaires qui y habitaient. 


\section{TABLEAU V}

Concessionnaires de la seigneurie de Beauport

en 1668

\begin{tabular}{|c|c|c|c|c|c|c|}
\hline \multirow[t]{2}{*}{ Nom } & \multicolumn{3}{|c|}{ Recensements } & \multirow[t]{2}{*}{ Mariage } & \multirow{2}{*}{$\begin{array}{c}\text { Arpents } \\
\text { (1667) }\end{array}$} & \multirow{2}{*}{$\begin{array}{l}\text { Occupation } \\
\text { (1667) }\end{array}$} \\
\hline & 1666 & 1667 & 1681 & & & \\
\hline Nicolas Bélanger & $\mathbf{x}$ & $\mathbf{x}$ & $\mathbf{x}$ & $11 / 1 / 60$ & 12 & Habitant \\
\hline René Siret & & & $\mathbf{x}$ & $8 / 9 / 70$ & - & - \\
\hline Henri Chastel & & $\mathbf{x}$ & & $8 / 1 / 84^{1}$ & - & Travaillant \\
\hline Jean Langlois & $\mathbf{x}$ & $\mathbf{x}$ & $\mathbf{x}$ & $15 / 10 / 68$ & - & Travaillant \\
\hline Denis Avisse & $\mathrm{x}$ & $\mathbf{x}$ & & avant $1666^{2}$ & - & Domestique \\
\hline Jean Gibaut ${ }^{3}$ & $\mathbf{x}$ & $\mathbf{x}$ & & $26 / 7 / 62$ & 7 & Habitant \\
\hline Jacques Tardif & & $\mathbf{x}$ & $\mathrm{x}$ & $6 / 10 / 69$ & - & Travaillant \\
\hline Pierre Toupin & & & $\mathrm{x}$ & $30 / 9 / 70$ & - & - \\
\hline Jacques Sivariaux & & $\mathbf{x}$ & $\mathbf{x}$ & $17 / 10 / 72$ & - & Domestique \\
\hline Jean Perrier & & & $\mathbf{x}$ & $1669(?)^{5}$ & - & - \\
\hline Pierre Sasseville ${ }^{6}$ & $\mathbf{x}$ & $\mathbf{x}$ & & $8 / 9 / 70$ & - & Domestique \\
\hline Robert Galien & & $\mathbf{x}$ & $\mathbf{x}$ & $8 / 9 / 70$ & - & Travaillant \\
\hline Pierre Langlois & & & & & & \\
\hline
\end{tabular}

1 Date du contrat de mariage (Duquet).

2 On voit, dans le recensement de 1666, qu'il était volontaire, marié en France. Il mourut en janvier 1679.

3 Avait déjà reçu une concession de Joseph Giffard le 20 juillet 1667 (Vachon).

4 Il s'agit de Jacques Savaria ou Savariaux.

5 Un premier enfant est baptisé en août 1670 .

6 Avait déjà obtenu le 27 février 1665 une concession des Jésuites (Vachon). 
des nouveaux venus (d'où le système des engagés qui assurait un apprentissage nécessaire). Huit de ces concessionnaires de 1668 occupaient la même terre en 1681 ; les cinq autres étaient morts (Sasseville, Avisse et peut-être Gibaut) ou établis ailleurs (Chastel et Savariaux). Les remarques de l'auteur sur la suite des contrats et sur le passage éphémère d'un certain nombre de concessionnaires dans la colonie ne s'appliquent donc point ici, sinon à l'introuvable Pierre Langlois.

En 1668 encore, Paul Vachon signa quatorze titres de concession, accordés par Mgr de Laval à des colons de l'île d'Orléans. Dix de ces contrats portent la date du 10 mars. De nouveau, une "série" de concessions! Or, treize titres se révèlent des confirmations de concessions antérieures. Voici les renseignements utiles: [Voir tableau VI, page 213.]

Ce tableau montre, comme le précédent, à quel point, si l'on en peut juger par les concessionnaires de 1668, la population agricole de la colonie était stable. Toutes les terres visées par les confïmations de titres de 1668 , mise à part celle de Jean Ouimet sur laquelle on ne peut se prononcer, sont encore la propriété des premiers concessionnaires. Seul, entre-temps, Jean Charpentier s'était départi momentanément de la sienne et l'avait reprise pour la vendre à la fin de 1668 . De ces treize concessionnaires, dix occupaient la même terre en 1681 et, pour la plupart, ils $\mathrm{y}$ étaient installés depuis près de vingt ans. Voilà bien d'autres concessions qui eurent une suite. Mais, au-delà de cet aspect de la discussion, la stabilité des concessionnaires qu'on remarque dans les tableaux V et VI commence à me faire douter d'une autre affirmation de l'auteur - affirmation que rien dans son texte ne paraît autoriser - sur la "grande mobilité" de la population. Sur quoi l'auteur s'est-il fondé pour écrire que "ces gens [...] venaient et repartaient, [et] passaient sans laisser beaucoup de traces" (p. 413) ?

Selon l'auteur encore, seize concessionnaires mentionnés dans le greffe de Becquet pour la seule année 1667 n'apparâ̂traient ni au recensement de 1666, ni dans le Dictionnaire de Tanguay annoté par Godbout et Auger, ni dans les registres de la prévôté (p. 412). En 1667, Becquet signa les minutes de quarante-quatre concessions, toutes datées du 20 mars, pour le compte de Jean-François Bourdon, seigneur de Dombourg ou Neuville. Ces minutes sont toutes perdues et on ne les connaît que par la brève inscription du répertoire: noms du seigneur, du concessionnaire et la date. Il est assez piquant que l'auteur ne fasse point mention de ce fait et surtout qu'il prétende avoir 


\section{TABLEAU VI}

Concessionnaires de l'île d'Orléans en 1668

(Confirmations de concessions antérieures)

\begin{tabular}{|c|c|c|c|c|c|}
\hline Nom & $\begin{array}{r}\operatorname{Rec} \\
1666\end{array}$ & $\begin{array}{c}\text { ensem } \\
1667\end{array}$ & $\begin{array}{l}\text { ents } \\
1681\end{array}$ & 1ère concession & $\underset{(1667)}{\text { Arpents }}$ \\
\hline Jean Ouimet & $\mathbf{x}$ & $\mathbf{x}$ & $\mathbf{x}$ & ? & 6 \\
\hline Charles Allaire & $\mathbf{x}$ & $\mathbf{x}$ & $\mathbf{x}$ & $1661(?)^{1}$ & 6 \\
\hline Jean Cordeau ${ }^{2}$ & $\mathbf{x}$ & $\mathbf{x}$ & & Duquet, $9 / 2 / 65$ & 4 \\
\hline René Bauchet ${ }^{3}$ & $\mathbf{x}$ & $\mathbf{x}$ & $\mathbf{x}$ & Becquet, 10/2/66 & 3 \\
\hline Jacques Meneux 4 & $\mathbf{x}$ & $\mathbf{x}$ & $\mathbf{x}$ & $1665^{5}$ & 3 \\
\hline Jean Charpentier ${ }^{B}$ & $\mathbf{x}$ & $(\mathrm{x})$ & & Duquet, $9 / 2 / 65$ & - \\
\hline Symphorien Rousseau & & $\mathbf{x}$ & $\mathbf{x}$ & $1664(?)^{7}$ & 7 \\
\hline François Dupont & $\mathbf{x}$ & $\mathbf{x}$ & $\mathbf{x}$ & Audouart, juin 62 & 9 \\
\hline Grégoire Deblois & $\mathbf{x}$ & $\mathbf{x}$ & $\mathbf{x}$ & $1662(?)^{8}$ & 8 \\
\hline Jean Duvert 9 & & & & Duquet, $9 / 7 / 64$ & - \\
\hline Pierre Gaulin ${ }^{10}$ & $\mathrm{x}$ & $\mathrm{x}$ & $\mathrm{x}$ & Audouart, 22/1/62 & 6 \\
\hline Nicolas de Launay & $\mathrm{x}$ & $\mathrm{x}$ & $\mathrm{x}$ & Audouart, $22 / 1 / 62$ & 14 \\
\hline Fabien Prezeaux ${ }^{11}$ & $\mathbf{x}$ & & $\mathbf{x}$ & $1667(?)^{12}$ & - \\
\hline
\end{tabular}

1 Vachon, 10/9/61: concession à Louis Chapelain, entre Martin Boullard et Charles Allaire.

2 Ou Cardeau (recens. 1666) et Corbeau (recens. 1667).

3 Boucher au recens. de 1666 et Baucher au recens. de 1667.

4 Appelé Jacques Manouf au recens. de 1681.

5 AQ, NF 25, 2173. Sans mois ni quantième.

${ }^{6}$ Lors du recens. de 1667 , sa terre était occupée par Pierre Lat. Il l'avait reprise avant la concession du 10 mars 1668 , et la revendit le 30 novembre 1668 (Vachon) à Maurice Arrivé.

7 Duquet, 23/6/64: concession à François Dupont, entre Symphorien Rousseau et Grégoire Deblois.

8 Audouart, juin 62: concession à François Dupont entre Jean Charpentier et Grégoire Deblois.

$9 \mathrm{Ou}$ Levert. Voir un bail à ferme de Jean Levert à René Bauchet, Becquet, 15/7/66. terre.

10 En 1681, sa veuve, remariée à Marc Bareau, occupe encore cette Presseau.

11 Fabien Prusseau au recens. de 1666. On trouve aussi Perusseau et

12 Vachon, 1/3/67: concession à Jean Marandeau entre Fabien Presseau et Mathurin Croisset. 
relevé "dans le [...] greffe de Romain Becquet [...] 16 concessionnaires ..." Seize concessionnaires qui, selon l'auteur, seraient à toutes fins pratiques des inconnus. Peut-être n'a-t-il point suffisamment poussé sa recherche? Pour ma part, j'ai identifié quarante-trois de ces quarante-quatre concessionnaires. Qu'il me suffise de noter que trente-deux d'entre eux (ou leur veuve) apparaissent au recensement de 1681, dont vingt-cinq dans la seigneurie de Neuville ${ }^{103}$. Pour ceux-là, point de problème: ils ont laissé des traces nombreuses de leur vie au Canada. Il en va de même pour René Duverger, Samson Auger, Jacques Pasquier Nony dit Larose, Jacques Brunet, Charles de Lorice dit Jambon, Jacques Largilier (compagnon de Jolliet au Mississipi), Jean et François Pelletier, qu'on retrouve fréquemment dans diverses sources et en particulier dans les greffes des notaires. Jean Courtois, pour sa part, apparaît dans le Dictionnaire de Tanguay, et il s'est marié au pays, probablement en 1670; Claude Plet dit Le Médecin, c'est le Claude Pillet du recensement de 1666 et le Claude Pelette de celui de 1667; Jean Léonardeau, c'est le propre domestique de Bourdon, nommé Jean Léonard̉ au recensement de 1667. Reste un seul inconnu, Charles Pin, à comparer aux seize dont parle l'auteur (p. 412)!

Tout aussi exagérée apparaît une autre affirmation de l'auteur voulant que vingt-cinq des cent quinze concessionnaires qui auraient reçu leurs titres notariés de Duquet, Becquet et Vachon en $1667^{104}$ et de Vachon en 1668 ne soient point connus par ailleurs (p. 416). C'est donc 21,7\% de ces concessionnaires qui n'auraient pas laissé de trace dans la colonie, pour employer

103 Ce sont, à Neuville: Louis Bonnodeau, Antoine Bordeleau, la veuve d'Antoine Boutin, Pierre Bouvier, Jean Chesnier, Charles Davault Laplante, Louis de Lisle, Antoine de Serre, Jean Dubuc, Léonard Faucher, Jean Fauconnet, Pierre Faudeux, Pierre Ferrey, Jean Garnier, Robert Germain, Jean Hardy, Jean Hayot, Nicolas Langlois, Jean de Lastre, Etienne Léveillé, Etienne Papillon, la veuve de Jean Pin, Michel Rognon, la veuve de Robert Sénat et Nicolas Silvestre; à la Côte Saint-François-Xavier: la veuve de Jean-Baptiste de La Rue et Jean Migneron; à la Pointe aux Ecureuils: Pierre Lefebvre; dans le fief Verdun: Laurent Lormier; à Champlain: Pierre Mercereau; à l'île d'Orléans: Jean Rioux; et à Portneuf: Mathurin Cormiau, lequel est le Mathurin Corriveau qui apparaît déjà dans l'aveu et dénombrement de Portneuf le 3 septembre 1677 ( $R A P Q, 1925-26: 341)$ et le Martin Corvault de l'acte de concession de 1667; c'est aussi le Mathurin Cornuau de Tanguay, marié à Québec le 6 octobre 1670, qui recevait le 30 mai 1672 (Rageot) une confirmation de sa concession de 1667.

104 On se rappellera que, pour l'auteur, quatre notaires seulement exerçaient en 1667 dans le gouvernement de Québec (p. 409, note 17); or, l'un d'eux, Claude Auber, ne signa cette année-là aucun acte de concession. Pour fins de comparaison, je m'en suis tenu à l'échantillonnage de l'auteur, suffisant à condition d'être bien étudié. 
une expression chère à l'auteur. Cela n'est point. Outre les vingt-six concessionnaires des tableaux $\mathrm{V}$ et VI et les quarantequatre du paragraphe précédant celui-ci, il s'en trouve, dans les greffes des notaires nommés plus haut, en 1667 et en 1668, quarante-neuf autres, pour un total de cent-dix-neuf - et non point de cent quinze. (Les chiffres de l'auteur continuent d'être inexacts ...) Or, de ces concessionnaires, quatre-vingt-huit apparaissent au recensement de 1681 et sont bien identifiés ${ }^{105}$; vingt-neuf autres sont connus pour s'être mariés au Canada et pour y être morts, ou tout au moins pour être mentionnés dans les recensements, les registres de la prévôté et du Conseil souverain, et surtout dans les greffes des notaires ${ }^{108}$; deux seulement me sont complètement inconnus: Pierre Langlois (frère de Jean, d'après l'acte de concession) et Charles Pin (dont l'acte de concession est perdu: il y a peut-être erreur au répertoire). Deux concessionnaires sur cent-dix-huit, soit un sur cinquanteneuf, plutôt qu'un sur cinq, comme le prétend l'auteur! Or, avec Pierre Langlois et Charles Pin, deux autres seulement, Jean Léonardeau et Claude Plet, ne paraissent pas avoir passé plus de deux ou trois ans dans la colonie. N'a-t-on point comme moi le sentiment que les affirmations répétées de l'auteur sur les concessionnaires qui ne laissèrent pas de trace dans la colonie et sur la "grande mobilité" de la population ne sont absolument pas fondées? Une fois de plus, et d'une manière bien irréfléchie, l'auteur donne de la colonie canadienne au milieu du XVIIe siècle une image entièrement fausse, parce que, d'une part, il ne connaît ni le système des engagés tel qu'on le pratiquait alors

105 Aux concessionnaires désignés dans les tableaux $\mathrm{V}$ et VI et dans la note 103 comme apparaissant au recensement de 1681, il faut ajouter: Jean Marandeau, Etienne Dauffin, Jean Chambre, Noël Leblanc, Pierre Paradis, Mathias Campagnart, Gabriel Roger, Jacques Hardy, Jacques Chapelin, Jacques Jahan, Julien Dumont, François Daneau, Claude Lefebvre, Jean Brochu, Pierre Rondeau, Martin Poisson, Méderic Blouin (sous le nom d'Emery Blouart), Abel Turcot, Mathurin Dubé, Nicolas Audet, Pierre Filleteau, Pierre Blais (Belé), Jean Jouanne, Jacques Bidet, André Morin, Jean de Rainville, Pierre Vallée, Jacques Lemarié, Abel Sagot, Mathieu Costé, Noël Costé, Jean Costé, Jean [sic] Butor (Pierre Buteau), Jean Picard, Pierre Parent, Barthelemy Bareau (Verreau), Jean Guyosne et Claude Bouchard d'Orval.

106 Ce sont: Henri Chatel, Denis Avisse, Jean Gibaut, Pierre Sasseville, Jean Cordeau, Jean Charpentier, Jean Duvert (ou Levert), René Duverger, François et Jean Peltier, Samson Auger, Jacques Brunet, Jacques Pasquier Nony dit Laroze, Claude Plet dit Le Médecin, Jean Léonardeau (Léonard), Jean Courtois, Jacques Largillier, Jean Bourasseau, Louis Leparcq, Adrien Izabel, Charles de Rainville, Paul Denis de Hautbois, Sylvain Leveau (Veau), Etienne Morel, Charles Delcourt dit Marolle, Charles de Lorice dit Jambon, Jean Iger, Louis Tassel et Guy Boidin dit Saint-Martin. 
ni les procédures pour la concession des terres, et que, d'autre part, il n'a pas pris le temps de faire, dans les greffes des notaires, des recherches suffisamment sérieuses sur les concessionnaires et les mutations de propriété. Il devient de plus en plus évident que cet historien ignore tout de ce qui est propre à la période dont il parle.

\section{Les registres du Conseil souverain}

Il n'y a pas lieu de nous arrêter sur le court paragraphe que l'auteur consacre à cette série extrêmement importante de documents judiciaires et administratifs (p. 410s.), dont j'ai longuement parlé dans mes commentaires sur "les ordonnances des intendants et des gouverneurs", sinon pour compléter brièvement les renseignements donnés antérieurement. Car, selon l'auteur, le Conseil souverain agirait, sur le plan judiciaire, "comme cour d'appel" uniquement, en plus de jouer "un rôle important dans l'administration de la colonie". $\mathrm{Y}$ aurait-il là une nouvelle maladresse qui lui ferait dire moins qu'il n'eût voulu ? Te ne le crois pas, puisqu'il répétera que le conseil était "la cour d'appel" (p. 421). De même, dans le paragraphe sur la Prévôté de Québec, qui suit immédiatement celui que je discute en ce moment, il décrira cette dernière juridiction comme "une cour civile et criminelle de première instance", sans plus (p. 411). L'organisation judiciaire de la colonie comprendrait donc deux types de cours de première instance: les tribunaux seigneuriaux - auxquels il fait deux courtes allusions (pp. 415 et 423) - et les prévôtés, dont les appels ressortiraient également au Conseil souverain, seule cour d'appel. Or, tel n'était point le cas. A tous les niveaux, même à celui du conseil, l'on jugeait en première instance. Les appels des tribunaux seigneuriaux ressortissaient en général aux prévôtés ${ }^{107}$; ceux des prévôtés et du bailliage de Montréal, au Conseil souverain; des arrêts du conseil, on ne pouvait appeler qu'au roi.

"Le Conseil souverain, toujours selon l'auteur, donne une image partielle de la société québécoise [sic], car on n'y retrouve qu'un nombre restreint d'individus, surtout des criminels, et les personnages importants de la colonie" (p. 410). Si je connaissais, pour ma part, une source qui donnât une image complète de la société du gouvernement de Québec, je la lirais, l'apprendrais par cour et prendrais ma retraite. Peut-être l'auteur badine-t-il tout à coup ? Je ne veux pas croire que les criminels dont il parle soient les juges de ce tribunal, mais les justiciables; néanmoins,

107 Voir, par exemple, AQ, NF 19, I, 1ère partie: 29v.s., 43v. 
il serait surprenant qu'on trouvât parmi ces derniers une majorité de criminels et de gens importants. Par quelle sorte de discrimination cela eût-il été possible? C'est ce que l'auteur se garde bien de dire. Comme j'aime les situations claires, j'ai fait l'index onomastique des jugements et délibérations du Conseil souverain pour les années 1667 et 1668 et j'ai ainsi relevé trois cent quarante-quatre noms, à l'exclusion des Français de France qui y sont mentionnés à l'occasion; pour ce qui est des criminels, j'en ai rencontré cinquante et un, dont vingt-huit sont des trafiquants d'eau-de-vie - des criminels si l'on veut, mais dans une acception un peu généreuse de ce mot; quant aux "personnages importants de la colonie", j'eusse aimé que l'on me fournît la norme au-delà de laquelle un individu appartenait à cette catégorie. Au reste, à quoi tout cela rime-t-il? J'eusse préféré que l'auteur, tenant sa promesse, fît la critique externe de cette série de documents.

Peut-être estime-t-il l'avoir faite, cette critique externe, pour avoir terminé son paragraphe par les remarques suivantes:

Les renseignements précis sur la société sont aussi assez rares car le greffier n'a généralement transcrit au registre que l'arrêt rendu par la cour. On ne dispose donc [?] ni des exploits d'assignations [sic], ni des requêtes présentées sous forme de grief et moyen d'appel; et on déplore surtout l'absence de tous les rapports faits par des "conseillersenquêteurs". (p. 410)

Quoi qu'il en dise, les procès-verbaux du Conseil souverain sont aussi instructifs que ceux de la prévôté; le greffier notait en général les faits utiles à l'interprétation de la sentence, comme du reste on le faisait à la prévôté, ni plus ni moins. Il suffit, pour s'en rendre compte, d'examiner avec un peu d'attention les registres des deux cours. L'auteur lui-même n'a-t-il pas cité la requête de Jean Frouin à l'encontre de Marguerite Lebeuf avec tous les détails indispensables - qu'il n'a pas compris - tirés tout ronds des registres du conseil (p. 417) ? Quant aux exploits d'assignation, aux requêtes et aux rapports d'enquête, documents auxquels j'ajouterai les interrogatoires et les conclusions des procureurs généraux, il s'en trouve en assez grand nombre dans les dossiers et les pièces détachées du Conseil souverain $(\mathrm{AQ}, \mathrm{NF}$ 13 et 14), dans la collection de pièces judiciaires et notariales (AQ, NF 25) et aux Archives du Séminaire de Québec. Il en est de même pour les documents semblables de la prévôté, la plupart perdus aussi, bien que, dans ce cas, l'auteur n'en souffle mot (p. 411).

Un peu plus loin, il reviendra sur les "conseillers-enquêteurs", dans le corps d'un paragraphe aux énoncés beaucoup 
trop généraux et trop théoriques pour que l'on évalue exactement leur portée quant aux institutions de la Nouvelle-France:
Ajoutons à cela que la tâche des officiers de justice était beaucoup plus importante que le simple règlement des litiges. En effet, au début du règne absolutiste et centralisateur de Louis XIV, le gouvernement royal de la Nouvelle-France n'avait pas atteint sa forme parfaite : l'administration du Cana- da comportait encore de sérieuses dérogations à la hiérarchie des fonctions. Comme en France d'ailleurs, certaines adminis- trations conservaient et exerçaient des pouvoirs non dûment sanctionnés par les édits du roi. Cette décentralisation du pouvoir se manifeste bien, par exemple, au Conseil souverain qui pouvait commettre des gens pour faire enquête ou régler des litiges. (p. 422s.)

J'aurais souhaité d'autres exemples de "cette décentralisation du pouvoir", car je ne vois pas comment le fait pour le Conseil souverain de "commettre des gens pour faire enquête ou régler des litiges" pourrait ne pas avoir été dûment sanctionné par les édits du roi", Louis XIV ayant lui-même conféré ce droit, très explicitement et sous sa propre signature, au Conseil souverain dans l'édit de création de ce tribunal en avril $1663^{108}$ ! Voilà bien d'inutiles gargarismes, puisque les structures administratives de la Nouvelle-France ne furent jamais identiques à celles de la France, non plus que les pouvoirs, droits et privilèges des officiers et des administrateurs. C'est une tendance que je remarque depuis quelques années chez certains jeunes historiens, sous l'influence par ailleurs bénéfique de maîtres français, de vouloir à toute force retrouver dans la colonie des réalités propres à la métropole au lieu de chercher comment on adapta les institutions, les lois et les coutumes du royaume au contexte bien particulier de la colonie canadienne.

Poursuivant sa comparaison sourde en faveur des registres de la prévôté, l'auteur termine ses commentaires sur les jugements et délibérations du Conseil souverain par cette constatation qu' "il n'y a [dans ces registres] que 124 procès-verbaux comprenant 15 ordonnances et 25 ordres d'insinuations [sic]." (p. 410s.) Or, il s'en trouve, pour 1667 et 1668, cent quatrevingt-six. On est loin de compte, mais pas autant qu'il y paraît à première vue: l'auteur, en effet, sans prévenir, donne encore une fois les chiffres de l'année 1667 seulement, avec bien sûr la marge habituelle d'erreur. Il $y$ a, en effet, cent vingt-six "procès-verbaux" dans les registres de 1667. A-t-on remarqué

108 Edits, ord., I : 37-39. 
que, dans le cas des ordonnances, l'auteur ne nous a référés qu'à celles de 1667 (p. 408, note 13) ; que, dans celui de la correspondance générale, il n'a cité qu'un mémoire, de 1667 encore (p. 409) ; qu'il a limité ses statistiques sur les actes notariés à l'année 1667 (p. 409) et qu'il agit de même pour les registres du Conseil souverain? De toutes les sources qu'il utilise dans son article, une seule, les registres de la Prévôté de Québec, porte sur les deux années qu'il prétend étudier. J'y vois un vice de méthode qui explique pour une bonne part les nombreuses erreurs que comporte cette étude.

\section{Les registres de la Prévôté de Québec}

Les registres de la prévôté sont "la meilleure source de renseignements sur la vie à Québec [sic] au milieu du XVIIe siècle" (p. 411). On s'y attendait!

Les registres de cette cour [...] sont, pour cette période, plus riches que toute autre source connue, car ils touchent de plus près une plus grande portion de la population: deux fois plus que les actes notariés. (p. 411)

On s'interrogera à bon droit sur la conception de la vie qu'affiche ce jeune homme pour en trouver la meilleure image dans une cour de justice, et sur le sens exact de l'expression "toucher de plus près" dans la dernière phrase citée; cette expression, il la reprendra un peu plus loin en l'appliquant aux actes notariés et aux registres de la prévôté "qui touchent le peuple de près" (p. 415). Mais laissons dans le vague ce qui est par trop brumeux et arrêtons-nous à une affirmation plus importante:

Les registres de la Prévôté de Québec en 1667 et 1668 contiennent exactement 1490 procès-verbaux dont environ 1200 sont des litiges, faisant 800 à 900 causes et concernant plus de 1100 personnes. (p. 411)

Pour une fois que l'auteur donne un chiffre qu'il prétend exact - je ne l'ai pas vérifié —, voyez la série d'approximations qui suit tout aussitôt: environ 1200 litiges, 800 à 900 causes, plus de 1100 personnes. (Comment réussit-il à comprimer "environ 1200 litiges" dans "800 à 900 causes" ?) Ne me fiant plus à ses statistiques, j'ai dressé systématiquement l'index de tous les noms contenus dans les registres de la prévôté ${ }^{109}$ pour les

109 L'auteur ne donne ici aucune référence aux registres de la prévôté. Ils sont classés, aux Archives du Québec, sous la cote NF 19. Les causes pour les années 1667 et 1668 se trouvent dans les registres $I, 1^{\mathrm{e}}$ partie, ff. 6 à 46 et $2^{\mathrm{e}}$ partie, ff. 1 à 118 , dans le registre II et dans le registre III, ff. 1 à 11 . 
deux années qui nous intéressent et j'en ai compté 1015 ; j'ai fait de même pour les actes notariés de ces années, mais en ne retenant que les noms des parties contractantes, et j'en ai trouvé 970 . - "Plus de 1100 personnes", dit l'auteur, soit "deux fois plus que [dans] les actes notariés", lesquels devraient partant contenir quelque 550 noms. On voit tout de suite l'écart entre l'affirmation et la réalité. Première conséquence du fait, noté précédemment, qu'il compare les chiffres de deux années pour la prévôté à ceux d'une seule année pour les actes notariés, dont l'index pour 1667 comprend en effet 543 noms, soit sensiblement la moitié de "plus de $1100 " 110$. Mais il y a un autre élément fort important auquel l'auteur n'a point pris garde: 543 noms pour 1667 et 970 pour 1667 et 1668 , cela représente les parties contractantes seulement; or, il se trouve, dans ces actes, une grande quantité de noms en plus de ceux des parties. J'ai choisi au hasard, dans le greffe d'Auber, trois minutes de l'année $1667^{111}$, et j'y ai compté 43 noms, en plus de ceux des 6 parties contractantes. C'est dire que la marge entre les 970 noms des actes notariés et les 1015 des registres de la prévôté serait vite comblée si l'on s'avisait d'indexer les premiers au complet comme je l'ai fait pour les seconds, et que l'auteur serait forcé d'inverser les termes de sa comparaison.

Je n'ai pas à revenir sur la valeur des renseignements qu'on trouve dans ces registres, question que j'ai abordée précédemment, non plus que sur les ordonnances de ce tribunal, dont j'ai également parlé. Tout au plus noterai-je qu'il eût été essentiel de mentionner la série des insinuations de la prévôté (voir note 90 ), dont l'auteur ne dit rien; il a, de même, négligé les insinuations du Conseil souverain ( $\mathrm{AQ}, \mathrm{NF} 11$ ), pourtant fort importantes. Au reste, rien de ce qu'il eût fallu trouver dans une bonne critique externe n'a été dit relativement aux archives du Conseil souverain et de la Prévôté de Québec.

A dire le vrai, l'auteur s'est montré, dans toute cette seconde partie, d'une impuissance désespérante à conduire, voire à entreprendre, une véritable critique externe des sources. Non seulement a-t-il omis des séries importantes de documents et

110 Par quel accident l'auteur arrive-t-il à une estimation à peu près exacte pour les actes notariés de 1667 quand il en a oublié 215 au point de départ (ceux de Rageot et de Filion), comme je l'ai expliqué précédemment? On dirait que c'est par erreur seulement qu'il peut atteindre une exactitude approximative.

$111 \mathrm{Ce}$ sont les actes suivants: accord et transaction entre Barthelemy Tesson et Jacques Genest (27 février), cession et donation par Romain Trespagny à Robert Drouin (29 juin 1667) et contrat de mariage de Noël Racine et Marguerite Gravel (11 septembre 1667). 
mal compris celles qu'il a retenues, mais encore a-t-il, par suite de son ignorance de l'administration et de ses erreurs de méthode, jeté en terre, tout au long de cette prétendue analyse de sources, des semences empoisonnées. Il ne faudra point se surprendre d'avoir à récolter des fruits véreux dans la troisième partie, consacrée à la vie dans le gouvernement de Québec en 1667 et 1668 .

\section{Etude : la vie dans le gouvernement de Québec}

J'ai accepté, jusqu'ici, de descendre sur le terrain de l'auteur et de jouer son jeu en feignant de croire que la critique externe - aussi appelée critique d'érudition - consiste uniquement à replacer les documents "dans le cadre de l'administration gouvernementale" (p. 406) ; j'en ferai de même, dans cette troisième partie, en ayant l'air persuadé qu'une étude sur la vie dans le gouvernement de Québec peut se limiter à quelques considérations sur le chiffre de la population, sa composition et son activité dans les secteurs de l'agriculture, du commerce, des métiers et de la justice (?). Ne quittant point mon rôle de critique, je m'interdirai encore de refaire l'étude de l'auteur; il me suffira d'éprouver la solidité de ses affirmations et de crier gare aussi souvent qu'il sera nécessaire. Au reste, beaucoup de questions soulevées dans cette partie ont été discutées dans la précédente. Je n'y reviendrai pas.

\section{La population}

L'étude de la population du gouvernement de Québec en 1667 et 1668 se réduit à un examen du recensement de 1666 . Ex abrupto l'auteur se demande quelle est la "valeur" de ce recensement et "jusqu'à quel point [il est] complet". Il semble donc qu'il veuille prolonger ici sa critique des sources. Quoi qu'il en soit, pour "préciser cet inconnu [sic]", il a imaginé de comparer "la liste des gens figurant au recensement avec l'index tiré des registres de la Prévôté":

Le recensement de 1666 [dénombre] 885 mâles de plus de 16 ans dans le gouvernement de Québec [...] Or, un peu plus de 900 hommes figurent à l'index des registres de la Prévôté [...] pour les années 1667 et 1668. Mais tous n'allaient pas devant la justice : [...] au total, 459 hommes de plus de 16 ans qui figurent dans le recensement de la région [sic] de Québec [...] ne se présentèrent pas devant la Prévôté au cours des deux années suivantes. Ajoutons ces 459 personnes recensées, absentes des procès-verbaux de la Prévôté, aux 900 qui s'y présentèrent, la population masculine 
de plus de 16 ans dans la région [sic] de Québec atteint alors le chiffre de 1359 , soit $50 \%$ de plus que le nombre recensé. ${ }^{112}$ (p. 411s.)

Voilà, s'écrie l'auteur, "un chiffre étonnant et fantastique"! Pourtant, tout cela n'est guère nouveau: on a depuis longtemps - généalogistes en tête - déploré les nombreuses lacunes du recensement de 1666. Pour ma part, j'ai écrit en 1962, en généralisant peut-être un peu trop, que, dans les premiers recensements de la colonie, il "manque généralement le quart, quand ce n'est pas le tiers de la population"113. Cinquante pour cent "de plus que le nombre recensé", cela revient à dire, n'est-ce pas, qu'il manque au recensement un tiers des personnes qu'il y avait à recenser ...

Si le hasard veut que, pour une fois, l'auteur et moi semblions d'accord, je dois néanmoins corriger ses statistiques et condamner sa méthode. Selon lui, on compterait 885 hommes de plus de 16 ans dans le recensement du gouvernement de Québec en 1666. Or, il y en a 876, dont 13 apparaissent en double ${ }^{114}$. C'est donc, d'après ce document, 863 hommes "de plus de 16 ans" qui habitaient le gouvernement de Québec en 1666, et non point $885^{115}$. Voici la répartition géographique de cette population mâle, compte tenu des noms en double : [Voir tableau VII, page 223.]

Comme il s'agit de savoir, selon la méthode proposée par l'auteur, quels sont les noms contenus dans les registres de la prévôté qui ne se retrouvent point dans le recensement de 1666,

112 L'auteur n'hésite pas à prendre certaines libertés avec les mathématiques: "plus de 900" devient, quelques lignes plus bas, 900 exactement; ce 900 est additionné à 459 ; le total de 1359 auquel il arrive ainsi ne devrait-il pas être "plus de" 1359 ou, à la rigueur, "moins de" 1400 ? L'auteur ignore peut-être que le recours aux mathématiques, en histoire, a justement pour but de substituer l'exactitude aux approximations, souvent aberrantes.

113 André Vachon, "Etat des recherches sur le régime français (16321760)", dans Recherches sociographiques, III, 1-2 (janvier-août 1962) : 21. 114 Outre les cinq noms en double dont j'ai fait état dans la note 94, on trouve encore ceux-ci : Jacques Billaudeau (RAPQ, 1935-36 : 70 et 79), Jacques Bodin (et Bourdon), sieur de La Grange (pp. 72 et 76), Pierre Duchesne (pp. 69 et 82), René Esmond (pp. 72 et 80), Nicolas Leblon (pp. 75 et 80), Pierre Paillereau (pp. 68 et 76), Marin Boucher (pp. 56 et 81), Guillaume Boucher (pp. 56 et 81). Il y a deux autres répétitions probables, dont je n'ai pas tenu compte faute d'une preuve décisive : Jacques Hardy (pp. 59 et 84) et François Marceaux (pp. 70 et 84).

115 Les 885 noms de l'auteur correspondent approximativement, m'a-t-il semblé, aux mâles de 16 ans et plus; or, il parle constamment des mâles "de plus de 16 ans". Nouvelle maladresse d'expression? 
TABLEAU VII

Mâles de plus de 16 ans

dans le gouvernement de Québec en 1666

\begin{tabular}{lrcr}
\multicolumn{1}{c}{ Lieux } & Noms & En double & Total \\
\hline Québec & 249 & - & 249 \\
Beaupré & 186 & 2 & 184 \\
Beauport & 66 & - & 66 \\
Ile d'Orléans & 187 & 11 & 176 \\
Saint-Jean & 68 & - & 68 \\
Sillery & 60 & - & 60 \\
N.-D. des Anges & 55 & - & 55 \\
Lauzon & 5 & 13 & 5 \\
Total & 876 & & 863 \\
\hline
\end{tabular}

afin d'indiquer le pourcentage au moins approximatif de la population omise au recensement, il faut, pour ne pas fausser inutilement un calcul déjà plus que hasardeux, défalquer encore des 863 noms auxquels nous sommes arrivés ceux de 14 domestiques et de 30 prêtres et religieux. Douze domestiques, en effet, sont désignés dans le recensement par leur prénom seulement, et deux autres sont anonymes. Ce sont 14 individus auxquels la comparaison entre les index de la prévôté et du recensement ne peut donc pas s'appliquer. Par ailleurs, les prêtres et les religieux, de l'aveu même de l'auteur (p. 412), n'allaient pas devant la prévôté - bien que quelques-uns y soient nommés à l'occasion: ce serait donc gonfler indûment les données et vicier les résultats que de les retenir aux fins d'une comparaison qui, en l'occurrence, est impossible, d'autant que tous les jésuites recensés dans le gouvernement de Québec, par exemple, n'y résidaient point et qu'il existe des moyens beaucoup plus simples et plus sûrs de savoir avec exactitude quels étaient les prêtres et les religieux qui en 1666 vivaient dans ce gouvernement. C'est par conséquent sur la base de 819 noms qu'il faudra refaire le calcul de l'auteur.

Quant aux registres de la prévôté, ils comporteraient, selon l'auteur, "un peu plus de 900" noms d'hommes pour les années 1667 et 1668. J'ai dit précédemment que mon index de ces mêmes registres pour ces années comprend 1015 noms. Puisqu'il faut ici ne s'intéresser qu'aux mâles, je retranche de ces 1015 noms 
ceux de 141 femmes ${ }^{116}$. Il reste 874 mâles. Toutefois, il faut encore soustraire de l'index de la prévôté tous les noms qui grossiraient artificiellement la population de 1666: d'abord les soldats du régiment de Carignan, non recensés en 1666, au nombre de $37^{117}$; 49 Européens et colons qui en 1666 habitaient ailleurs que dans le gouvernement de Québec; 22 individus décédés avant le recensement de 1666; et enfin, comme je l'ai fait pour le recensement, les prêtres et les religieux, dont 10 figurent dans l'index de la prévôté. C'est, au total, 118 noms qu'il faut déduire des 874 auxquels nous étions arrivés. Aux fins de la comparaison proposée par l'auteur, on doit donc retenir 756 mâles de plus de 16 ans.

Cette comparaison devant se faire sur des bases différentes de celles de l'auteur, il est évident qu'il faut examiner le cas des " 459 hommes [...] qui figurent dans le recensement [et qui] ne se présentèrent pas devant la prévôté..." Or, sur les 756 noms de l'index de la prévôté, j'en ai trouvé 404 qui ne sont point aü recensement. Si j'additionne ces 404 noms aux 819 retenus pour le recensement, j'obtiens un total de 1223, soit une augmentation (sur la base de 819) de 49,3\%, à comparer à 1359 pour l'auteur - ce qui représenterait, dans son cas, une augmentation de $65,9 \%$. Les omissions au recensement seraient donc moins nombreuses que ne l'affirme l'auteur ${ }^{118}$.

Ni le chiffre de la population mâle de plus de 16 ans proposé par l'auteur (1359) ni le mien (1223) ne sauraient être valables, cependant, non seulement parce que, dans le premier cas, les données de départ sont fausses, mais surtout parce que la méthode

116 L'auteur dit qu'on y trouve "près de 200 femmes" (p. 419). Ses chiffres sont fort approximatifs, mais son addition est "à peu près" correcte : "un peu plus de 900 hommes" + "près de 200 femmes" = "plus de 1100 personnes" (p. 411).

117 L'auteur, qui les a tout de même inclus dans son calcul, en estime le nombre dans les registres de la prévôté à "une vingtaine peut-être" (p. 412).

$118 \mathrm{Je}$ m'efforce en vain de comprendre la façon de travailler de l'auteur. S'il a réellement trouvé, dans le recensement de 1666, 459 noms d'individus qui ne figurent pas dans les registres de la prévôté, c'est qu'il avait en main l'index de ces registres; l'ayant en main, il lui était facile, par exemple, d'en extraire les fiches portant des noms féminins et de les compter exactement; de même, il pouvait tout aussi aisément compter le nombre total de ses fiches. Pourquoi, s'il avait un tel fichier, s'est-il contenté d'évaluer à "plus de 1100 " le nombre de ces fiches et à "près de 200 " le nombre des femmes? S'il n'avait pas ce fichier, il lui a fallu procéder par estimation : comment dès lors a-t-il pu arriver à un chiffre aussi précis que le 459 dont je viens de parler? 
adoptée par l'auteur est inacceptable. Cela ne l'empêche pas de s'accrocher à ces 1359 individus et de tenter de montrer, sinon l'exactitude, au moins la vraisemblance de ce chiffre: "les facteurs que entrent en ligne de compte, écrit-il, semblent s'équilibrer" (p. 412). Ces facteurs sont de deux sortes: ceux qui sont "susceptibles d'augmenter ce nombre" et ceux qui sont "susceptibles" de le "diminuer". Il y en a deux, selon lui, qui pourraient augmenter le chiffre de la population. Le premier nous est familier et nous savons maintenant ce qu'il faut en penser:

Des individus peuvent ne figurer ni au recensement ni dans les registres de cour. Ainsi dans le seul greffe [sic] de Romain Becquet, et pour la seule année 1667 , j'ai relevé 16 concessionnaires de terre qui ne figurent ni dans le recensement, ni dans le Tanguay [sic] annoté par Archange Godbout et Roland-J. Auger, ni dans les registres de cour de la Prévôté. (p. 412)

C'est la théorie de l'auteur sur les nombreux colons qui ne laissaient pas de "traces" de leur trop bref passage dans la colonie: la population de 1666 pourrait donc s'accroître de beaucoup d'inconnus. Et l'auteur d'ajouter:

En fait les documents de contrôle ne couvrent que deux années (1667-1668 [sic]) et n'ont été tirés que d'une seule source : les registres de la Prévôté de Québec.

Il est vrai que, si l'on avait étendu la comparaison aux registres de la prévôté des années 1669 et 1670 , par exemple, l'on aurait trouvé beaucoup plus de noms prétendument omis dans le recensement, mais quelle preuve aurions-nous eue que ces individus de 1669 et de 1670 étaient dans la colonie en 1666? - Le deuxième facteur "susceptible d'augmenter ce nombre" ne pourrait rien augmenter, bien au contraire, et le passage que lui a consacré l'auteur touche à l'incohérence:

L'étude des types de cause [sic] démontre et suppose 119 presque toujours la nécessité, pour ceux qui comparaissent, d'un séjour suffisamment long à Québec [sic] pour avoir contracté des engagements et y avoir fait défaut ${ }^{120}$, ce qui porte à croire que plusieurs étaient à Québec en 1666. (p. 412)

119 Comment "l'étude" peut-elle "supposer la nécessité . . .", alors qu'il n'est pas question ici d'une nécessité (au sens de condition) préalable à l'étude, mais bien du résultat de l'étude?

$120 \mathrm{Il}$ semble supposer ici que la plupart des transactions étaient à long terme, après avoir affirmé le contraire précédemment (p. 410). Par ailleurs, l'auteur suppose encore que les 900 et quelques individus mâles de son fichier apparaissent tous devant la cour comme demandeurs ou défendeurs, alors que beaucoup y sont nommés comme témoins ou d'une façon incidente. 
Puisqu'il s'agit ici de "ceux qui comparaissent" devant la prévôté, comment l'auteur n'a-t-il point vu qu'ils sont déjà comptés parmi les "plus de 900" et donc parmi les 1359, et que partant ils ne sauraient accroître la population présumée de 1666! Mais encore, puisque tous les individus nommés dans les registres de la prévôté sont compris sans exception dans le chiffre de 1359 et que, par ailleurs, l'auteur écrit qu'il est porté "à croire que plusieurs étaient à Québec en 1666", j'en conclus qu'un certain nombre, de l'aveu même de l'auteur, n'étaient probablement pas à Québec en 1666 et que, par conséquent, loin de nous présenter un facteur d'accroissement, l'auteur prêche ici pour une diminution de "ce nombre".

Après s'être arrêté aux facteurs qu'il croyait (à tort) "susceptibles d'augmenter ce nombre" de 1359 mâles de plus de 16 ans, l'auteur énumère ceux qui sont "susceptibles" de le "diminuer" (p. 412). On aura du mal à découvrir sa pensée, si toutefois on y parvient. Les deux premiers facteurs de diminution sont les "décès" et "les départs vers la France, vers Trois-Rivières ou Montréal ou pour faire la traite des fourrures". En discutant précédemment de l'index de la prévôté, j'ai tenu compte, on s'en souviendra, des noms des personnages décédés avant 1666 ou résidant ailleurs que dans le gouvernement de Québec. L'auteur, lui, ne s'en était point préoccupé, ce qui explique pourquoi il a indûment gonflé de 71 individus la population présumée de 1666. Le plus curieux, c'est qu'il parle ici de diminution. Essayons de nous y retrouver: si le personnage décédé ou déménagé après 1666 apparaît au recensement, le "nombre" ne variera pas; si le même personnage n'apparaît pas au recensement, de deux choses l'une: ou il est nommé dans les registres de la prévôté (ou dans tout autre document) avant ou après son décès ou son déménagement, ce qui aurait pour effet d'augmenter encore une fois la population mâle de 1666; ou il n'est pas nommé dans ces documents, ce qui laisse le total de 1359 inchangé. Je ne vois pas que ces facteurs puissent diminuer en rien le résultat de 1359 auquel l'auteur est arrivé. Un troisième facteur, selon lui, est "l'absence des soldats dans le recensement". L'auteur ajoute qu' "ils semblent toutefois très peu nombreux devant la cour". Peu importe leur nombre, ils sont déjà compris parmi les 1359 mâles de 1666, l'auteur ne les ayant point déduits de ses 900 et quelques hommes et jeunes gens. Ce troisième facteur ne peut donc pas faire varier le chiffre de 1359 .

L'auteur ajoute, enfin, sans indiquer si c'est là un facteur susceptible d'augmenter ou de diminuer le chiffre de la popula- 
tion, qu' "il faut aussi tenir compte des Québécois [?] qui firent partie de l'expédition de Courcelles [sic]".

Ayant quitté Québec le 9 janvier 1666, avec 600 hommes dont 45 Canadiens, dit Gustave Lanctôt, Courcelles n'y revint pas avant la mi-mars. ${ }^{121}$ Or, Cyprien Tanguay "a établi de façon indiscutable . . que le dénombrement de 1666 avait été fait dans les mois de février et mars" [RAPQ, 1935-36 : 1]. (p. 412s.)

L'auteur semble suggérer que les 45 Canadiens de l'expédition n'apparaissent point au recensement, ce dernier ayant été fait en leur absence. Cela est à vérifier. René-Louis Chartier de Lotbinière était de cette expédition, dont il a laissé un récit burlesque en vers, et il apparaît au recensement; Laurent Benoit, de l'île d'Orléans, y participa aussi ${ }^{122}$, et il n'est pas recensé. De sorte que, même si je voulais "tenir compte" de ce fait, je ne saurais pas comment le faire, faute de posséder la liste des 45 miliciens "québecois". Il est évident que l'auteur n'en a pas la moindre idée lui-même, et ce petit passage n'a pu être placé là que pour impressionner la galerie. Malheureusement, il comporte une affirmation erronée, que l'on répète depuis Tanguay, sur le moment où fut dressé le recensement.

Quand donc ce recensement fut-il fait? Pour le savoir, il faut en comparer les données avec celles des registres paroissiaux, quand cela se peut. Or, dans le gouvernement de Québec, une telle comparaison n'est possible que pour les seigneuries de Beaupré et de l'île d'Orléans, et pour la ville de Québec. A Beaupré et à l'île d'Orléans, le recensement fut, en grande partie, dressé très tôt au début de l'année, en janvier et au commencement de février plutôt qu'en février et mars comme le prétend Tanguay. Il fut toutefois complété un peu plus tard, semble-t-il, car on y retrouve un couple marié le 8 mars (BaillargeonGoindreau, $R A P Q, 1935-36: 74)$ et deux enfants d'un mois (Charles Allaire, p. 80, et Catherine Gobeil, p. 50) nés en mars. Le cas le plus troublant est certes celui de la famille de René Esmond, qui apparaît en double au recensement (pp. 72 et 80) : la première fois, François Esmond a 12 jours et la deuxième, six mois ! Peut-être y a-t-il erreur et faudrait-il lire 6 semaines ? Mais Marie Esmond avait 17 mois quand son frère avait 12 jours, et 2 ans au moment où il avait 6 mois! En dépit de semblables mystères, on peut affirmer que le gros du recense-

${ }^{121}$ Alors qu'on s'attend ici à une référence à l'historien Lanctôt, cité dans la phrase, l'auteur se réfère à W. J. Eccles...

122 Jug. et délib., I : 433. 
ment fut fait en janvier et au début de février à Beaupré et à l'île d'Orléans. - Qu'en est-il maintenant de Québec? Une partie en fut faite en janvier, mais beaucoup d'inscriptions sont d'avril, de mai et de juin. Mossion dit Lamouche, par exemple, y est recensé avec sa femme, Anne Tavernier (p. 13), qu'il avait épousée le 15 mai ; Jeanne Duguay y est déclarée veuve d'Antoine Le Boesme (p. 18), lequel fut enseveli le 23 avril; par ailleurs, Louise Lemire, baptisée le 10 mai 1666, et François Guyon, baptisé le 3 mars, n'étaient pas nés lorsqu'on a recensé leurs familles ( $p p .15$ et 17). La confection du recensement a donc traîné pendant plusieurs mois à Québec, mais n'a pas dépassé le mois de juin, alors qu'allait s'ouvrir la saison de la navigation et que débarquerait le contingent annuel des immigrants.

De son rapide examen du recensement de 1666, l'auteur conclut qu" "il y avait [...] à Québec [sic] plus d'hommes qu'on ne l'a dit". "Il me semble alors un peu illusoire, ajoute-t-il, de prétendre faire des études démographiques à partir de la seule source que constitue le recensement de 1666." (p. 413) Il ne pouvait pas prononcer d'une façon plus explicite sa propre condamnation. Il a entièrement négligé le recensement de 1667 , par exemple, dans ce qu'il présente néanmoins comme une étude de la population du gouvernement de Québec au milieu du XVIIe siècle, et de surcroît il n'a pas su corriger les lacunes du recensement de 1666 de manière à le rendre utilisable. Car tout ici est affaire de méthode. En étudiant de front les recensements de 1666 et de 1667, il eût enrichi le premier de quelques centaines de noms peut-être; en outre, eût-il comparé son index des registres de la prévôté avec d'autres sources ( $v . g$. actes notariés et registres du Conseil souverain) antérieures à la saison de navigation de 1666, il eût été en mesure de déterminer avec certitude quels individus rencontrés dans les registres de la prévôté (ou dans toute autre source postérieure au recensement de 1666) étaient dans la colonie au début de l'année 1666. C'est la seule façon de répondre à la question qu'il s'est posée. La comparaison qu'il a choisi de faire n'aurait été acceptable - bien qu'elle eût été trop restreinte - que si personne n'avait immigré dans la colonie, et plus particulièrement dans le gouvernement de Québec, en 1666,1667 et 1668 . Or, postérieurement au mois de juin 1666, où se termina le recensement dans la ville de Québec, et avant la fin de l'année 1668, des centaines d'engagés, de volontaires et de chefs de famille débarquèrent vraisemblablement à Québec. Sans discernement, l'auteur, lorsqu'il a recueilli leurs noms dans les registres de la prévôté, les a ajoutés à la population de la colonie au moment du recensement de 1666. 
Combien d'individus mâles, âgés de plus de 16 ans, sont-ils venus dans la colonie en 1666, 1667 et 1668 ? On sait, grâce à Talon, que 978 personnes sont "passées en Canada" par les soins de la Compagnie des Indes occidentales "ez années 1665, 66, 67 et 68 non compris les soldats qui y sont demeurez" 123 ; or, en 1665 , il en était arrivé, encore par l'entremise de la compagnie, $429^{124}$, ce qui laisse, pour les trois saisons de navigation qui nous intéressent, 548 immigrants pris en charge par la compagnie. Mais il est certain que celle-ci n'était pas le seul agent d'immigration: en 1666, par exemple, alors qu'elle ne fit passer que 35 personnes ${ }^{125}$, Talon annonce l'arrivée de 90 filles à marier ${ }^{126}$. Je n'ai pas pour le moment le chiffre total de l'immigration pour 1666, 1667 et 1668, et j'ignore (sauf pour 1666 où les 35 immigrants transportés par la compagnie sont des hommes) quelle est la proportion des mâles parmi ces immigrants. Néanmoins, ajoutés aux centaines de soldats qui s'établirent dans la colonie en 1667 et 1668, les immigrants mâles de 1666 à 1668 suffisent à fausser toutes les données de l'auteur et partant le résultat de son calcul. Il a beau arguer qu'il fallait avoir eu le temps de contracter des engagements et d'y faire défaut pour aller devant la prévôté (p. 412), il oublie manifestement un certain nombre de choses: par exemple, que des nouveaux venus se présentent devant la cour dès leur débarquement, soit pour se plaindre de mauvais traitements subis sur le navire, soit pour répondre à des plaintes du capitaine; que la période d'adaptation mutuelle de l'engagé et du maître suscite des désaccords ou des attitudes qui ont leur écho devant la prévôté; que ces nouveaux venus peuvent apparaître devant la cour comme témoins ou peuvent y être nommés d'une façon incidente et sans qu'ils soient directement impliqués dans une cause quelconque, etc. De toute façon, le raisonnement de l'auteur ne vaut pas dans le cas des centaines de soldats du régiment de Carignan qui s'établirent dans la colonie, car ils y étaient depuis 1665. Il est assez piquant que, parmi ses "facteurs susceptibles d'augmenter" ou de "diminuer" son chiffre de 1359 mâles, n'apparaisse point l'immigration postérieure au recensement de 1666 .

Si, au lieu de comparer globalement les noms tirés des registres de la prévôté pour 1667 et 1668 à ceux du recensement

123 "Correspondance échangée entre la cour de France et l'intendant Talon ...", RAPQ, 1930-31 : 106 .

124 Ibid., 103.

125 Ibid., 104.

126 Ibid., 57. 
de 1666, on les compare pour chacune des années, on observera un écart grandissant entre les noms qui apparaissent au recensement et ceux qui n'y apparaissent point. Il n'est pas sans intérêt, à cet égard, d'examiner le petit tableau suivant:

TABLEAU VIII

Comparaison entre l'index de la Prévôté de Québec pour 1667 et 1668 et celui du recensement de 1666

\begin{tabular}{lrrrrrr}
\hline & 1667 & $\%$ & 16681 & $\%$ & Total & $\%$ \\
\hline $\begin{array}{l}\text { Noms dans l'index } \\
\text { de la prévôté }\end{array}$ & 539 & 100,0 & 217 & 100,0 & 756 & 100,0 \\
$\begin{array}{l}\text { Au recensement } \\
\text { de 1666 }\end{array}$ & 278 & 51,4 & 74 & 34,1 & 352 & 46,4 \\
$\begin{array}{l}\text { Absents au recense- } \\
\text { ment de 1666 }\end{array}$ & 261 & 48,6 & 143 & 65,9 & 404 & 53,6 \\
\hline
\end{tabular}

1 Il s'agit des noms nouveaux, qui n'apparaissent pas dans l'index de la prévôté pour l'année 1667.

Je puis, bien sûr, affirmer que 53,6\% des hommes nommés dans les registres de la prévôté en 1667 et 1668 n'apparaissent pas au recensement de 1666; mais il est beaucoup plus éclairant de distinguer selon les années, comme je viens de le faire, de façon à mettre en lumière l'écart de $17,3 \%$ entre l'année 1667 et l'année 1668. Ne puis-je pas présumer avec quelque chance d'exactitude que cet écart est dû en partie aux immigrants des étés de 1666 et de 1667 à tout le moins ? En 1667, de janvier à septembre, il a pu se rencontrer devant la prévôté des immigrants de l'année 1666, et de septembre à décembre, des nouveaux venus de l'année 1667. - Tout cela, évidemment, serait à vérifier. Il reste que le calcul proposé par l'auteur, ses données de base, ses conclusions et sa méthode sont irrecevables.

Après avoir souligné "une autre conclusion [qui] se dégage de cet aperçu de la population : sa grande mobilité", dont on sait désormais ce qu'il faut penser, l'auteur s'arrête, dans son "survol", à la composition de la population du gouvernement de Québec en 1667 et 1668. Il y a bien, dans le gouvernement, des ecclésiastiques et des nobles, mais il ne traitera que du peuple "qui constituait la majeure partie de la société et que les historiens ont étudié et classifié" (p. 413). 
L'étude des sources révèle toutefois des facteurs qu'il importe de souligner. Le gouvernement de Québec comptait plus de domestiques et d'engagés que de ménages.

Voilà un autre coup d'épée dans l'eau : le gouvernement de Québec comptait 301 domestiques, dont 229 étaient des engagés (voir plus haut tableau IV) et 355 ménages (compte tenu de 7 familles qui sont en double au recensement) ${ }^{127}$.

Or, le statut social de ces domestiques était mal défini. D'une part, ils constituaient une catégorie sociale inférieure, d'autre part, ils avaient des droits auxquels ils tenaient fermement.

Nouveau coup d'épée dans l'eau, je le crains. Examinons, cependant, les exemples donnés par l'auteur de "droits auxquels [les domestiques] tenaient fermement":

Ainsi, le lieutenant général de la Prévôté de Québec condamna trois femmes accusées d'avoir battu un domestique à faire amende honorable au maître de cet engagé; jugement que le Conseil souverain renversa au profit du domestique humilié. (p. 413)

Rétablissons d'abord les faits: Jacques Dumesnil (prénommé Pierre au recensement de 1666), domestique de Robert Giffard, et non pas engagé, avait été battu, non par trois femmes, mais par un homme, Germain Langlois, et deux femmes, Anne Ardouin, veuve de Jacques Badeau, et Jeanne Badeau, sa fille. Ce n'est point le lieutenant général qui prononça la sentence, mais le juge sénéchal de Beauport, qui avait condamné le trio à demander pardon à genoux au sieur Giffard et à cent vingt-neuf livres d'amende. Ce ne fut point le Conseil souverain qui modifia la sentence en appel, mais le lieutenant général de la Prévôté de Québec, qui condamna solidairement les trois inculpés à vingt livres, la moitié payable à Dumesnil, et aux dépens de l'appel'128. Voilà ce que l'auteur appelle "renverser [le jugement] au profit du domestique humilié" ! - Examinons tout de suite le deuxième exemple donné par l'auteur :

Par contre, l'un d'entre eux [domestiques] refusa de payer un matelas parce que d'autres y avaient couché. (p. 413)

Il me faut encore rétablir les faits : il ne s'agissait pas de payer un matelas, mais la bourre seulement du dit matelas; en outre, si le domestique refusait de la payer, c'est tout simplement

127 Voir note 114. Guillaume Boucher, fils de Marin, était célibataire. $128 \mathrm{AQ}, \mathrm{NF} 19, \mathrm{I}, 2^{\mathrm{e}}$ partie : 29s. - L'auteur donne cette référence, mais n'en donne point aux registres du Conseil souverain, et pour cause ! 
parce qu'on la lui réclamait par erreur, le matelas n'étant point à son usage, mais à celui d'autres valets. Le texte, pourtant très clair, n'a pas du tout le sens ni la portée que lui donne l'auteur : "Et par le deffendeur a esté demandé payement de la bourre d'un matelats aud. demandeur Et par le demandeur a esté replique q.l [qu'il] n'a point esté chargé dud. matelats q. [que] les autres vallets y ont cousche."

Il ne m'apparaît point que, dans le second exemple, il y ait eu l'ombre d'un débat autour d'un droit quelconque du domestique. Dans le premier, il est vrai, la cour réduit considérablement la sentence du juge sénéchal de Beauport en portant l'amende de cent vingt-neuf à vingt livres et en n'obligeant plus les trois complices à demander pardon au sieur Giffard; en outre, la moitié des vingt livres seraient versées à Dumesnil, lequel avait droit, selon le juge, au remboursement des journées employées à la poursuite du procès ${ }^{129}$. Voilà qu'il est question d'un droit; or, ce droit était reconnu à tout le monde, parties ou témoins, en première instance ou en appel, et ne fut jamais contesté à qui que ce soit, autant que je sache; surtout, il est à remarquer que ce n'est point Dumesnil qui appela de la sentence du juge seigneurial, mais les trois inculpés, et qu'en appel la sentence fut réduite très sensiblement (de cent neuf livres) en leur faveur, alors que le domestique n'y gagna rien, sinon une compensation de dix livres pour la perte de son salaire. Si Dumesnil avait tenu "fermement" à ses droits, c'est lui qui se serait empressé d'interjeter appel. En somme, les deux exemples de l'auteur n'étayent pas du tout son affirmation.

Mais il y a autre chose : beaucoup de domestiques étaient des volontaires et des travaillants, et beaucoup d'entre eux avaient un métier"130. Or, selon l'auteur toujours, "les hommes de métier [...] jouissaient d'un statut assez élevé" (p. 414). Le perdaient-ils, ce statut, en allant travailler pour les jésuites ${ }^{131}$ ou pour tout autre maître (au sens moderne de patron) ? C'est

129 Loc. cit.

130 Dans le gouvernement de Québec, en 1666, 24\% des domestiques recensés étaient des volontaires et des travaillants, et le tiers d'entre eux, des artisans; il y avait encore 139 autres volontaires et travaillants susceptibles de prendre un maître, dont 60 avaient un métier. (Voir tableau IV).

131 Voir, dans le recensement de 1666, la liste des "domestiques" (p. 4) ou "hommes de travail" (p. 5) des Jésuites de Québec, parmi lesquels il y a six artisans et deux instituteurs ( $R A P Q, 1935-36: 4$ et 5). Remarquons que "domestiques" et "hommes de travail" sont ici employés comme synonymes, puisqu'ils désignent le même groupe d'individus. 
ce que l'auteur aurait dû nous expliquer pour éviter de paraître en contradiction avec lui-même sur ce point particulier. Et qu'en était-il exactement des cinquante engagés du recensement de 1666 qui avaient un métier ( $c f$. tableau IV) ? - Les hommes de métier, selon l'auteur, "jouissaient" donc "d'un statut assez élevé". Il n'en donne aucune preuve. Ces artisans "cherchaient [en outre] à protéger leurs intérêts particuliers" :

Ainsi, quand un charpentier refusa de faire un plancher et affirma qu'aucun homme de métier à Québec ne ferait ce travail, le procureur général [sic] intervint vigoureusement pour dénoncer cette "pratique des artisans". (p. 414)

On comprendra que les charpentiers refusaient de faire les planchers; or, il s'agit d'un plancher que Jean Poitras avait antérieurement "convenu" de faire pour le compte de Jean Madry. Le menuisier - car c'était son métier - affirma qu'il "ne le feroit point ny autres ouvriers de Québec", mais on ignore la raison de ce refus. Selon l'auteur, le procureur fiscal aurait dénoncé cette "pratique des artisans"; en citant entre guillemets ces trois derniers mots, l'auteur laisse croire qu'il les a tirés tels quels de l'original, ce qui n'est pas le cas. Le procureur ne dit pas qu'il est au courant d'une pratique condamnable des artisans, mais que, si Poitras disait vrai, ce serait une mauvaise pratique : "ouy sur ce le pr [procureur] fiscal qui a dit qua la response dud poitras Il appert dune mauvaise pratique qui Seroit en usage entre les artisans au prejudice du publicq ..."132. Ce texte ne prouve pas nécessairement, à mon avis, que les artisans de Québec aient été solidaires de Poitras, lequel a pu s'exprimer ainsi par pure bravade.

De plus, un homme de métier appelé à témoigner sur la construction d'une cheminée ne manqua pas de signaler que ce type de travail devrait être réservé à des experts. (p. 414)

S'il peut, à la rigueur, subsister quelque doute sur l'interprétation que j'ai donnée du texte précédent (relatif à la "mauvaise pratique" des artisans), il n'en existe pas dans le cas présent. L'auteur parle d'un homme de métier appelé à témoigner sur l'état d'une cheminée, et donne une double référence. Examinons, partant, les deux textes auxquels il nous renvoie. Dans le premier, il s'agit d'une réclamation contre Pasquier Nony, à cause d'une cheminée qui menace ruine pour avoir été mal faite : Pasquier répond que la cheminée fut faite "Il y a cinq ans" et que la garantie ne vaut plus; le tribunal "ordonne que lad. cheminée

$132 \mathrm{AQ}, \mathrm{NF} 19, \mathrm{I}, 1^{\text {ere }}$ partie : 44. 
sera visitée par gens experts" ${ }^{133}$. Dans le second, Charles Amiot demande que Pierre Loygnon - qui, d'après le recensement de 1666, n'était pas un artisan - "soit condamne de hausser sa cheminée" à cause des risques "daccident"; Loygnon répond par sa femme, qui comparaît pour lui, que "si par Experts et gens accommodant il est juge necessaire delever sa cheminée Il en demeure daccord Et pour cette fin il nomme Mathurin Roy pr [pour] son arbitre" ${ }^{134}$. Il n'y a donc rien de commun, dans les deux textes, avec le récit de l'auteur. Les recours à des experts, dont il est ici question, n'ont certainement pas la portée qu'il aimerait peut-être leur conférer: l'arbitrage des artisans dans les domaines de leur métier a-t-il plus de signification, sur le plan social, que l'arbitrage de l'habitant chargé d'évaluer les dommages causés aux grains d'un voisin, par exemple ? L'auteur, on en conviendra, n'a rien dit qui puisse nous convaincre ou que les artisans jouissaient "d'un statut assez [?] élevé", ou qu'ils "cherchaient à protéger leurs intérêts particuliers", ou que les domestiques avaient "des droits auxquels ils tenaient fermement". Il n'aura prouvé qu'une chose: qu'il ne sait pas lire ou qu'il sollicite les textes.

Immédiatement après avoir parlé des hommes de métier au "statut assez élevé", l'auteur affirme que "le statut légal de la femme était aussi [?] imprécis" (p. 414). Or, il ne fut question précédemment du "statut légal" ni des domestiques ni des artisans, mais plutôt, si je ne m'abuse, de leur statut social. Quoi qu'il en soit, voici la suite de ce paragraphe :

$\mathrm{Si}$ elle [la femme] pouvait prendre action [sic] en justice et représenter d'autres personnes, un homme pouvait se dégager de tout engagement et de toute dette contractée [sic] par sa femme s'il avait pris la précaution d'avertir les marchands de ne conclure aucune transaction avec elle. (p. 414)

Je ne sais point si cela est suffisant pour parler d'un statut légal imprécis, mais la situation ici décrite se présenta une fois ${ }^{\mathbf{1 3 5}}$. Est-il légitime de généraliser à partir d'un seul cas ?

L'auteur, enfin, sans dire un mot des commerçants, des fonctionnaires, des habitants, des coureurs de bois, etc., comme si la colonie n'était peuplée que de domestiques, d'artisans et heureusement! - de femmes, termine son étude de la population en notant "l'absence quasi totale d'Indiens dans les docu-

133 Ibid., II : $110 \mathrm{v}$.

134 Ibid., II : $117 \mathrm{v}$.

135 Ibid., I, 1 ère partie : $34 \mathrm{v}$. 
ments administratifs de la Nouvelle-France". Cette absence nous vaut une phrase particulièrement remarquable, à l'avenant de son étude sur la population, qu'elle termine :

Leur absence reflète une imposition de structures aux coloniaux français dont s'exemptèrent les Amérindiens et un refus de la population indigène à s'assimiler ou à se laisser assimiler; elle manifeste surtout l'existence de deux mondes totalement distincts par leur mode de vie, leur aspiration et leur gouvernement. [sic]

\section{Activité de la population : la traite des fourrures}

Dans cette nouvelle partie, l'auteur décrira les "occupations de cette population". Ces occupations sont: la traite des fourrures et l'agriculture, "deux secteurs d'activité bien connus", auxquels "s'ajoutent le commerce ${ }^{136}$ et la justice [?]". Le cas de la traite des fourrures est vite réglé :

Il est inutile d'épiloguer bien longtemps sur le commerce des pelleteries, car, bien que base du développement de la colonie, Québec [sic] n'en est touché qu'indirectement après 1650. (p. 414)

Je m'empresse de faire une nouvelle remarque exégétique: ce n'est point le gouvernement de Québec qui est la "base du développement de la colonie", bien que l'auteur l'affirme en toutes lettres, mais la traite des fourrures. Il ne faut pas se laisser tromper, en effet, par la marge qu'il y a trop souvent entre ce qu'il pense et ce qu'il écrit. - Ce que l'auteur consent à nous dire de cette première occupation est extrêmement ténu et ne nous apprend rien. On se demandera pourquoi, après 1650 , le gouvernement de Québec n'est qu' "indirectement touché" par le commerce des pelleteries - alors qu'il l'est très directement par la traite de l'eau-de-vie - et ce que veut dire "indirectement". Peut-être n'y a-t-il point de commerçants de fourrures dans ce gouvernement, ni de coureurs de bois, ni de fonctionnaires chargés du contrôle de la traite, de la réception et du marquage des peaux, de la perception du "quart du castor", de l'entreposage et de l'expédition de cette précieuse marchandise ? On eût apprécié qu'au moins il expliquât ce qu'il entend exactement par le passage suivant, que l'on rencontre quelques pages plus loin:

Enfin, on ne peut concevoir la théorie du commerce principal - celui du castor en Nouvelle-France - et les besoins de la colonie, sans tenir compte de ses [sic] effets multiplicommerce?

${ }^{136}$ La traite des fourrures ne devrait-elle pas être comprise dans le 
cateurs. Et si le commerce du castor constituait le pôle de croissance de la colonie, l'échange et la vente de produits qui [?] se greffaient à [sic] ce secteur primordial pouvaient occuper plus de gens que la traite des pelleteries elle-même. (p. 417)

En somme, au sujet de la traite des fourrures, l'auteur continue ce qu'il a commencé de faire en parlant de la population, c'est-àdire qu'il lance deux ou trois affirmations plus ou moins alambiquées et passe à autre chose avant de s'expliquer. Il finit par ne rien dire, tout en ayant l'air de dire quelque chose, ou par dire des sottises.

\section{Activité de la population: l'agriculture}

Comme la traite des fourrures, la culture de la terre "constituait [...] un besoin vital pour la colonie". Ce truisme énoncé, l'auteur révèle les deux questions qu'il entend examiner: "ce mode de vie occupait-il la majorité de la population québécoise [sic], et en fait, pratiquait=on une agriculture de subsistance ou produisait-on en vue des marchés ?" (p. 415) A la première question, l'auteur, oubliant qu'il l'avait posée, ne répond pas... A la seconde, dont les éléments paraissent devoir s'exclure l'un l'autre, on ne pouvait donner, semble-t-il, qu'une réponse précise. Or, l'auteur trouvera le moyen de concilier l'inconciliable: on pratiquait une agriculture de subsistance, mais on vendait son surplus sur les marchés (p. 417) !

Analysons un peu sa démarche. Âyant posé ces deux questions, il affirme que

...les deux grandes séries de documents qui touchent le peuple de près [?], soit les actes notariés et les registres de cour de la Prévôté [,] permettent de préciser l'importance et la nature de cette agriculture. (p. 415)

Que n'a-t-il complété les données de ces deux sources, sans doute importantes, par celles du recensement de 1667, dont j'ai expliqué non seulement l'utilité, mais la nécessité, pour une étude sur le rendement agricole de la colonie ! Ce recensement lui eût permis de répondre facilement à la première question et lui eût fourni des renseignements précieux qui eussent éclairé et enrichi ceux qu'on trouve dans les actes notariés et dans les registres de la prévôté. - Se limitant aux deux sources dites, l'auteur en tire un tableau, qu'il me faut maintenant commenter.

Dans ce tableau à deux volets, il prétend comparer les données des registres de la prévôté à celles des actes notariés. 
Or, première faiblesse, les six éléments constitutifs de chacun des volets ne correspondent pas les uns aux autres. Comment, dès lors, comparer ce qui n'a rien en commun (par exemple le troisième élément de chaque volet: le "travail des hommes de métier" et les "contrats de mariage") ? C'est bien ce qu'entend faire l'auteur, pourtant - mieux: ce qu'il croit avoir fait, puisqu'il écrit: "la comparaison des données tirées de ces deux séries de documents met en opposition directe et frappante l'activité agricole et l'activité commerciale", et qu'il parle même de "la portée de [ses] conclusions sur l'importance relative de ces secteurs d'activité" (p. 415). Seconde faiblesse, à laquelle il nous a déjà habitués: les chiffres tirés de la prévôté portent sur deux ans (1667 et 1668), ceux des actes notariés sur une année (1667) - et sur une partie seulement des actes notariés de cette dernière année, comme je l'ai expliqué précédemment. En outre, le premier volet du tableau, consacré aux registres de la prévôté, est inutilisable, même pris en lui-même. L'auteur, en effet, par je ne sais quelle fantaisie, a cru bon de compter les "procès-verbaux" plutôt que les causes, faussant ainsi toutes les perspectives, puisqu'une seule cause donnait souvent lieu à plusieurs procès-verbaux. Et encore: il nous avertit que ses tableaux "ne comprennent pas les actes ou procès-verbaux peu nombreux et portant sur des sujets divers comme les donations et inventaires de biens, les quittances, les vols, les bagarres et les procès de succession." (p. 415, note 35 ) Or, il a déjà affirmé que les registres de la prévôté pour 1667 et 1668 comportent "exactement 1490 procès-verbaux" (p. 411); nous savons par ailleurs que les actes notariés pour l'année 1667 sont au nombre de 458 ( $c f$. tableau III). Si j'additionne les chiffres du premier volet, je trouve un total de 765 procès-verbaux, et si je fais de même pour le deuxième volet, je trouve 189 actes notariés. Il y a donc 725 procès-verbaux de la prévôté et 269 actes notariés dont l'auteur n'a pas tenu compte: est-ce là ce qu'il qualifie d" "actes ou procès-verbaux peu nombreux" ? Croirai-je que les procès-verbaux omis ne concernent que des vols, des bagarres et des procès de succession, comme il l'affirme ${ }^{137}$ ? Enfin, le nombre des procès-verbaux de la prévôté et celui des actes notariés n'étant pas identiques, les chiffres des deux tableaux n'ont point la même valeur relative, de sorte qu'il eût fallu - à supposer que les éléments des deux volets eussent été comparables - les traduire en pourcentages.

${ }^{137}$ A la page 416, par exemple, il parle d" "une trentaine de procès [devant la prévoté] relatifs à la location d'hommes, d'animaux et de services pour les besoins de la ferme." Ces procès n'apparaissent pourtant pas dans son tableau. 
A vrai dire, j'ai beau citer les chiffres de l'auteur, je n'y crois pas. Ce sont tout au plus des approximations déguisées. Voyez, par exemple: dans le premier volet, je trouve 300 "échanges ou ventes de marchandises" et 223 "réclamations d'argent", pour un total de 523; or, un peu plus loin, ce chiffre deviendra "500 transactions d'affaires [sic]" (p. 417). Autre exemple: dans le même volet, je vois 23 procès-verbaux relatifs à la "jouissance de maison et de terre [sic]" et 13 relatifs aux "limites de terre [sic]", pour un total de 36 ; cela n'empêchera pas l'auteur de parler des " 35 litiges qui ont rapport à l'occupation de la terre" (p. 417). Le plus ennuyeux, c'est qu'il y a bien des chances pour que le chiffre exact ne soit ni l'un ni l'autre...

Bref, il m'apparaît absolument impossible de conclure quoi que ce soit de ce tableau. Si l'auteur, pour sa part, y a vu clair, ce ne peut être qu'à la lumière fallacieuse de son postulat de départ sur le caractère commercial de la Nouvelle-France. Plus loin, il tente d'éclairer la lanterne de ceux qui n'y voient goutte:

... malgré les apparences, l'analyse des causes entendıes par la Prévôté de Québec ne dément pas le caractère commercial de l'agriculture en Nouvelle-France; au contraire, elle le fortifie. (p. 416)

Cela est vraisemblable, mais l'auteur serait-il en train de se contredire pour avoir trop tôt oublié que la "comparaison" à laquelle il vient de se livrer "met en opposition directe et frappante l'activité agricole et l'activité commerciale" (p. 415) ? Contradiction qui ne ferait que s'ajouter à celle-ci: d'une part, l'auteur conclut au caractère commercial de l'agriculture; d'autre part, il affirme presque du même souffle qu'"on pratiquait une agriculture de subsistance" (p. 417). Au reste, tout cela n'est que verbiage et affirmations gratuites. Il a beau prétendre, par exemple, qu'il "existe plusieurs preuves" du caractère commercial de l'agriculture - caractère qu'il niera tout aussitôt pour le réaffirmer ensuite - (p. 416s.), il ne fait qu'évoquer des possibilités sans montrer que quiconque en ait jamais tiré parti. - S'attarder davantage à ce passage incohérent serait perdre son temps.

\section{Activité de la population: le commerce}

$\mathrm{Au}$ commerce, l'auteur accorde trois paragraphes (p. 417s.). Le premier s'appuie sur les conclusions du chapitre précédent, consacré à l'agriculture, et en tire, d'une façon toute spéculative, les conséquences sur la vie économique. Or, ces conclusions, on l'a vu, n'ont point été prouvées. La prétendue démonstration de l'auteur n'était qu'une vue de l'esprit, une sorte d'argument de 
convenance, sans rapport nécessaire avec la réalité, presque entièrement négligée. Voici le début de ce premier paragraphe :

L'agriculteur québécois [sic] partageait donc son temps entre la culture de la terre et le commerce de ses produits. Disposant de revenus, par la vente de sa surproduction, il devenait acheteur de marchandises utiles ou somptuaires [sic] et de services. La présence de 20 marchands ou bourgeois à Québec [?], à cette époque, indique cette tendance. (p. 417)

Le mot "tendance" a un sens restrictif : sommes-nous devant une pratique courante, généralisée, ou devant un mouvement qui s'amorce à peine ? Les deux premières phrases ne laissaient point prévoir cette atténuation; celle qui suivra sera encore plus affirmative. Nouvelle maladresse d'expression, qui traduit le désordre de la pensée ? - Il y aurait donc eu, à Québec (?), vingt marchands ou bourgeois (au XVIIe siècle, les bourgeois n'étaient pas nécessairement engagés dans le commerce...); les marchands vivaient de la vente de marchandises diverses (et non point de services, à ce que je sache) ; ces marchandises étaient achetées par une clientèle en partie formée d'agriculteurs (que l'auteur, néanmoins, présente ici comme l'unique achalandage des marchands) ; ces agriculteurs consacraient aux achats de marchandises les revenus de la vente, sur les marchés, des produits de la ferme. Il est bien possible, après tout, qu'il en ait été ainsi. C'est une hypothèse à vérifier, ce que n'a point fait l'auteur, malheureusement. Si l'on s'en tient à l'apport économique des seuls agriculteurs, il eût fallu répondre à de nombreuses questions. Quelle était la proportion des habitants vivant uniquement de leur exploitation agricole? Compte tenu du nombre de personnes que comptait un ménage, combien d'arpents fallait-il cultiver pour assurer sa subsistance ? Combien d'agriculteurs du gouvernement de Québec avaient en valeur, au recensement de 1667, un nombre d'arpents supérieur à la norme de subsistance ? Quelle était, au moins approximativement, l'importance des revenus provenant de la vente des surplus, mais aussi du bois de chauffage, de la viande de boucherie, du poisson, etc. ? Il n'est pas impossible de répondre à ces diverses questions, à condition d'être moins pressé que ne le sont les historiens de la nouvelle vague. - Rien donc n'a été démontré, rien n'a été prouvé. L'auteur en a peut-être eu momentanément conscience et s'est empressé de fournir ce qui lui paraît une meilleure preuve:

Les 500 transactions d'affaires [sic] qui font l'objet de procès en regard des 35 litiges qui ont rapport à l'occupation de la terre prouvent bien mieux l'importance de l'activité commerciale à Québec [sic] au milieu du XVII' siècle. 
Pour que cette preuve en soit une, il faudrait que fussent remplies les deux conditions suivantes: que le tableau de la page 415, que j'ai critiqué précédemment et dont sont tirés ces chiffres, eût quelque valeur, ce qui n'est point le cas; et que "l'occupation de la terre" fût, de sa nature même, une source aussi abondante de litiges que l'est l'activité commerciale, ce qui ne me paraît pas évident.

Fondé sur des affirmations gratuites, le premier paragraphe est donc constitué d'autres affirmations gratuites. Dans le second, l'auteur, qui aime plus qu'il ne faut la haute spéculation, va tenter de montrer qu'il convient tout à fait que les choses se soient passées comme il le prétend. Je n'en cite que le début:

D'ailleurs, l'accession de Richelieu au pouvoir en France avait fait entrer les théories de politique économique dans l'administration gouvernementale. Or, ces théories visaient en définitive le développement du commerce. Faudrait-il croire qu'après 40 ans, en travaillant dans du neuf, la politique coloniale française ait connu un échec complet? Or, d'une part, le Canada était suffisamment pourvu en canital humain et en ressources, sinon pour jouer un rôle dans le plan de la France, du moins pour que le programme français influençât le développement du Canada. D'autre part, les perspectives de profits, la centralisation du pouvoir et les revenus des habitants et des hommes de métier facilitaient l'extension de ce secteur d'activité. (p. 417)

Des vues de l'esprit aux affirmations gratuites ! Je prends le lecteur à témoin: l'auteur n'a point prouvé qu'il y ait eu dans le gouvernement de Québec des "perspectives de profits", ni que les habitants et les hommes de métier aient eu des revenus suffisants pour faciliter "l'extension" du commerce; quant à la "centralisation du pouvoir", non seulement ne l'a-t-il point démontrée, il l'a même niée dans son article: "cette décentralisation du pouvoir se manifeste bien, par exemple, au Conseil souverain ..." (p. 422). Il a si peu étudié les faits et donné si peu de "points de repère précis" (p. 407) que l'on pourrait substituer sans difficulté au présent paragraphe un passage aux affirmations toutes contraires, sans qu'aucun fait dans son article n'y vienne contredire. Voyez:

Bien que l'accession de Richelieu au pouvoir ait fait entrer les théories de politique économique dans l'administration gouvernementale, en Nouvelle-France, après 40 ans d'une guerre presque incessante contre les Iroquois, la politique coloniale française avait connu un échec quasi complet. Le Canada, en effet, ne disposait pas encore d'une main-d'auvre suffisante pour exploiter ses ressources et les perspectives de profits restaient assez lointaines et aléatoires. 
L'interchangeabilité de nos deux paragraphes prouve que l'auteur aborde l'histoire comme le ferait un faux prophète à rebours, sans se soucier des faits - ce dont il se vante, de surcroît:

... il est à remarquer que cette étude a son point de départ dans l'analyse externe des sources plutôt que dans les renseignements que recèlent les documents. En effet, hormis une certaine quantification [sic], il n'est pas tenu compte du contenu de ces sources. (p. 424)

Or, même dans la partie réservée à la critique des sources, il n'a "tenu compte" ni des faits, ni de la structure administrative, ni du contexte général de la colonie.

Les rares fois où il s'est référé à des textes précis, il n'a pas su les comprendre, ou du moins son imagination les a-t-elle ainsi transformés et moulés qu'en apparence ils se conformaient parfaitement à la nature de ses propos. On en trouve un autre exemple dans le troisième paragraphe consacré à l'étude du commerce dans le gouvernement de Québec. Dans ce paragraphe, l'auteur recourt au procédé facile - mais peu convaincant de l'anecdote:

Que de problèmes le paternalisme ${ }^{138}$ pouvait engendrer ! Ainsi, Marguerite Lebœuf obtint un délai de trois ans pour rembourser ses créanciers parce que son mari avait été pris par les Anglais sur les côtes françaises. Un peu plus tard, Jean Frouin, aussi poursuivi pour dettes, prouve que Marguerite Lebœuf lui était redevable de 450\#. Comme elle jouissait d'un délai, le Conseil souverain, dans un jugement à la Salomon, ordonna "qu'il sera pourvue au dict Frouin selon l'exigence des cas". (p. 417s.)

Eût-il été persuadé que les conseillers n'étaient ni des criminels ni des déments, l'auteur se fût interrogé sur cette décision insensée - du moins dans sa version des faits. Son esprit critique aurait dû l'alerter, en tout cas, devant ce "jugement à la Salomon". Examinons cette affaire de plus près. Le 26 avril 1667, Marguerite Lebeuf se présente devant le conseil et expose les faits suivants. Son mari, Gabriel Lemieux, naviguait de La Rochelle à Rouen, avec des marchandises pour une valeur de $2400 \sharp$. Le navire fut pris par l'ennemi et Lemieux dévalisé. Renvoyé en France sans argent ni marchandises, il dut emprunter pour survivre et pour payer son passage de retour au

138 Figaro possédait la langue anglaise parce qu'il connaissait le mot goddam, qui en fait le fond, le reste ne servant qu'à agrémenter quelque peu la conversation; nos faiseurs d'histoires, eux, maîtrisent parfaitement le régime français parce qu'ils tiennent en réserve les deux mots qui en sont toute l'explication: absolutisme et paternalisme. 
Canada. En conséquence, elle demandait un délai de trois ans pour satisfaire ses créanciers, en leur "payant l'interest". Contrairement à ce que raconte l'auteur, le conseil n'accorda pas le délai, mais ordonna "que ladite leBeuf fera appeler ses créanciers pour estre avec eux ordonné sur les fins de la diste Requeste"139. Le 4 juillet suivant, Marguerite Lebeuf apportait au conseil la liste des créanciers et le décompte de ce qu'elle et son mari leur devaient, et elle renouvelait sa demande pour un délai de trois ans. Le conseil ordonna de nouveau que les créanciers fussent réunis "jeudy prochain pour estre ordonné avec Eux sur le respy par elle demandé”. En attendant, il leur interdisait de "faire aucune poursuite" contre la requérante. ${ }^{140}$ Or, voici que, devançant les autres créanciers, Jean Frouin, le 7 juillet, présentait une requête au conseil. On le poursuivait pour dettes, et Marguerite Lebeuf lui devait $450 \sharp$. Le conseil ne pouvait-il pas ordonner qu'il fût remboursé en priorité ? C'est alors que les conseillers décidèrent "qu'il [serait] pourveu au dict Froüin selon l'exigence des cas" ${ }^{141}$. Autrement dit, quand chaque créancier aurait fait connaître ses demandes, le conseil jugerait de la suite à donner à la requête de Marguerite Lebeuf et de l'ordre de priorité des remboursements, s'il y avait lieu. C'est du reste ce qu'il fit ${ }^{142}$. - Les deux autres anecdotes étant sans intérêt - et la seconde se rapportant, sans avertissement, à l'année 1680 - je ne m'y arrête pas.

Avant de laisser ce chapitre sur le commerce, je veux relever l'absence de toute allusion aux marchands forains qui avaient l'habitude de passer l'été dans la colonie pour y écouler leurs marchandises, de même qu'aux associations entre commerçants du gouvernement de Québec et commerçants de La Rochelle, ceux du Canada n'étant guère que les représentants de ceux de France. Ces pratiques n'étaient pas sans importance, surtout si l'on songe à la quantité de numéraire qui retournait dans la métropole par leur moyen. On s'étonnera aussi - ou plutôt on ne s'en étonnera plus - que l'auteur n'ait point mentionné la Compagnie des Indes occidentales, seule autorisée de par sa charte à commercer en Nouvelle-France, et qu'il n'ait point fait état des luttes (fructueuses) de Talon et du Conseil souverain pour obtenir la liberté du commerce en faveur des colons. A dire le vrai, le sujet n'a pas été traité.

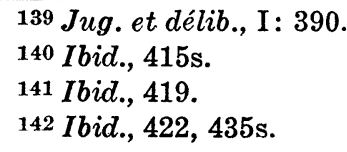




\section{Activité de la population: les métiers}

Ce paragraphe, qui porte comme titre "le travail" (?), n'avait pas été annoncé par l'auteur, qui devait parler successivement de la traite des fourrures, de l'agriculture, du commerce et de la justice (p. 414). En outre, il commence par ces mots: "Dernier aspect de l'activité des Québécois [sic], mais non le moindre, le travail des hommes de métier." (p. 418) Or, ce n'est point le dernier aspect, puisqu'il a promis de traiter de la justice et qu'en effet le prochain paragraphe lui sera consacré. Il faut donc en conclure que "dernier" signifie ici avant-dernier. Mais laissons ces bizarreries d'ordonnance et d'expression pour admirer sans tarder une phrase peu banale à la vérité ( $p .418)$ :

La diversité des besoins requis pour bâtir un pays rendait nécessaire le recours à un grand nombre d'hommes exerçant les métiers les plus divers, offrant leurs services et mettant leur compétence à la disposition de la population québécoise. [sic]

Observons une minute de silence - et poursuivons :

L'importance numérique des hommes de métier qui figurent au recensement de 1666, la diversité de leur occupation [sic] et les nombreux procès faisant suite à la location de services humains [sic] démontrent que l'immigration en NouvelleFrance correspondait généralement aux besoins de la colonie.

Quels étaient donc les besoins de la colonie ? L'auteur, que je sache, ne les a pas évalués avant de conclure que l'immigration correspondait à ces besoins, pas plus qu'il n'a calculé (ni même estimé) le nombre des hommes de métier au recensement de 1666 ; il n'a point par ailleurs inventorié les métiers représentés dans le gouvernement de Québec ni compté les membres de chaque corporation. L'eût-il fait, il lui aurait fallu défalquer de ces artisans ceux qui n'exerçaient point leur métier parce qu'ils étaient devenus agriculteurs à plein temps et ceux-là encore qui, en qualité d'engagés, faisaient chez un maître l'apprentissage de l'agriculture. - Lorsqu'il eut besoin d'un "faiseur de goudron", par exemple, Talon dut le faire venir de France; lorsqu'il eut besoin de charpentiers de navire, il dut encore les faire venir de France... L'auteur s'est-il bien assuré de la justesse de ses affirmations?

Ajoutons, sans plus insister, que ces documents caractérisent, en outre, le mode de vie d'une partie importante de la population.

Disons à notre tour, "sans plus insister" et en nous retenant de hurler, qu'il faut à tout le moins faire un effort pour décou- 
vrir de quels "documents" il est ici question (du recensement et des "procès" !), qu'on ignore de quelle "partie importante de la population" ces "documents" caractérisent le mode de vie, et surtout les caractéristiques de cette partie inconnue - mais importante - de la population. - Ce paragraphe est sans contredit l'un des sommets de l'article.

\section{Activité de la population: la justice}

On exprimera à bon droit quelque surprise de constater que la justice est ici préférée à l'industrie comme secteur d'activité de la population. L'auteur, de surcroît, ne se contentera pas de traiter de la justice comme d'un gagne-pain pour un certain nombre d'officiers, mais il en décrira le fonctionnement, énumérera les diverses étapes d'un procès, etc., dans un chapitre où la confusion de la pensée se traduira dans une ordonnance assez imprévisible des faits (si vraiment l'on peut parler de faits) et dans une forme terriblement déficiente. Ce chapitre lui donnera l'occasion de lancer quelques pierres dans la mare aux grenouilles qu'il a déjà battue plusieurs fois de son épée.

Il commence par une citation de Talon, extraite du "mémoire sur l'état présent du Canada" de 1667, dont nous avons déjà parlé : "quoyque composé d'habitans de différentes provinces de France dont les humeurs ne symbolisent [s'harmonisent] pas toujours, [le peuple] m'a paru assez uny dans tout le temps de mon séjour". Ce passage lui inspire la remarque suivante: "C'est pourtant ce peuple uni qui faisait deux fois plus de procès que d'actes notariés en 1667" ( $p$. 418). Première pierre... Il n'a jamais dit combien il y eut de procès en 1667, mais affirme qu'on entendit, à la prévôté, un total de "800 à 900 causes" pendant les deux années 1667 et 1668 (p. 411), ce qui laisse, je suppose, un peu plus de 400 procès pour l'année 1667, année où les colons signèrent 458 actes notariés dans le gouvernement de Québec. Le peuple aurait donc "fait" autant d'actes notariés que de procès. Mais cela est sans importance, car l'auteur, qui ne sait point compter, ne sait pas davantage interpréter les résultats de ses savants calculs. Admirons plutôt l'art des transitions dans la suite de ce paragraphe et demandons-nous vers quel but on se dirige:

C'est pourtant ce peuple uni qui faisait deux fois plus de procès que d'actes notariés en 1667, sans compter que pour un procès-verbal [procès-verbal ou procès ?] inscrit au registre de la cour, il fallait au moins six étapes de procédure : la requête, l'acceptation de cette requête, la fixation de la date d'audition de la cause, la rédaction et la "délivrance" des 
exploits ou assignations [i.e. exploits d'assignation] et le procès lui-même. Il y avait là de quoi occuper bien des gens et gagner honnêtement sa vie. L'intérêt de ces registres [?] n'en est que plus grand, puisqu'il [sic] traduit [sic] plutôt un type de société qu'une mentalité chicanière”. (p. 418s.)

Qu'est-ce que c'est exactement qu'un "intérêt qui traduit un type de société" et, surtout, quel type de société est-il ainsi traduit? En si bonne voie, l'auteur a bien tort de ne pas expliquer pourquoi, malgré les apparences, les habitants de la Nouvelle-France n'avaient point une "mentalité chicanière". Enfin, s'il y avait vraiment, dans le domaine de la justice "de quoi occuper bien des gens", il aurait dû s'empresser de nuancer cette dernière affirmation, afin de ne pas se contredire un peu plus loin si les mots ont un sens dans un contexte donné - en écrivant qu'"il faut réaliser [sic] que l'historiographie traditionnelle a généralement considéré les fonctions judiciaires comme un mode de vie à temps plein alors que les officiers de justice n'exerçaient cette fonction [sic] que deux jours par semaine..." (p. 422)

Sur sa lancée, l'auteur donne maintenant certaines statistiques relatives à la "fréquentation" (p. 419) de la prévôté par la population:

Certains allèrent en cour [sic] assez souvent : 109, plus de dix fois en deux ans, dont [sic] 19 plus de 30 fois. Les 109 individus qui se présentèrent en cour [sic] plus de dix fois représentent bien les principaux secteurs d'activités [sic] de la vie [sic] à Québec [sic]. (p. 419)

Les 109 individus dont il parle sont en réalité 110. Additionnons les éléments de son tableau : 30 hommes de métier, 22 marchands, 21 habitants, 13 huissiers et notaires, 3 engagés et 21 "dont l'occupation est inconnue"; total: 110. Quoi qu'il en soit, ce tableau n'est d'aucune utilité, car l'auteur a compté les présences devant la cour au lieu des causes: une seule cause pouvait nécessiter la présence à plusieurs reprises d'un même individu. Par ailleurs, celui qui comparaissait comme témoin est compté sur le même pied que le demandeur et le défendeur, ce qui, encore une fois, fausse les perspectives; pis encore, il compte les procureurs et non les parties qu'ils représentent. Tableau sans valeur donc, suivi d'une note incompréhensible:

Les quatre premiers groupes [i.e. 30 artisans, 22 marchands, 21 habitants et 13 huissiers et notaires] sont d'importance égale [?], car les notaires et les huissiers, [sic] se présentèrent en cours [sic] plus souvent que les autres, agissant souvent comme procurateurs [sic]. 
"Procurateurs" ! On se croirait en pleine histoire romaine, ou peut-être dans l'une des républiques de Gênes ou de Venise. Il n'en est rien. Il s'agit plus simplement de la dernière découverte de l'auteur: la distinction entre procurateur et procureur. Le "procurateur", selon lui, "est une personne engagée par l'une des parties pour agir comme son représentant devant la cour." (p. 419, note 47) Cela ressemble diablement à l'une des acceptions de "procureur" que l'on trouve dans tout dictionnaire. J'ai tenu, néanmoins, à m'assurer que procurateur n'existe vraiment pas au sens de procureur: j'ai consulté des dizaines de dictionnaires, ceux de Trévoux, de Furetière, de l'Académie française (5e édition, 1805) et bien d'autres, et plusieurs encyclopédies. Nulle part je n'ai trouvé le mot "procurateur" dans le sens que lui prête l'auteur; je ne l'ai même pas trouvé dans les registres du Conseil souverain, et encore moins dans ceux de la prévôté, les uns et les autres donnant "procureur". Bien sûr, de nombreuses femmes agissaient comme "procuratrices", en particulier de leur mari; l'auteur s'est imaginé, à n'en point douter, que "procuratrice" est le féminin de "procurateur"! De quoi assécher d'un seul coup la mare aux grenouilles.

La "fréquentation" des cours de justice "par les Canadiens" déclenche chez l'auteur une série de considérations vagues, désordonnées et contradictoires:

Si la fréquentation assidue des cours de justice par les Canadiens peut illustrer son [sic] mode de vie, elle peut aussi refléter la mentalité de la population. Car l'adaptation à la réalité canadienne du système judiciaire français ne se fit jamais de façon improvisée. (p. 419)

Je vois mal le lien que l'auteur veut établir entre ces deux phrases unies par la conjonction "car". Par ailleurs, il semble s'exprimer comme si toute la population mâle se présentait régulièrement devant la cour; or, il a déjà affirmé - ce qu'il paraît oublier maintenant - que " 459 hommes de plus de 16 ans qui figurent dans le recensement [de 1667] ne se présentèrent pas devant la Prévôté au cours des deux années suivantes" (p. 412). Il serait donc dangereux de vouloir trop généraliser. Enfin, la deuxième phrase, sur l'adaptation du système judiciaire français à la réalité canadienne, implique qu'on apporta des changements, des modifications, à ce système. L'auteur, pourtant, s'empresse de nier ces changements:

L'on retrouve dans les cours de justice canadienne [sic] la même terminologie précise et détaillée [?] qu'en France. Ainsi, le Conseil souverain décrète des arrêts, et le juge de la Prévôté, [sic: prononce] des sentences. A la Prévôté de 
Québec, on faisait des requêtes verbales, civiles, personnelles ou hypothécaires; les jugements de cette cour étaient définitifs, préparatoires, provisionnels ou interlocutoires. (p. 419s.)

Donc, point de modifications, et partant point d'adaptation. C'est pourquoi, j'imagine, les Canadiens s'y retrouvaient aisément:

De plus, les nombreuses étapes à franchir avant de se présenter en cour [sic] ne semblent avoir ennuyé personne, pas même les illettrés. (p. 420)

En définitive, si j'interprète bien l'auteur, la "fréquentation" des "cours de justice" réflète "la mentalité de la population" par le moyen (?) des adaptations que l'on apporta ici au "système judiciaire français". Mais, ce système, on ne l'adapta pas, l'adoptant plutôt tel quel, de façon que les Canadiens, à qui il était familier alors qu'ils étaient dans la métropole (?), y recouraient sans embarras. - Quelle sagamité !

Le paragraphe suivant est consacré à l'énumération des étapes préalables au procès (p. 420s.). L'auteur a réussi à y introduire une ambiguité :

Talon voulait procurer à la colonie une justice gratuite et rapide. Il rédigea à cette fin un projet de règlement[s] pour alléger le fonctionnement de l'appareil judiciaire canadien. Toutes les requêtes en première instance ou en appel devaient lui être adressées, et c'est lui qui référait la cause à la cour de son choix. Une requête pouvait être verbale et Talon recommandait même que leur [sic] présentation se fasse le dimanche pour épargner du temps. On vit même la Prévôté rendre un jugement le dimanche pour la commodité des parties. La requête acceptée, la partie demanderesse ou l'office [sic] du juge - en l'occurrence le [sic] huissier [?] avertissait la partie poursuivie de se présenter en cour [sic].

[Etc.] (p. 420)

Dans la première partie de son article, l'auteur avait noté l'importance, selon les exigences de la critique externe des sources, "de préciser si un document constitue une entente ou n'est qu'une lettre [sic] d'intention" (p. 405). De même faut-il distinquer entre un projet de règlements et des règlements dûment adoptés et mis en vigueur par l'autorité compétente. Or, l'auteur parle ici d'un projet dont il ne dit nulle part s'il eut jamais force de loi. A cause de la mauvaise ordonnance de la matière, on verra à tort dans la suite du paragraphe un résumé du projet de Talon, qu'on croira partant n'avoir jamais été appliqué. On prêtera donc un sens hypothétique au verbe "devaient" de la troisième phrase, par exemple, tout en croyant que l'autre verbe, "référait", devait se lire: "référerait", alors que c'est dans son 
sens contraignant qu'on doit l'entendre, puisque la phrase est extraite d'un règlement du Conseil souverain adopté le 20 août $1667^{143}$ — règlement qui n'a rien à voir avec le projet de Talon adopté par le Conseil le 24 janvier précédent ${ }^{144}$. Cette ambiguïté est encore renforcée par le fait que la référence 48 et les quatorze suivantes ne correspondent point aux appels de note qu'on trouve dans le texte.

Après avoir décrit "le déroulement d'un procès" et parlé de la "hiérarchie des sentences" (p. 421), l'auteur s'arrête aux appels : le Conseil souverain, affirme-t-il, ... réduisait presque toujours la sentence donnée par le juge de la Prévôté. Logiquement, la répétition de ces changements aurait dû inciter le juge de la Cour [sic] inférieure à se mettre au pas. Mais il ne l'a pas fait. Son prestige et sa compétence n'étaient donc pas en jeu. Doit-on y voir une coutume à tel point acceptée et passée dans les mœurs que la justice se faisait exemplaire aux niveaux inférieurs et paternaliste aux niveaux supérieurs? (p. 421)

Ce passage, je n'en serais pas surpris, restera comme l'exemple parfait d'une pure vue de l'esprit, du manque absolu de perspectives, de l'abus des formules creuses et du ridicule achevé en histoire. En 1667 et 1668, le lieutenant général de la Prévôté de Québec rendit sentence dans "800 à 900 causes" (p. 411); dans le cas de vingt et une de ces sentences seulement, l'une ou l'autre des parties voulut interjeter appel: dans deux cas, l'appelant fut jugé "non recevable en son appel"; neuf sentences furent maintenues et dix seulement furent modifiées, neuf étant atténuées et une renforcée. L'auteur n'a-t-il pas senti que c'est seulement d'une décision sur cent, à peu près, qu'il s'agit ici ?

Dans ce même chapitre, l'auteur aborde deux questions connexes: la gratuité de la justice au XVIIe siècle, à laquelle il ne croit pas, et les revenus des officiers de justice, qu'il juge bien supérieurs aux estimations qu'on en a faites jusqu'ici. Après réflexion, j'ai décidé de ne point m'engager dès maintenant dans un débat à ce propos, car il me faudrait y consacrer une vingtaine de pages: j'y reviendrai plutôt dans un article réservé exclusivement à ces questions. Il m'a paru, en effet, que j'ai suffisamment abusé de la patience du lecteur, tout comme l'auteur a suffisamment éprouvé la mienne. Mais n'allons pas, en attendant une mise au point qui s'impose, lui faire aveuglément confiance. Voici un avant-goût du sérieux de son argumentation:

143 Jug. et délib., I : 447s.

144 Ibid., 374. 
... bien loin de rechercher en dehors de leurs fonctions un revenu suffisant pour vivre, [les officiers de justice] ont utilisé le prestige ou les revenus de leur emploi régulier pour accaparer un poste dans la justice. (p. 422)

Belle affirmation gratuite! L'auteur s'affichant comme le spécialiste de la Prévôté de Québec, allons y puiser notre réfutation. Au XVIIe siècle, c'est-à-dire de 1667 à 1700, neuf officiers de justice furent attachés à ce tribunal: les lieutenants généraux Louis-Théandre et René-Louis Chartier de Lotbinière; le lieutenant particulier Paul Dupuy de Lisloye (précédemment procureur du roi) ; les procureurs du roi Jean-Baptiste Peuvret de Mesnu, Louis Boulduc, Pierre Duquet et Jean-Baptiste Bécart de Grandville; et les greffiers Gilles et Charles Rageot. Or, aucun d'entre eux n'était en position d'utiliser "le prestige ou les revenus" d'un "emploi régulier" pour "accaparer" - le mot est fort - un office dans l'administration de la justice. Je l'affirme d'autant plus librement que j'ai rédigé la biographie de chacun d'eux pour le Dictionnaire biographique du Canada (tomes I et II) auquel je renvoie le lecteur.

L'auteur pourtant a trouvé un cas irréfutable d" "accaparement" d'un poste dans la justice. Ce n'est pas le seul, il paraît:

C'est le cas, entre autres, du marchand Jacques Le Ber, riche de plus de 200,000 livres et qui occupe un office au bailliage de Montréal. (p. 422, note 60)

Dépouillez les registres du bailliage de Montréal, aux Archives judiciaires de cette ville, et l'inventaire des officiers de justice des divers tribunaux de Montréal publié par Massicotte ${ }^{145}$, et vous constaterez que jamais Jacques Le Ber n'y a occupé un office de justice! Cependant - et cela prouve de nouveau la légèreté de l'auteur, son goût pour les généralisations hâtives et son ignorance de la procédure judiciaire en Nouvelle-France Le Ber fut appelé, une fois, en avril 1667, avec Jacques Le Moyne de Sainte-Marie, Nicolas de Mouchy, Louis Prud'homme, Pierre Picoté de Belestre et Louis Arthus de Sailly, comme assesseur à un procès criminel. Le rôle de l'assesseur était de conseiller le juge, dans un procès donné, sur la culpabilité ou la non culpabilité de l'accusé et, quand il y avait lieu, sur la sentence à rendre. L'assesseur n'était pas davantage un officier de justice que le juré dans notre système judiciaire moderne, et il n'en avait point les redoutables pouvoirs. Mais voyez les perspectives fan-

145 E.-Z. Massicotte, "Les tribunaux et les officiers de justice de Montréal sous le régime français", dans le Bulletin des Recherches historiques, XXXVII: 181. 
tastiques que ce petit événement passager dans la vie de Le Ber fait miroiter aux yeux de l'auteur:

Est-ce là l'exemple d'un bourgeois qui essaie de tout contrôler et d'orienter l'administration à son profit ?

Voilà comment on écrit la nouvelle histoire ...

\section{Conclusion}

La lecture d'un article comme celui que je viens d'analyser ne saurait laisser indifférent quiconque se préoccupe de l'avenir de notre historiographie, surtout qu'il ne s'agit pas ici d'un cas unique. Je me suis, pour ma part, posé d'angoissantes questions avant d'entreprendre cette critique. Ces questions, je me suis peu à peu déterminé à les soulever en guise de conclusion. Elles sont d'autant plus troublantes qu'il arrive que des études comme celle-ci soient dirigées par des professeurs de nos instituts d'histoire et rédigées par des auteurs qui ont eux-mêmes la responsabilité de former les futurs historiens et de diriger leurs thèses. Quelles normes président donc maintenant à la sélection des candidats pour qu'il soit possible d'obtenir les plus hauts diplômes universitaires avant d'avoir appris à penser correctement et à s'exprimer d'une façon compréhensible ? Quels principes régissent donc la formation des étudiants pour qu'il soit possible d'être proclamé historien avant d'avoir acquis un minimum de méthode et de culture historique ? Quelle image leur donne-t-on de leur futur métier pour que, frais émoulus des banquettes de l'université, ils se lancent tête baissée dans des sujets de recherche qui les dépassent manifestement ? Combien de temps encore faudra-t-il que ces jeunes gens découvrent par eux-mêmes et à leurs dépens les exigences effrayantes de leur métier et qu'ils trouvent seuls le courage d'y faire face après avoir subi un premier échec dont ils ne sont pas les seuls responsables?

Si la critique est souvent ingrate, elle est absolument nécessaire à la conservation et au progrès de la connaissance. Les anciens philosophes l'avaient compris, qui s'excusaient par ces mots de différer d'opinion avec leurs collègues:

Amicus Plato, sed magis amica veritas. 